\title{
Enantioselective Total Synthesis of Mandelalide A and Isomandelalide A: Discovery of a Cytotoxic Ring Expanded Isomer
}

Nagarathanam Veerasamy, ${ }^{\dagger}$ Ankan Ghosh, ${ }^{\dagger}$ Jinming $\mathrm{Li}^{\dagger}{ }^{\dagger}$ Kazuhiro Watanabe,,${ }^{\dagger, \ddagger}$ Jeffrey D. Serrill, ${ }^{\S}$ Jane E. Ishmael, ${ }^{\S}$ Kerry L. McPhail ${ }^{\S}$ and Rich G. Carter ${ }^{\star \dagger}$

${ }^{\dagger}$ Department of Chemistry, Oregon State University, Corvallis, Oregon 97331, USA

$\S$ Department of Pharmaceutical Sciences, Oregon State University, Corvallis, Oregon 97331, USA

‡ Laboratory of Synthetic and Medicinal Chemistry, Tohoku Pharmaceutical University, Sendai, Japan.

Electronic Supplementary Information: NMR Spectra 
Enantioselective Total Synthesis of Mandelalide $A$ and Isomandelalide A: Discovery of a Cytotoxic Ring Expanded Isomer

\section{Table of Contents}

\begin{tabular}{|c|c|}
\hline $\begin{array}{c}\text { Compound } \\
\#\end{array}$ & $\begin{array}{c}\text { Page } \\
\text { Number }\end{array}$ \\
\hline SI-3 & S3 \\
\hline SI-4 & S5 \\
\hline $\mathbf{9}$ & S7 \\
\hline $\mathbf{1 0}$ & S9 \\
\hline $\mathbf{1 1}$ & S11 \\
\hline $\mathbf{1 2}$ & S13 \\
\hline SI-9 & S15 \\
\hline $\mathbf{6}$ & S17 \\
\hline $\mathbf{1 5}$ & S19 \\
\hline $\mathbf{1 6}$ & S21 \\
\hline $\mathbf{1 7}$ & S23 \\
\hline $\mathbf{1 8}$ & S25 \\
\hline $\mathbf{2 5}$ & S27 \\
\hline $\mathbf{2 7}$ & S29 \\
\hline SI-13 & S31 \\
\hline SI-14 & S33 \\
\hline $\mathbf{2 0}$ & S35 \\
\hline $\mathbf{5 3}$ & S37 \\
\hline SI-16 & S39 \\
\hline SI-19 & S41 \\
\hline SI-20 & S43 \\
\hline $\mathbf{2 1}$ & S45 \\
\hline $\mathbf{7}$ & S47 \\
\hline
\end{tabular}

\begin{tabular}{|c|c|}
\hline $\begin{array}{c}\text { Compound } \\
\#\end{array}$ & $\begin{array}{c}\text { Page } \\
\text { Number }\end{array}$ \\
\hline $\mathbf{2 3}$ & S49 \\
\hline SI-21 & S51 \\
\hline SI-22 & S53 \\
\hline $\mathbf{2 4}$ & S55 \\
\hline SI-24 & S57 \\
\hline SI-26 & S59 \\
\hline SI-28 & S61 \\
\hline SI-29 & S63 \\
\hline SI-31 & S65 \\
\hline SI-32 & S67 \\
\hline $\mathbf{2 6}$ & S69 \\
\hline SI-34 & S71 \\
\hline $\mathbf{5}$ & S73 \\
\hline SI-35 & S75 \\
\hline $\mathbf{2 7}$ & S77 \\
\hline SI-36 & S79 \\
\hline SI-37 & S 81 \\
\hline $\mathbf{2 9}$ & S 83 \\
\hline $\mathbf{3 1}$ & S 85 \\
\hline $\mathbf{2}$ & S 87 \\
\hline
\end{tabular}



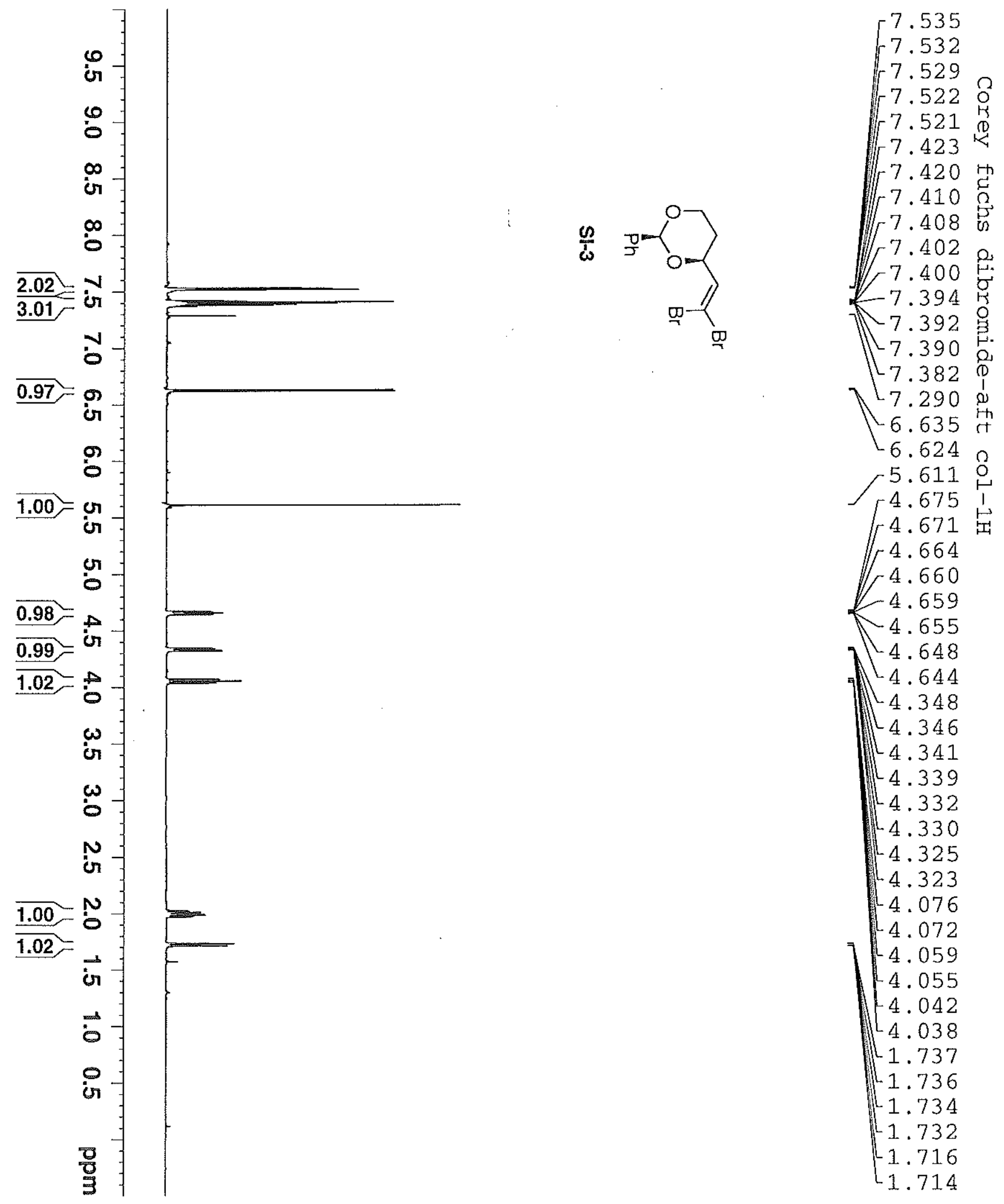

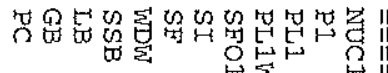

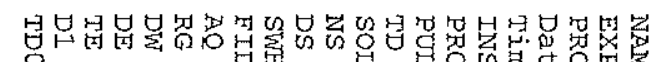

751
.423
7.420
7.410
7.408
7.402
7.400
7.394
7.392
7.390
7.382
7.290
6.635
6.624
5.611
4.675
4.671
4.664
4.660
4.659
4.655
4.648
4.644
4.348
4.346
4.341
4.339
4.332
4.330
4.325
4.323
4.076
4.072
4.059
4.055
4.042
4.038
1.737
1.736
1.734
1.732
1.716
1.714
73

$\rho_{1}^{2}$



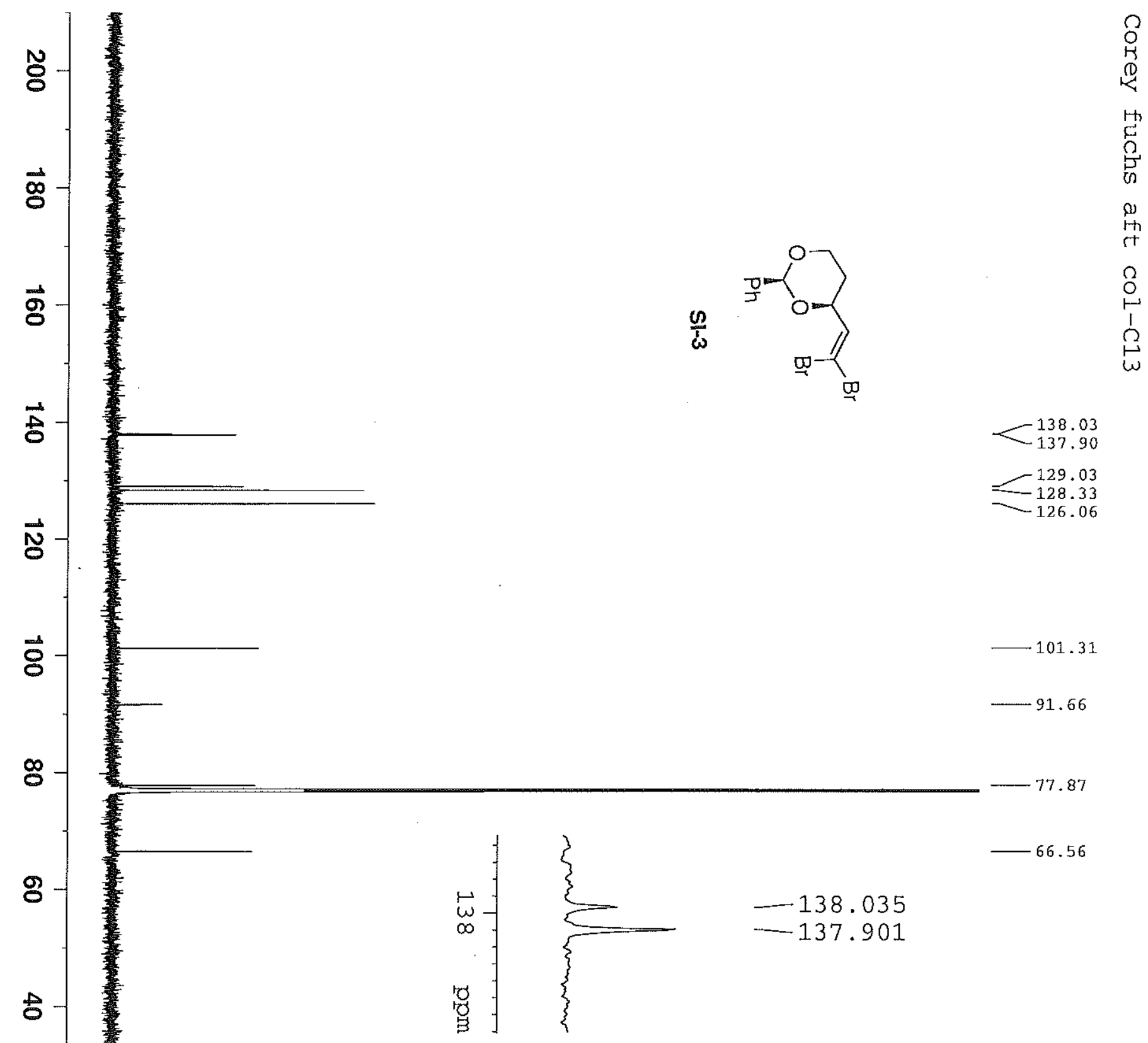

1

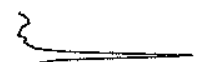

$-138.035$

$-137.901$

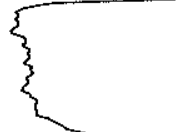

$-77.874$

$-29.28$

ง

1

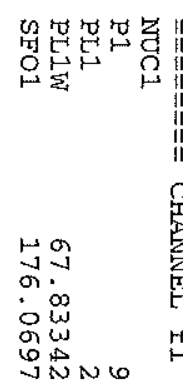

in

के

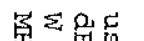

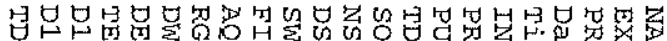

$0 \mapsto \mapsto$ 球则药

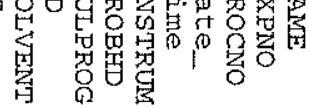

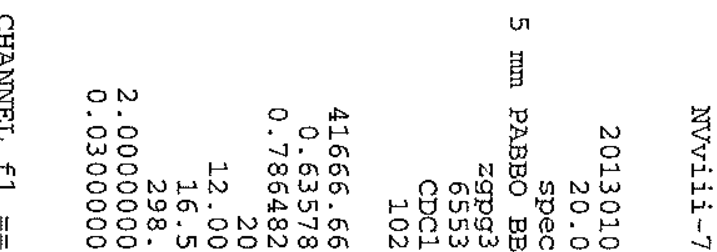

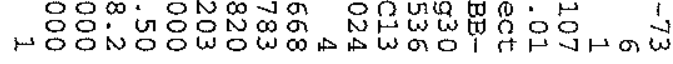

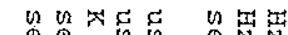



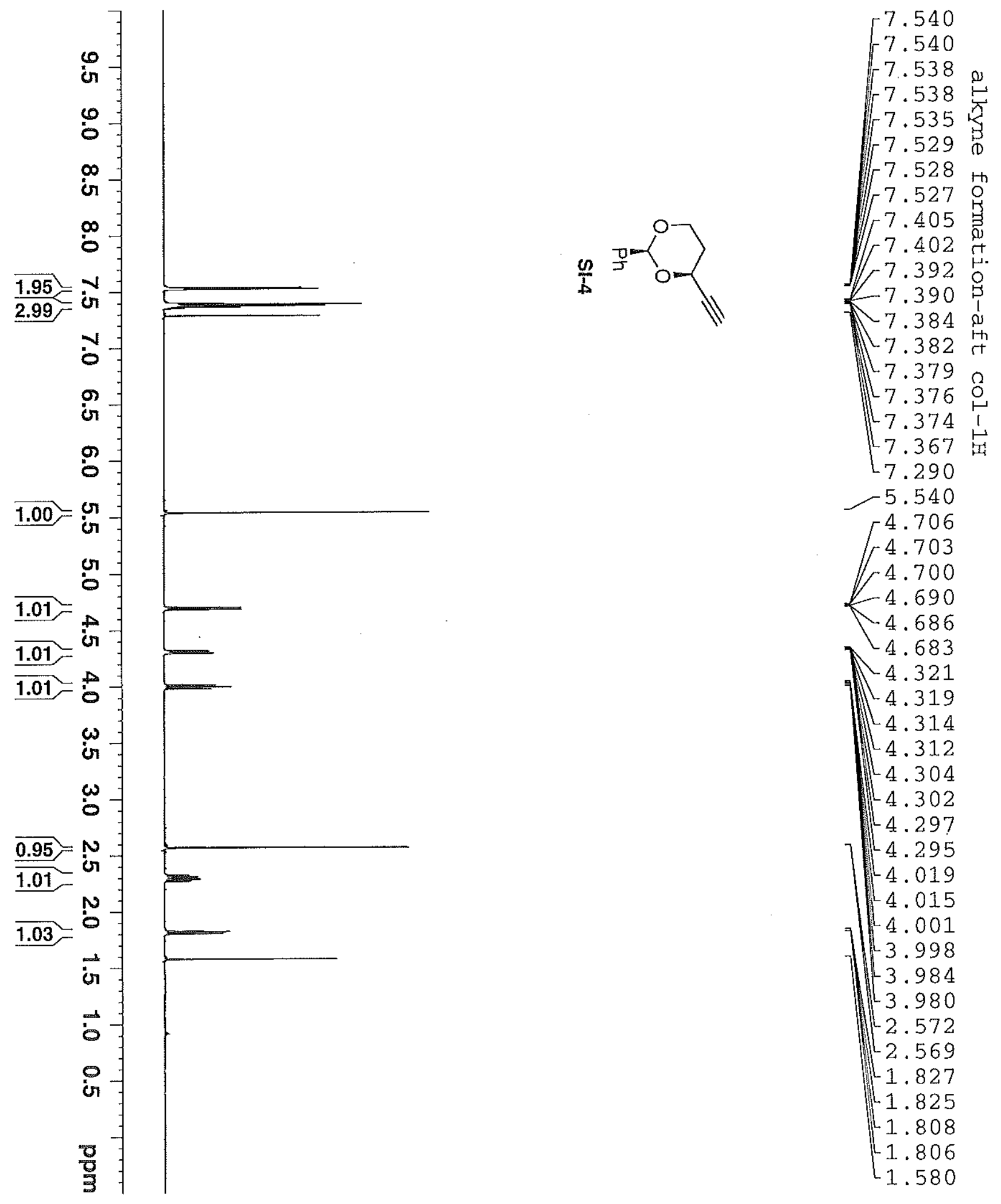

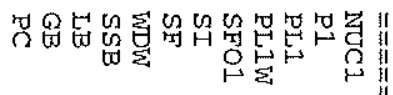

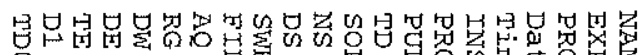

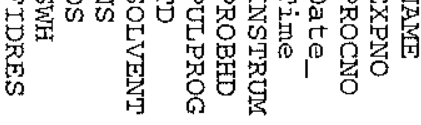




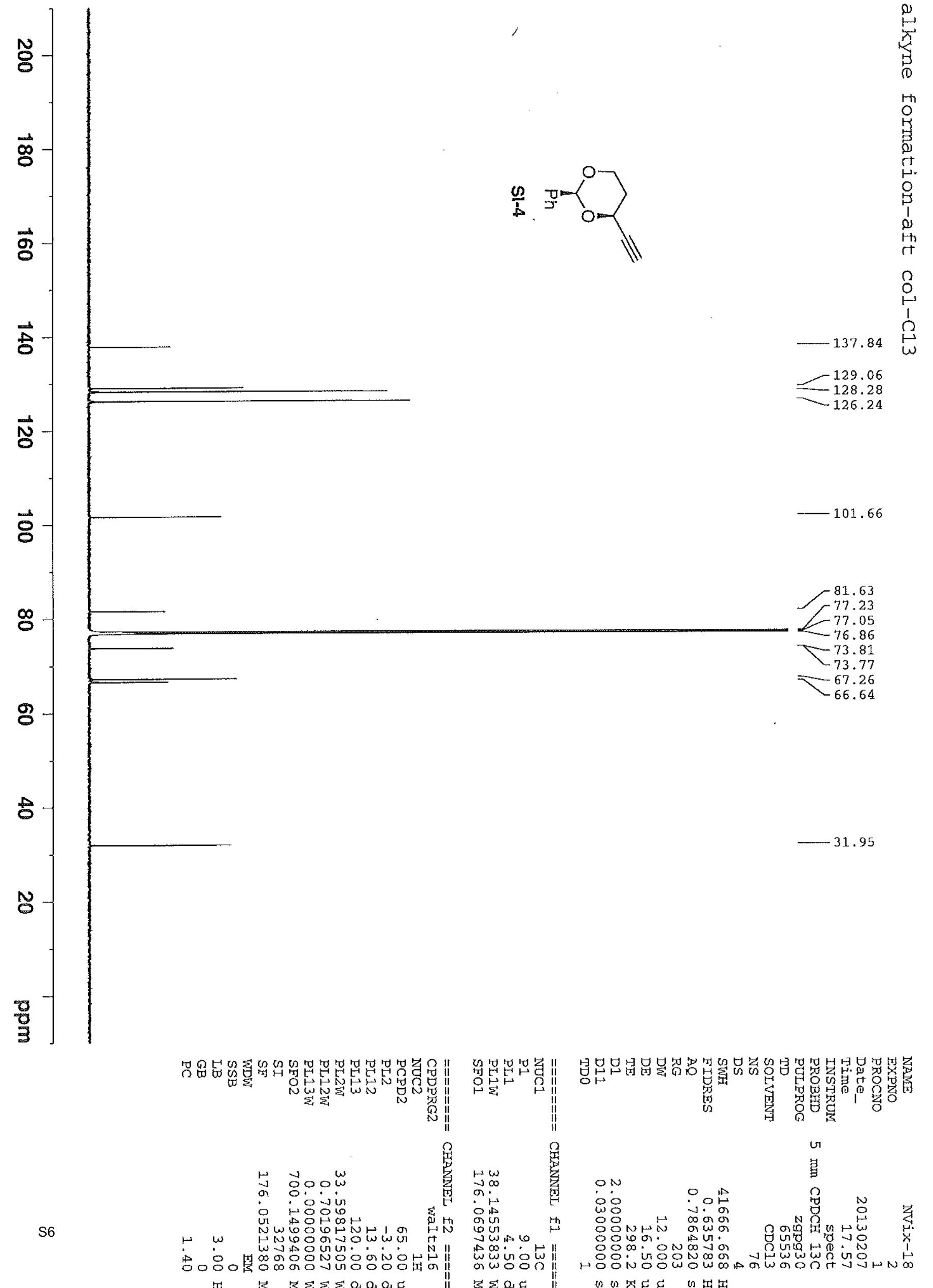




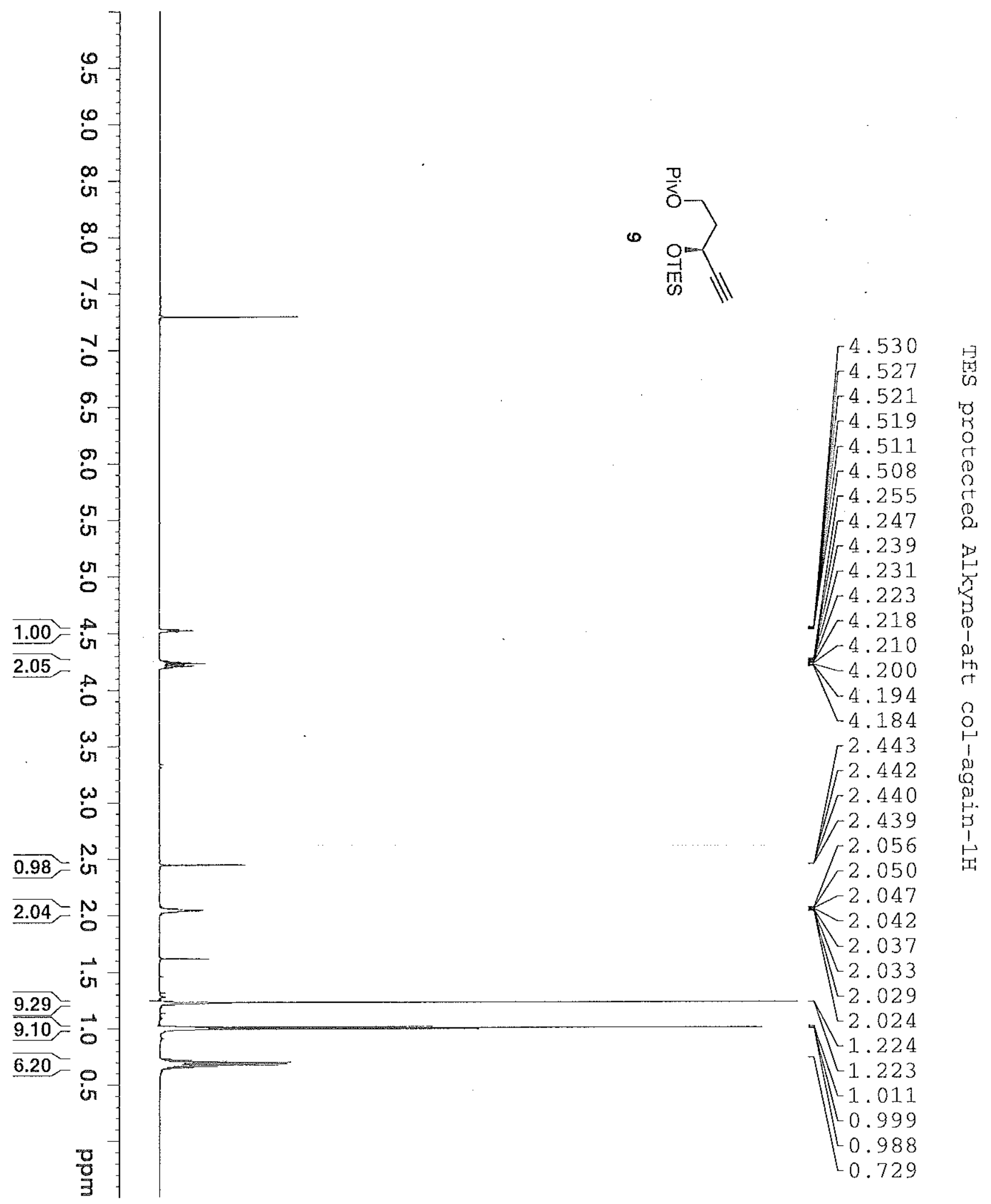

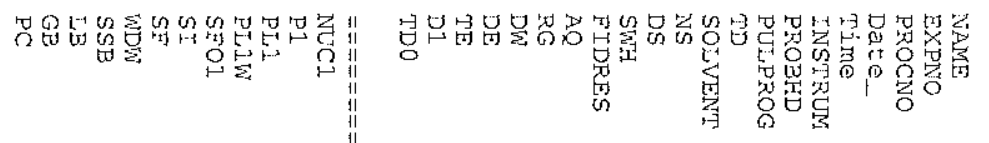




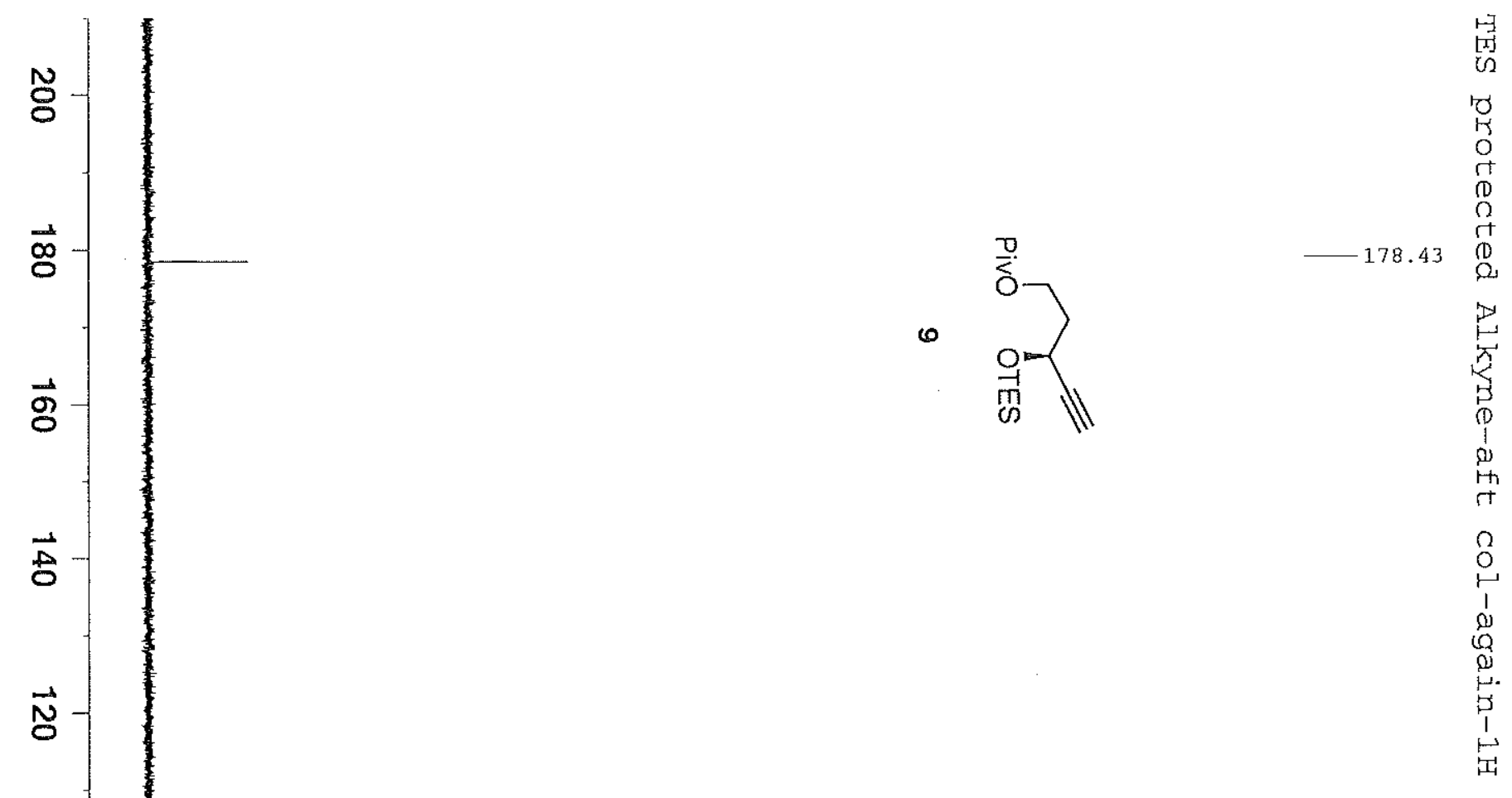

$\vec{\circ}$

$\infty$

8

(

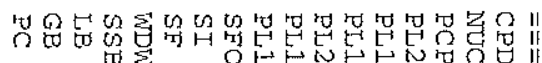

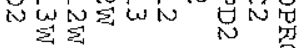

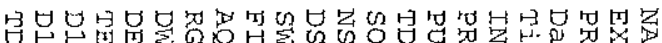
or

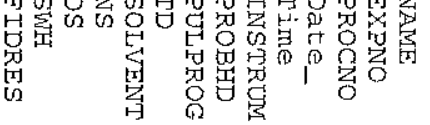

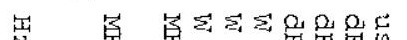
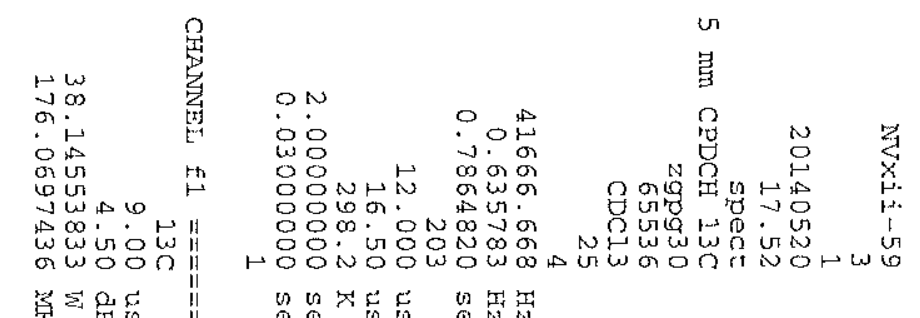


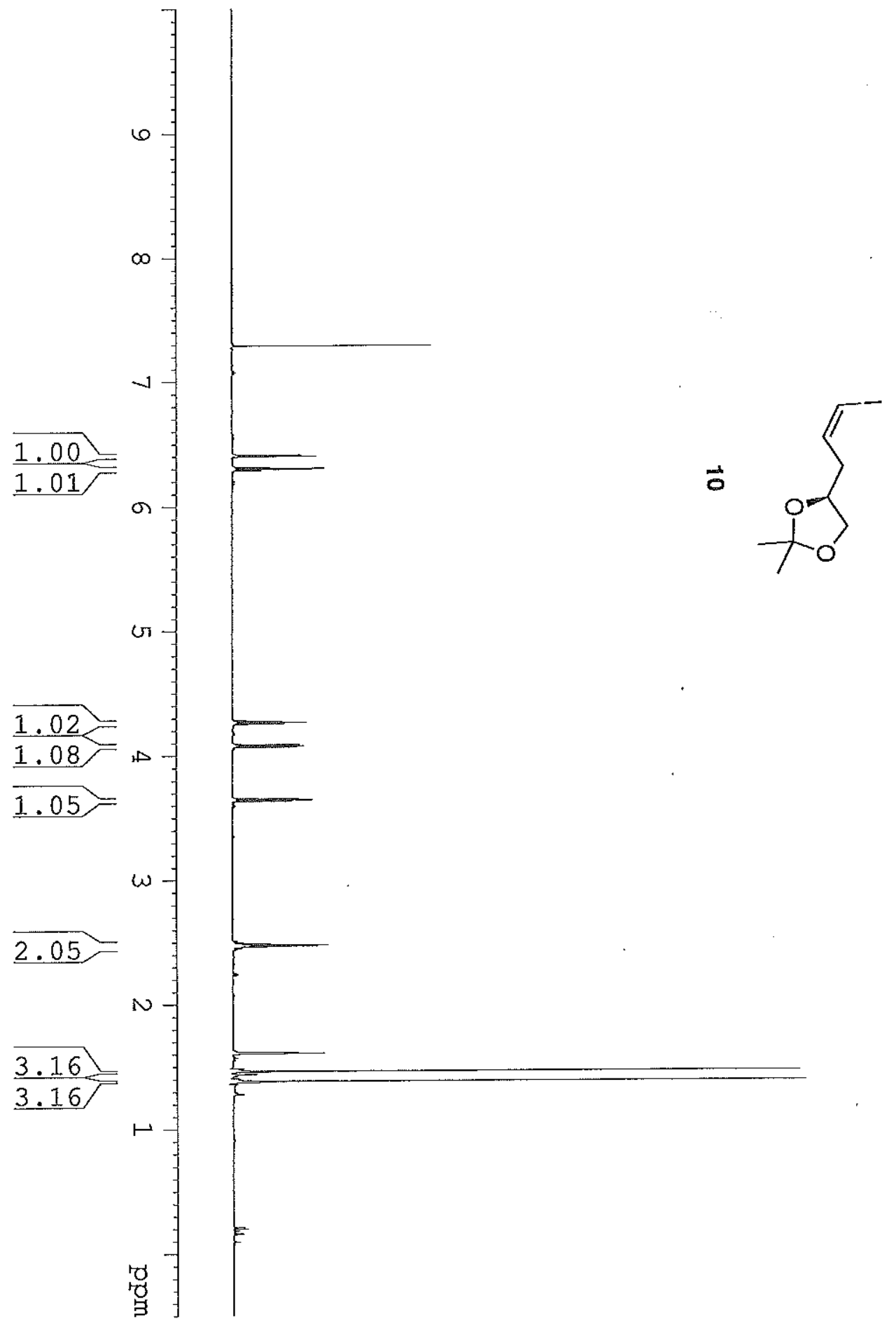

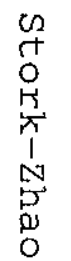

㸚

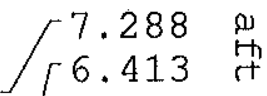

6.411

6.402

o

6.400
6.317

$-6.307$

$-6.297$

6.286

4.274

4.265

4.256

4.088

$4: 079$

$-4.077$

$-4.068$

$-3.655$

$-3.645$

3.644

3.634

2.487

$\leftarrow 2.485$

$-2.477$

2.469

2.461

2.459

$\sqrt{1.613}$

$-1.606$

1.462

1.383

1.378

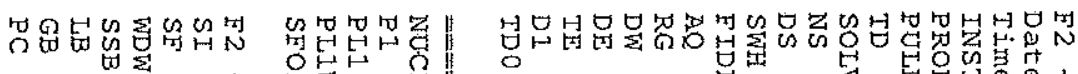

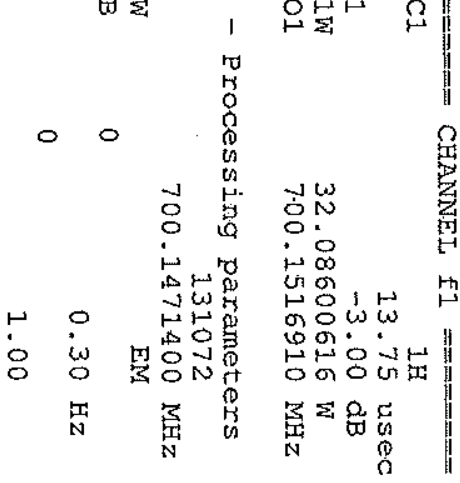

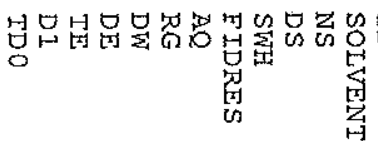

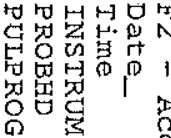

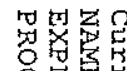

2
2
5
9
9 

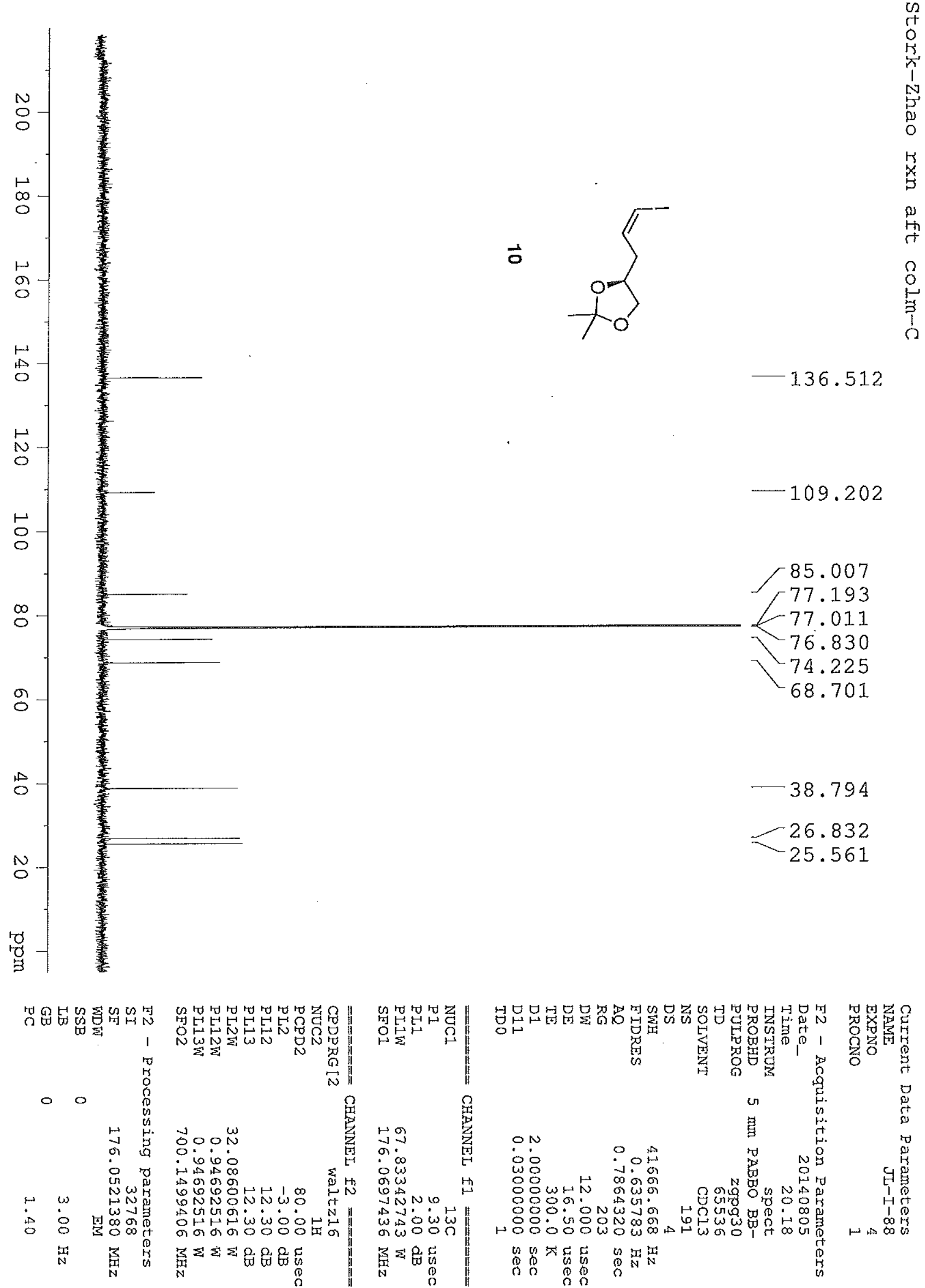


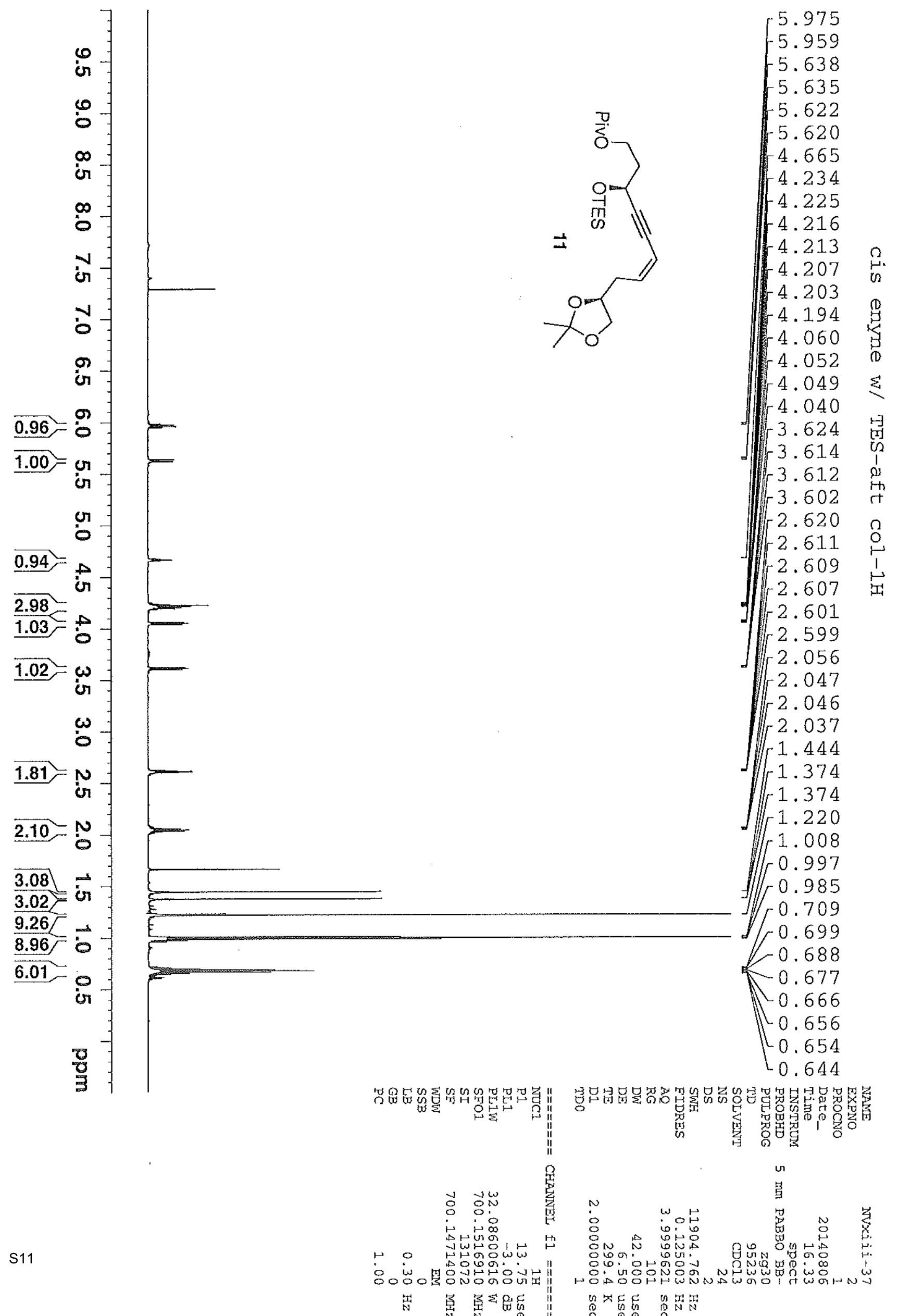




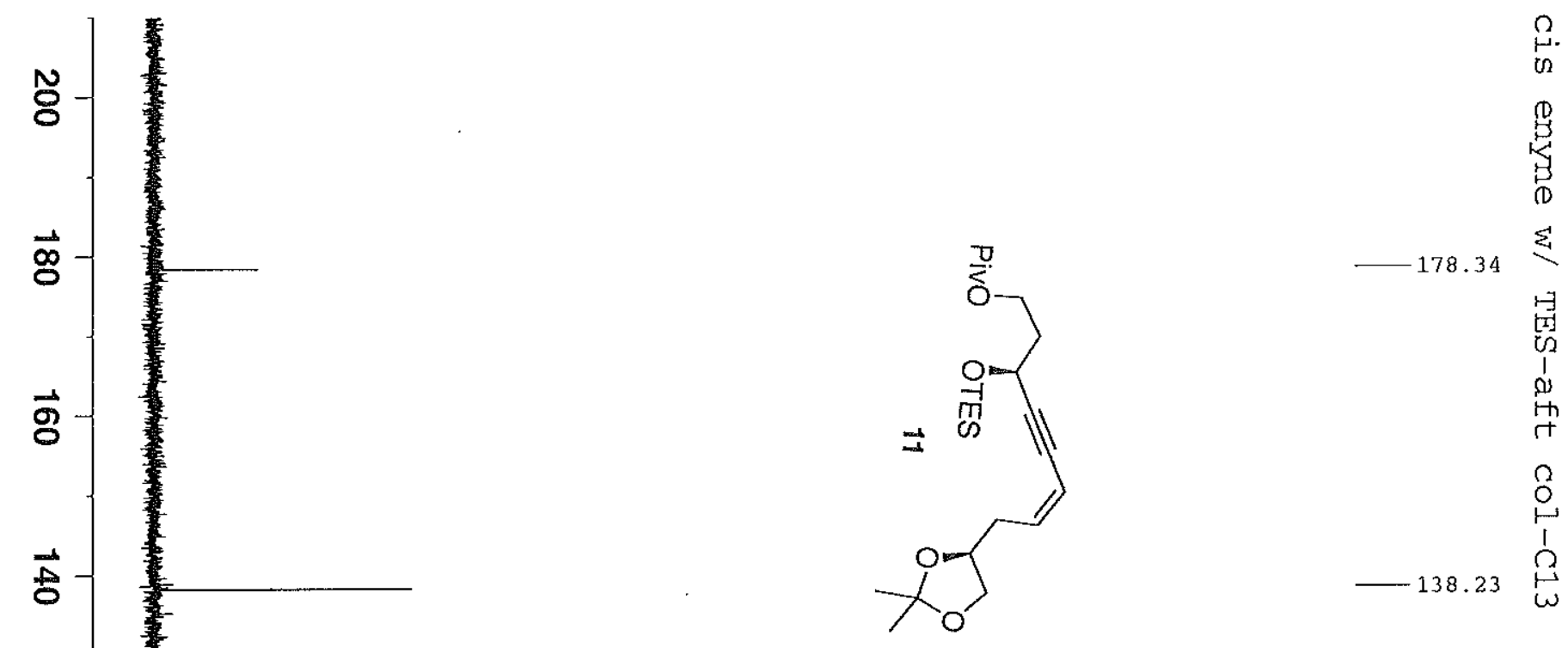

ø

$\vec{\nabla}$

8

8

P

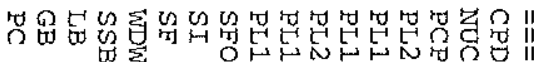

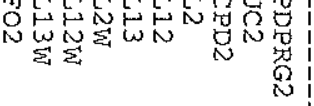

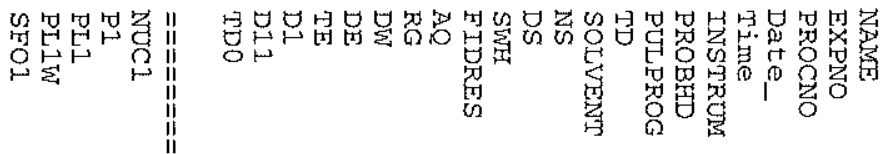

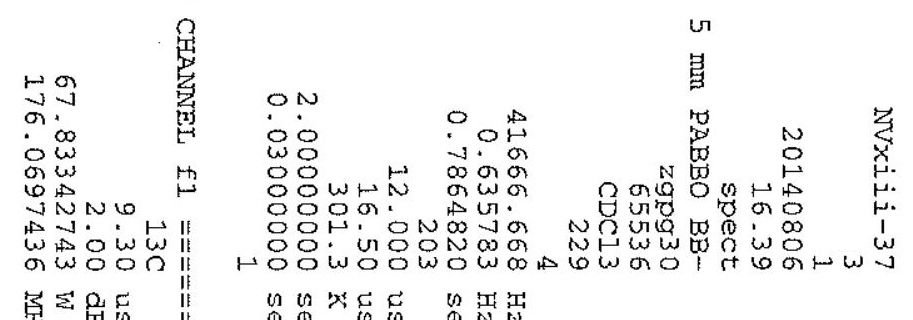




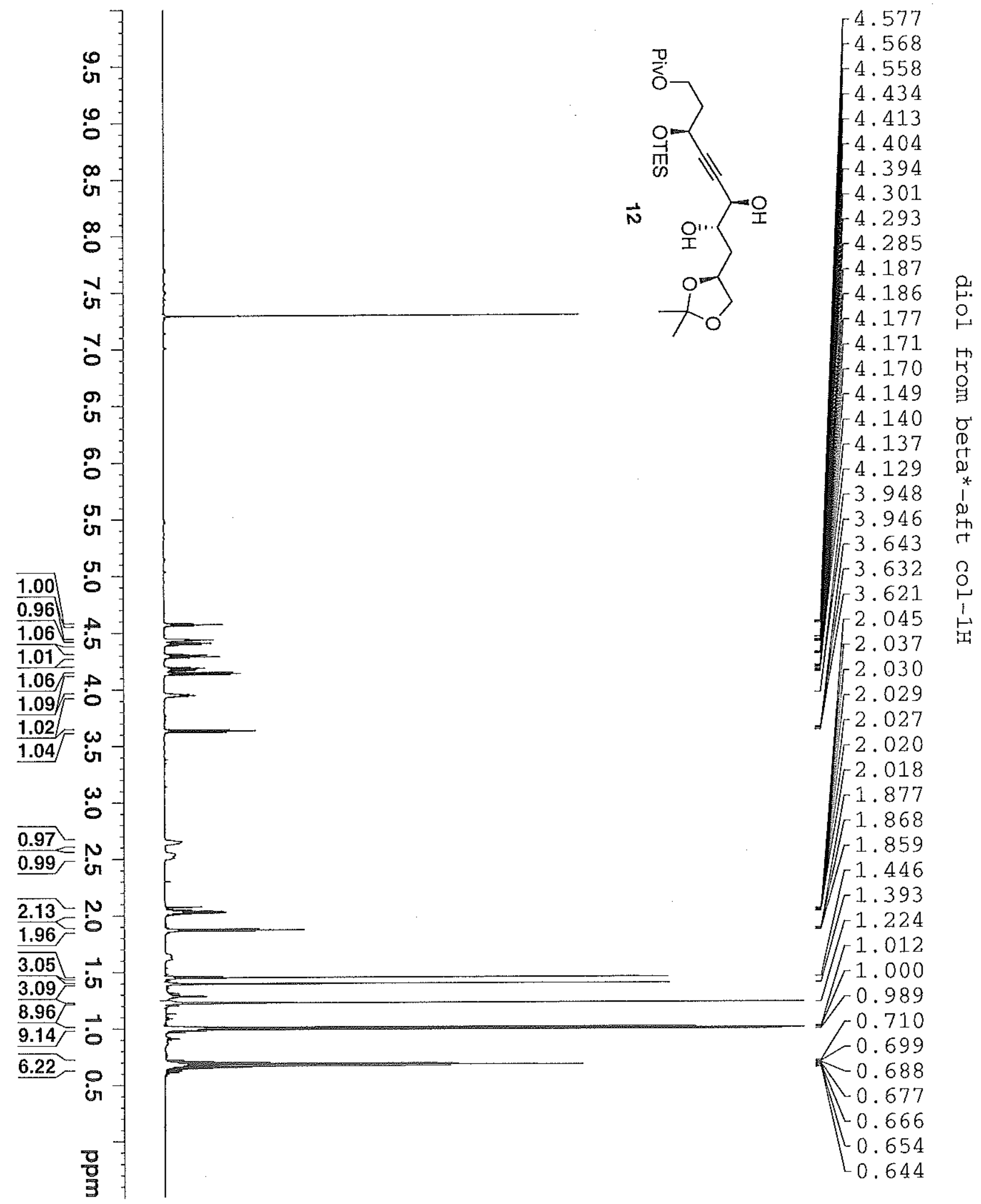

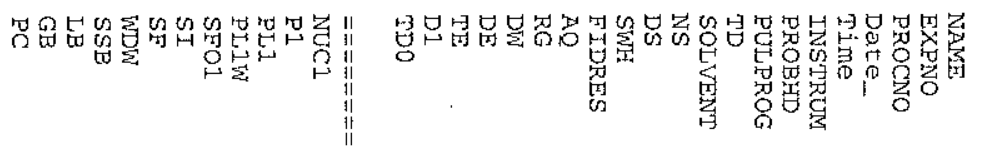

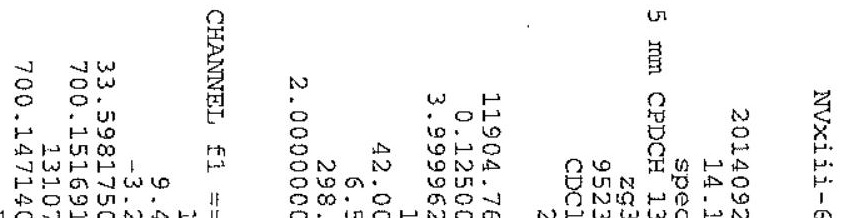



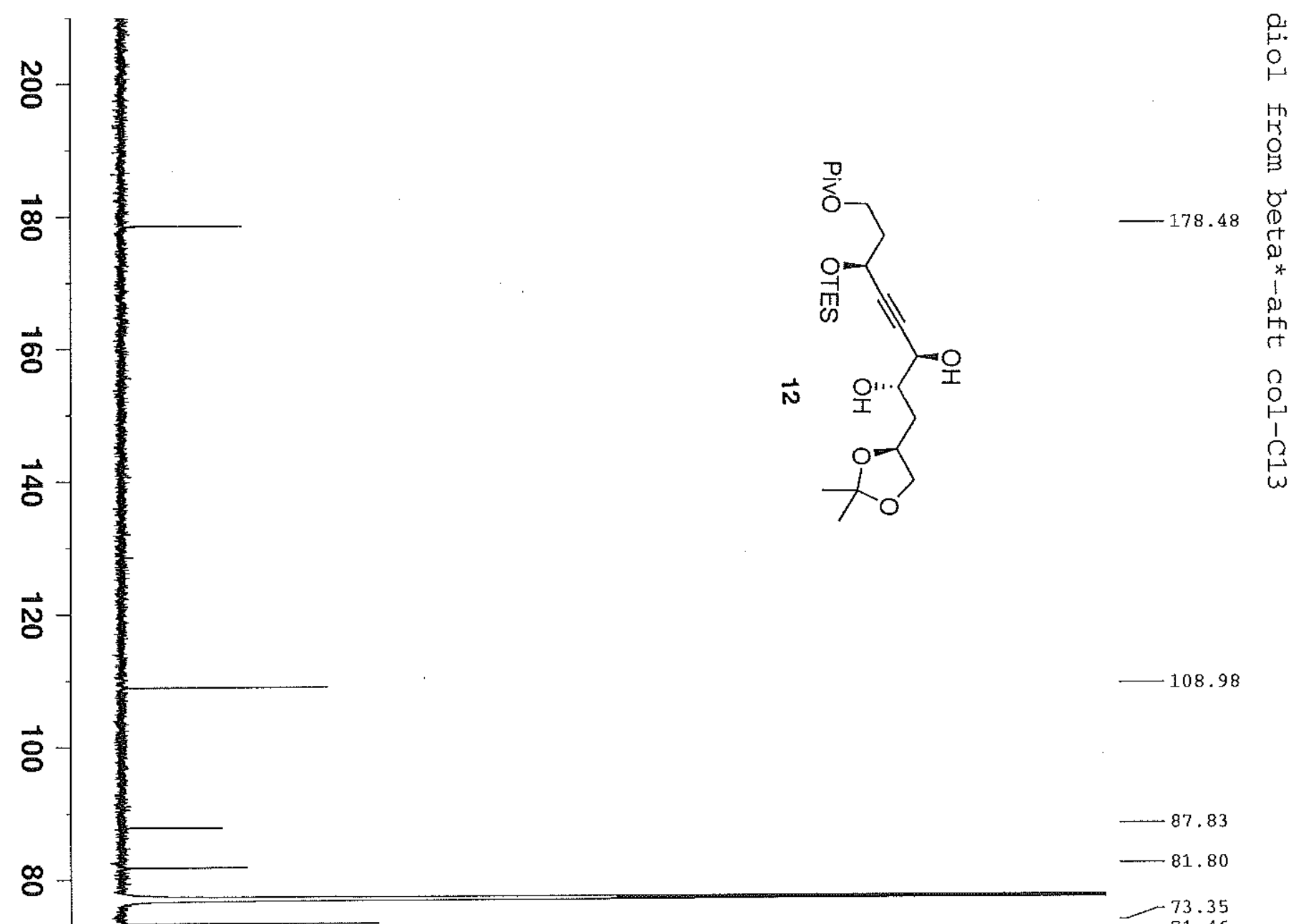

8

$8-\sqrt{2}$ -60.60
-59.44

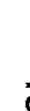

8
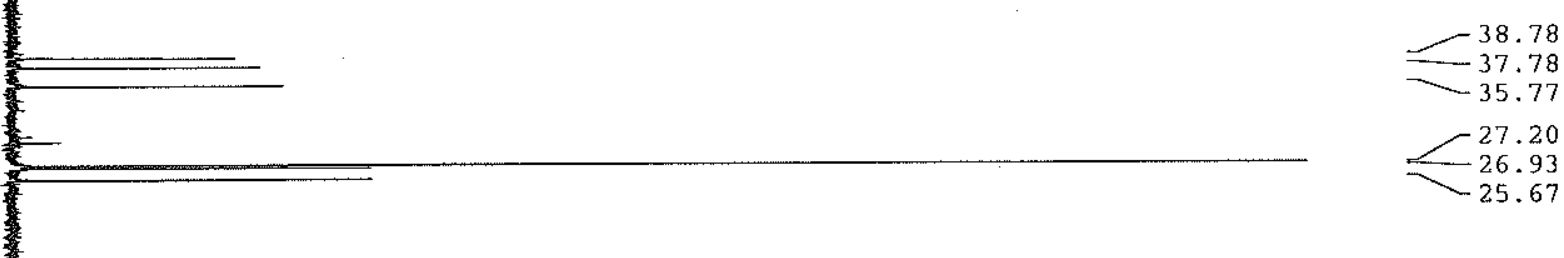

ง

$\frac{8}{3}-\frac{1}{10}$

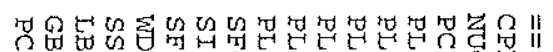

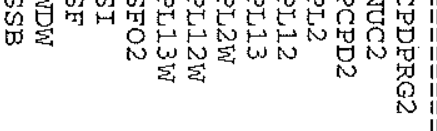

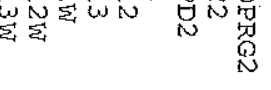

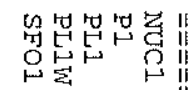

证

ง

- 0 in

요 1900

NWoOgrNH1

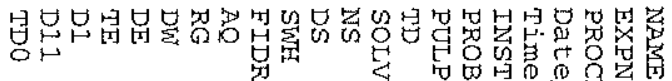

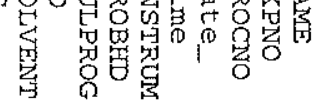

$-6.77$

$-4.68$

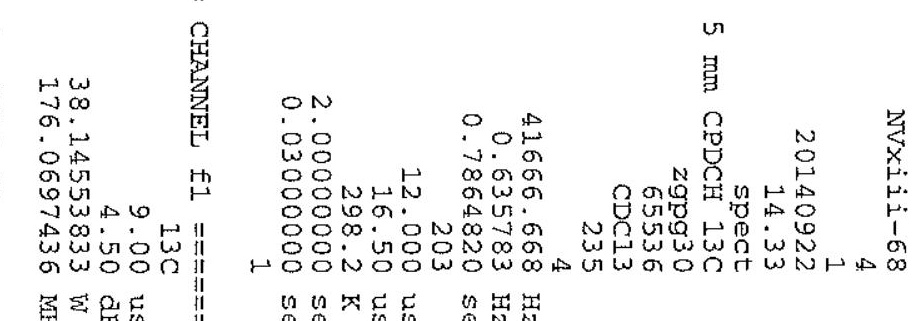



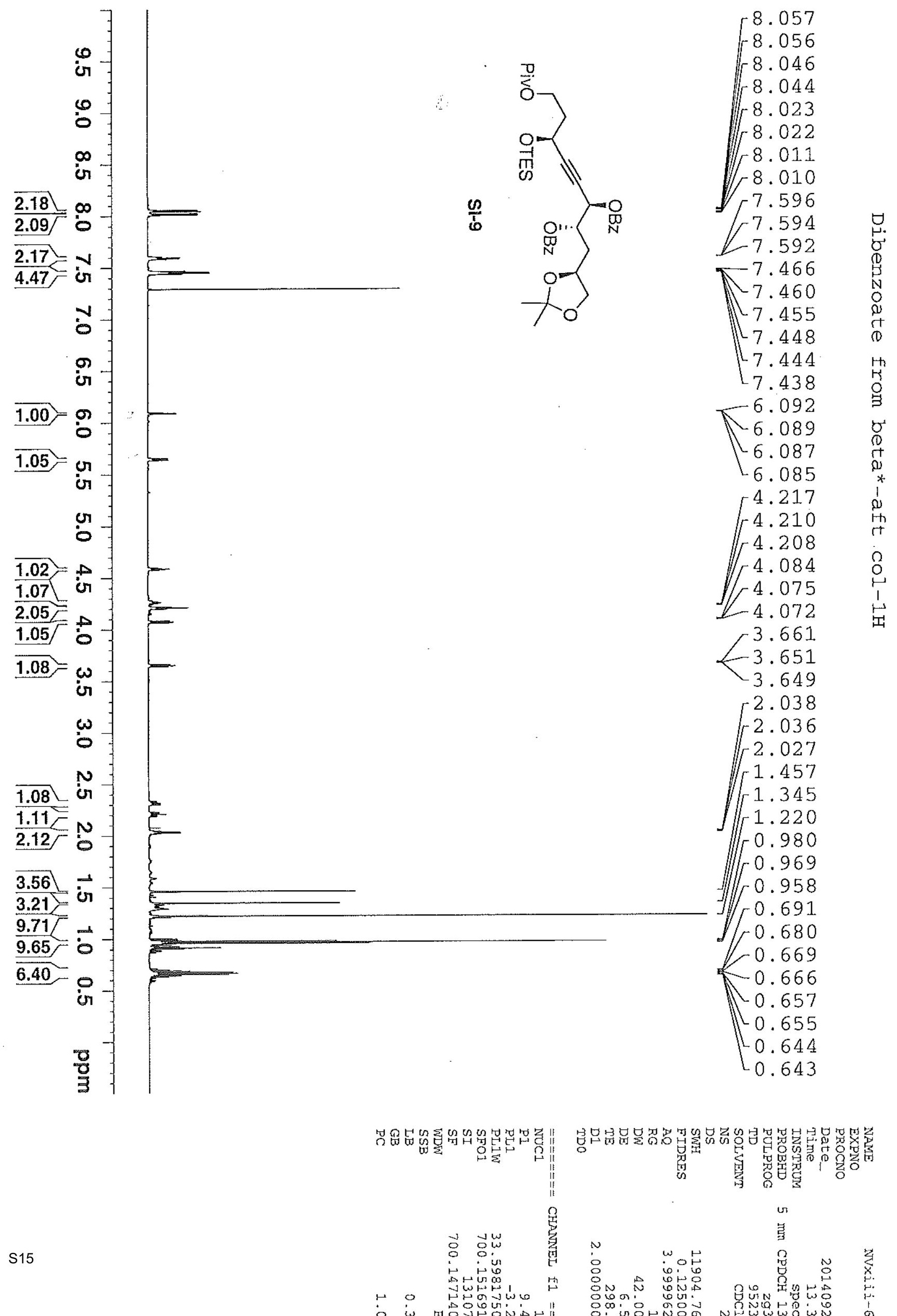


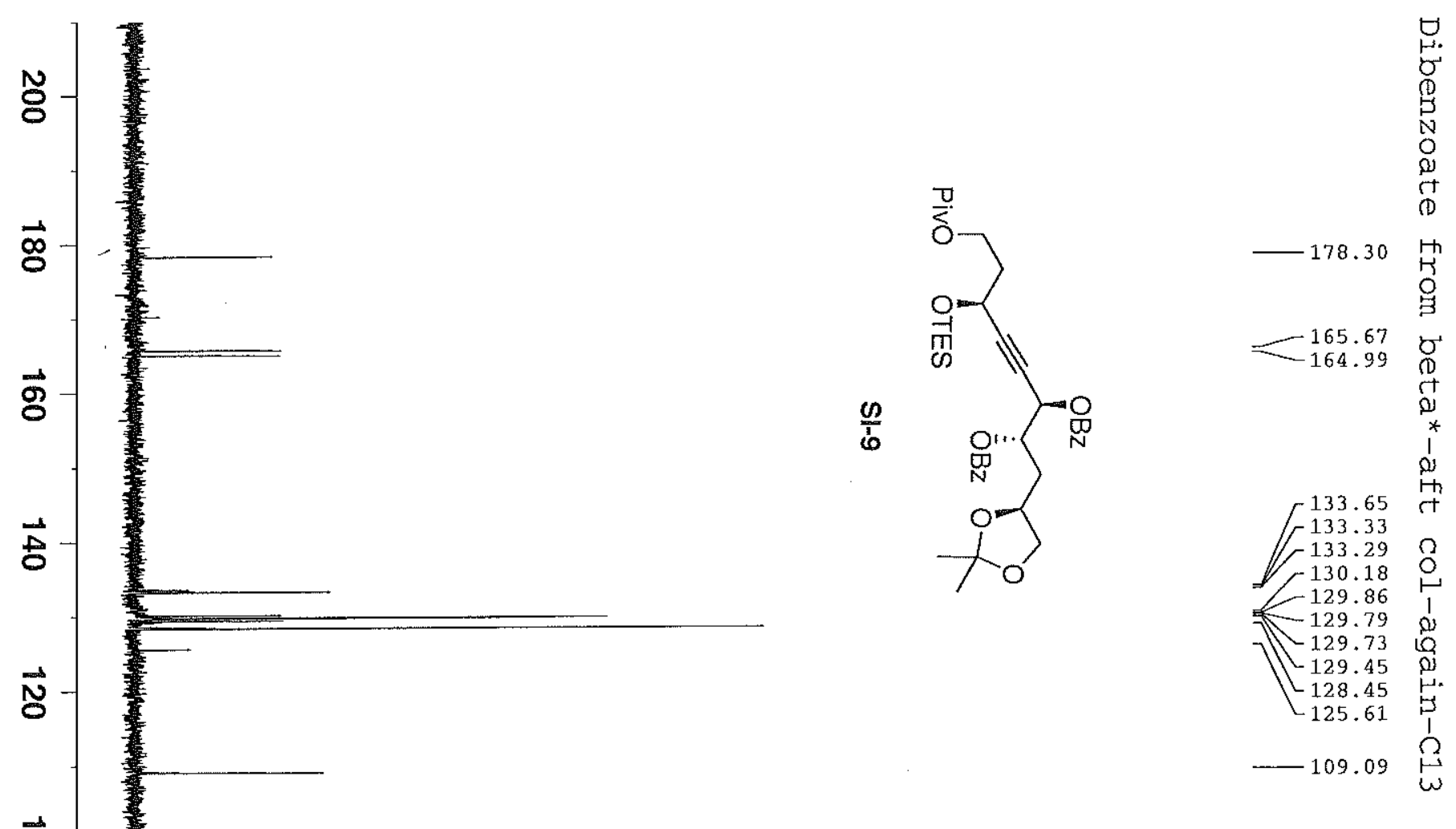

$\vec{a}$

\&

(n)

$:$

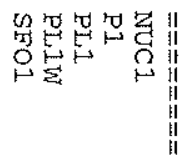

$\mapsto \omega$
wo
$o \omega$
0

o is

पu

is.

w owoon

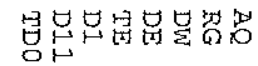
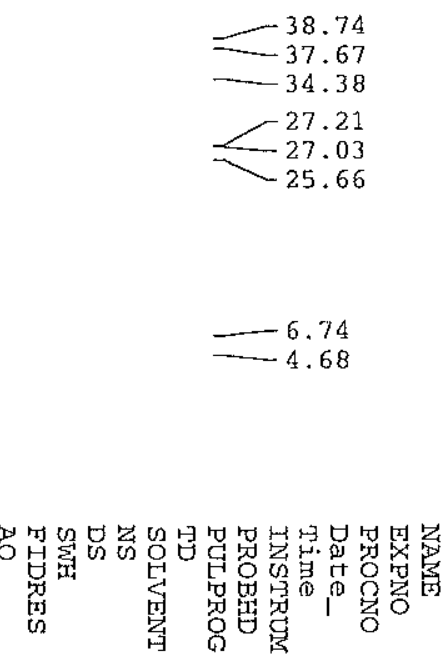

$-6.74$

$-3.68$

 $\sum 0 \leftleftarrows$

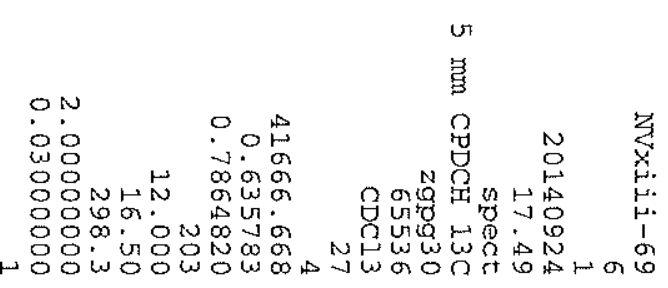




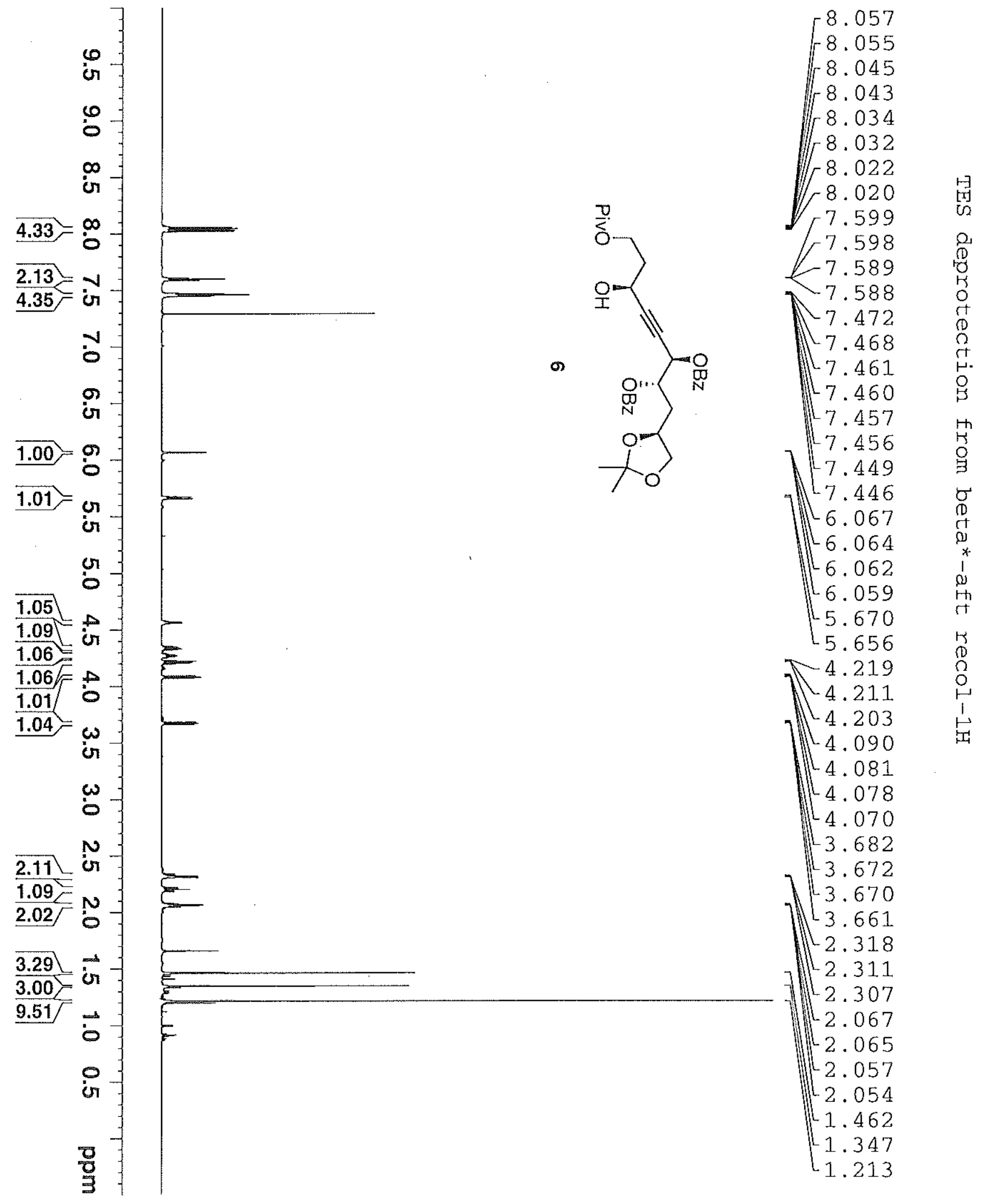

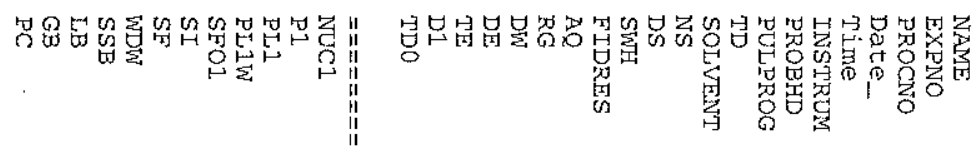




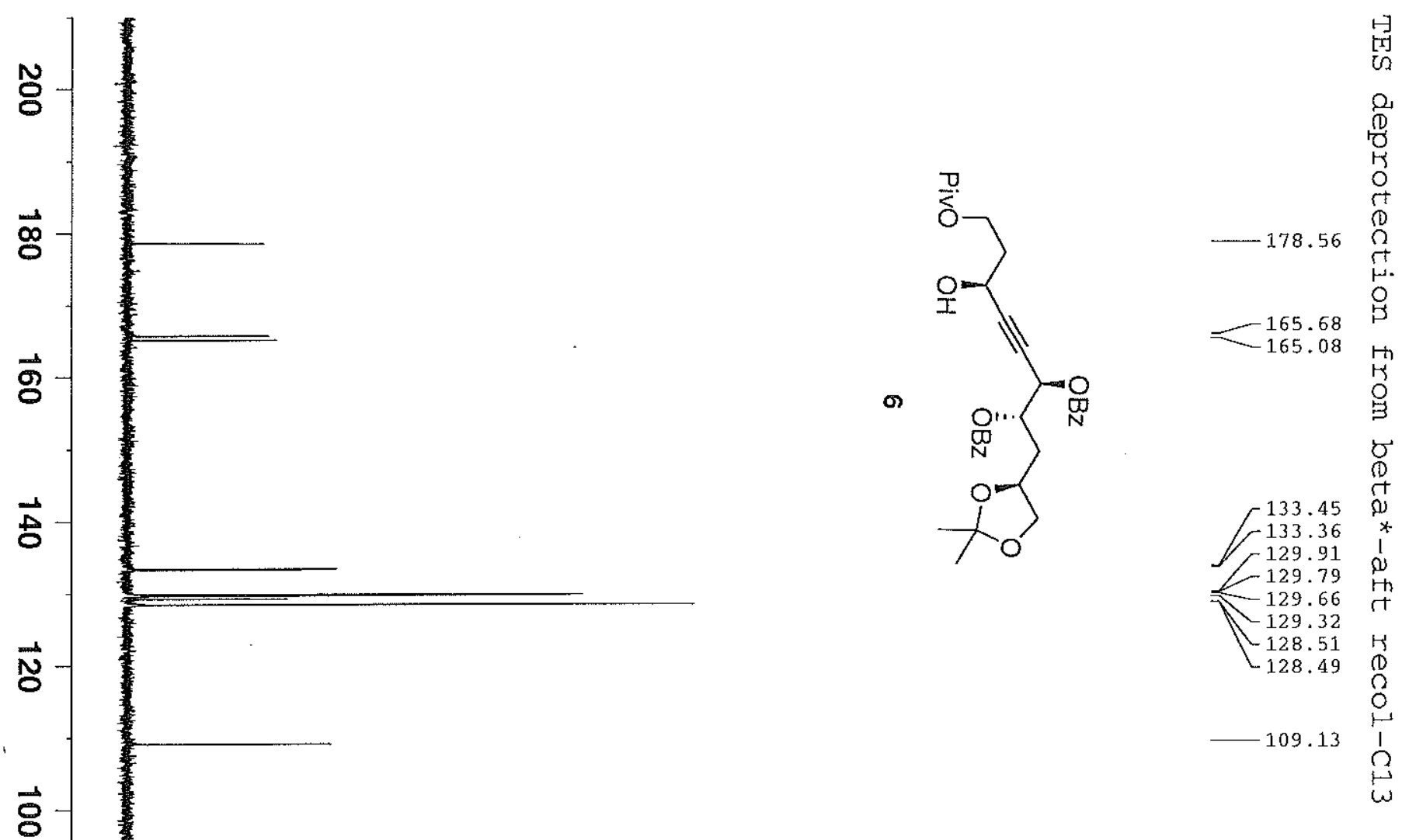

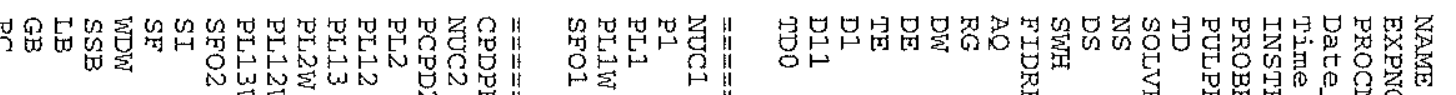
卷芝

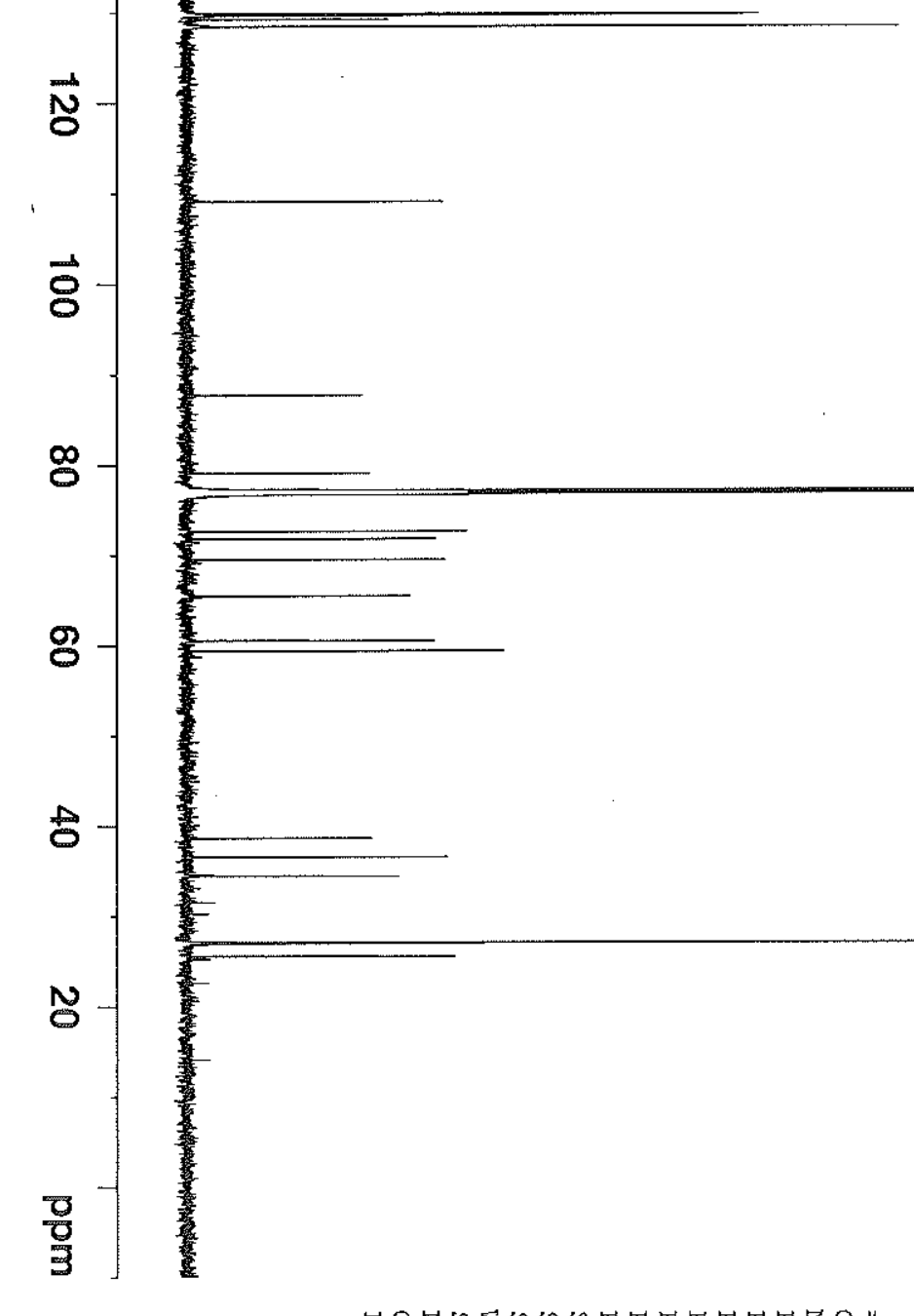

$-87.78$

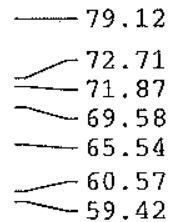

$-38.76$

-36.67
-34.52

$-27.19$

$-27.08$

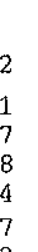




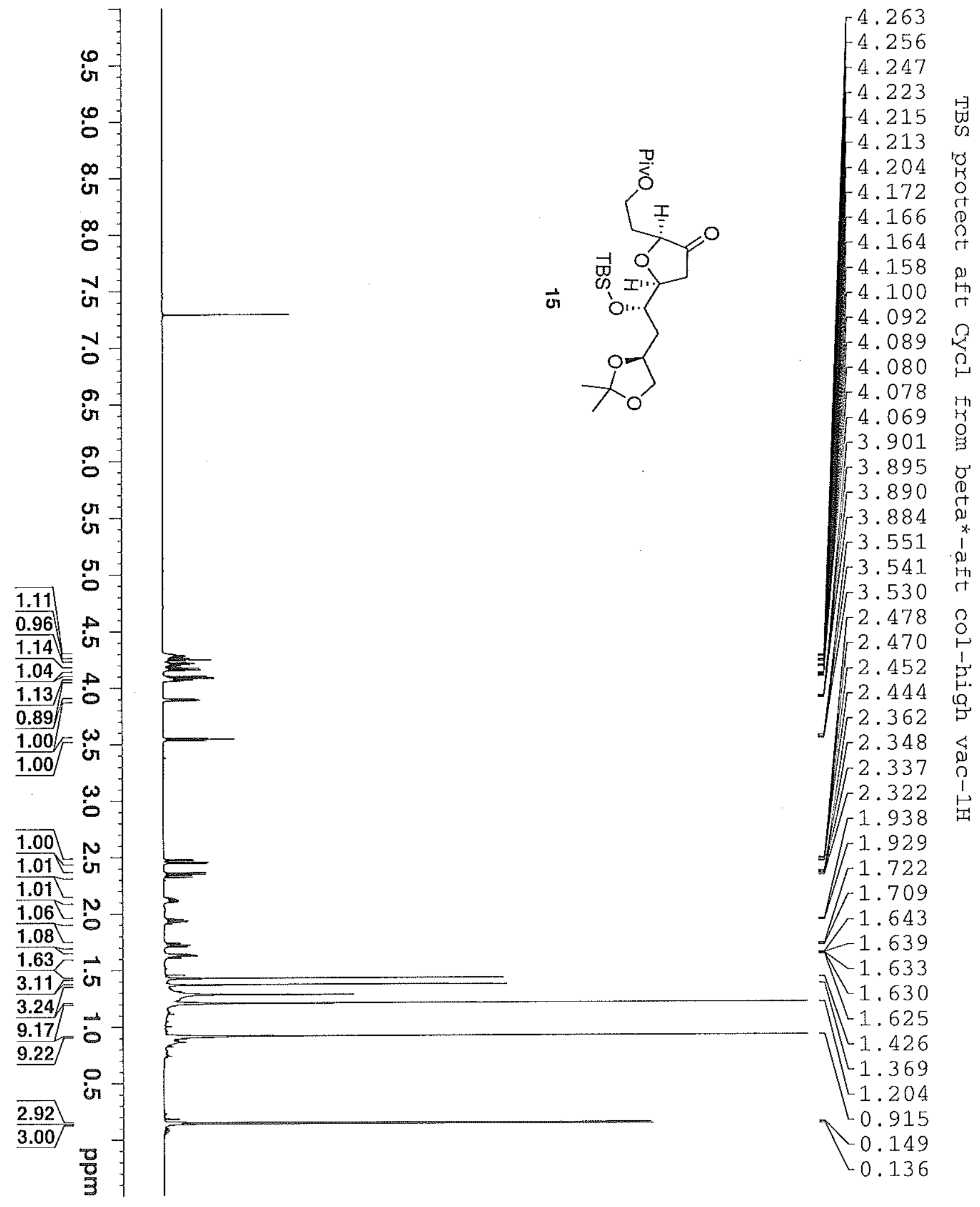

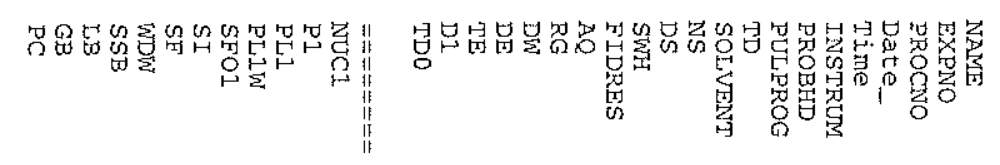

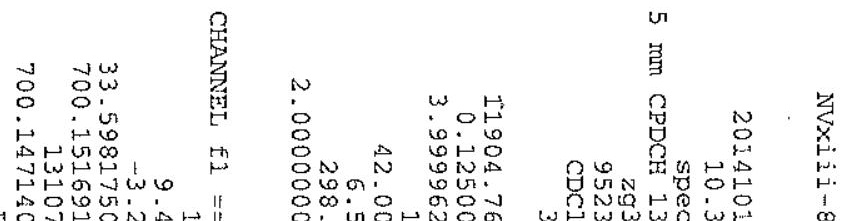




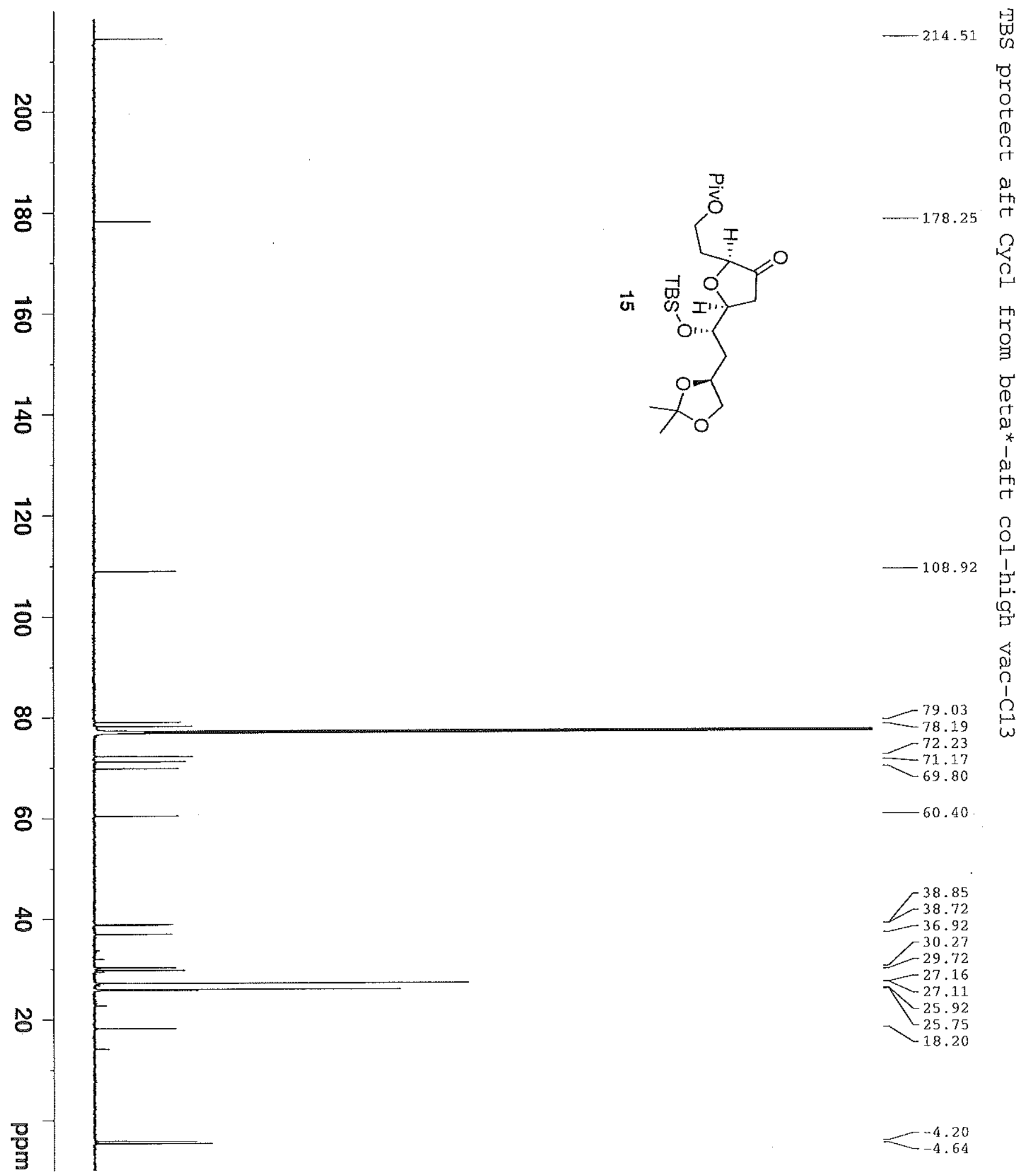

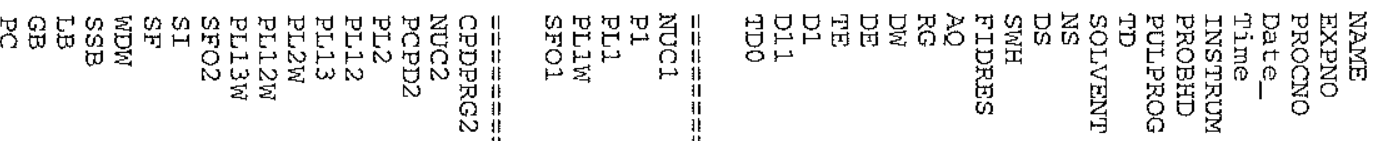



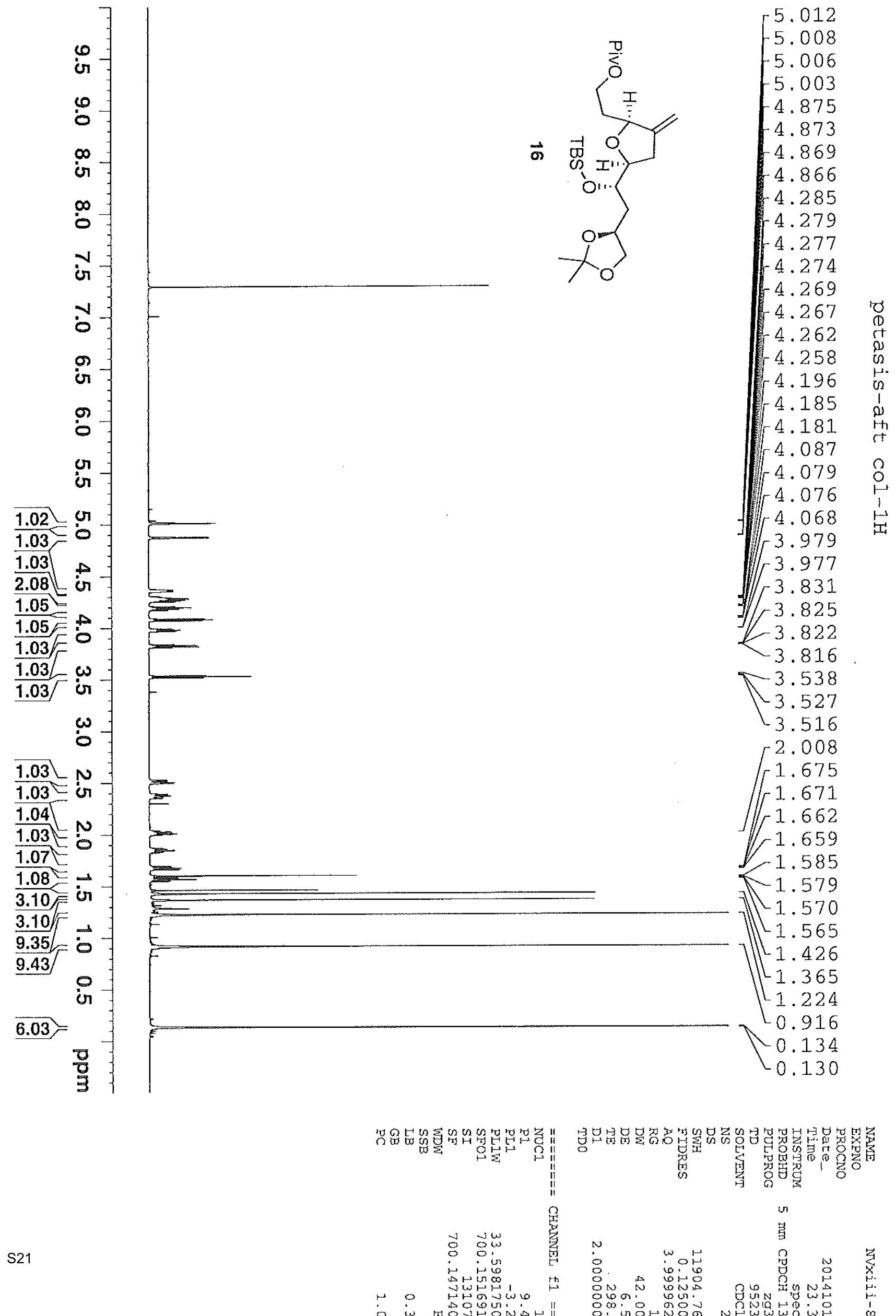


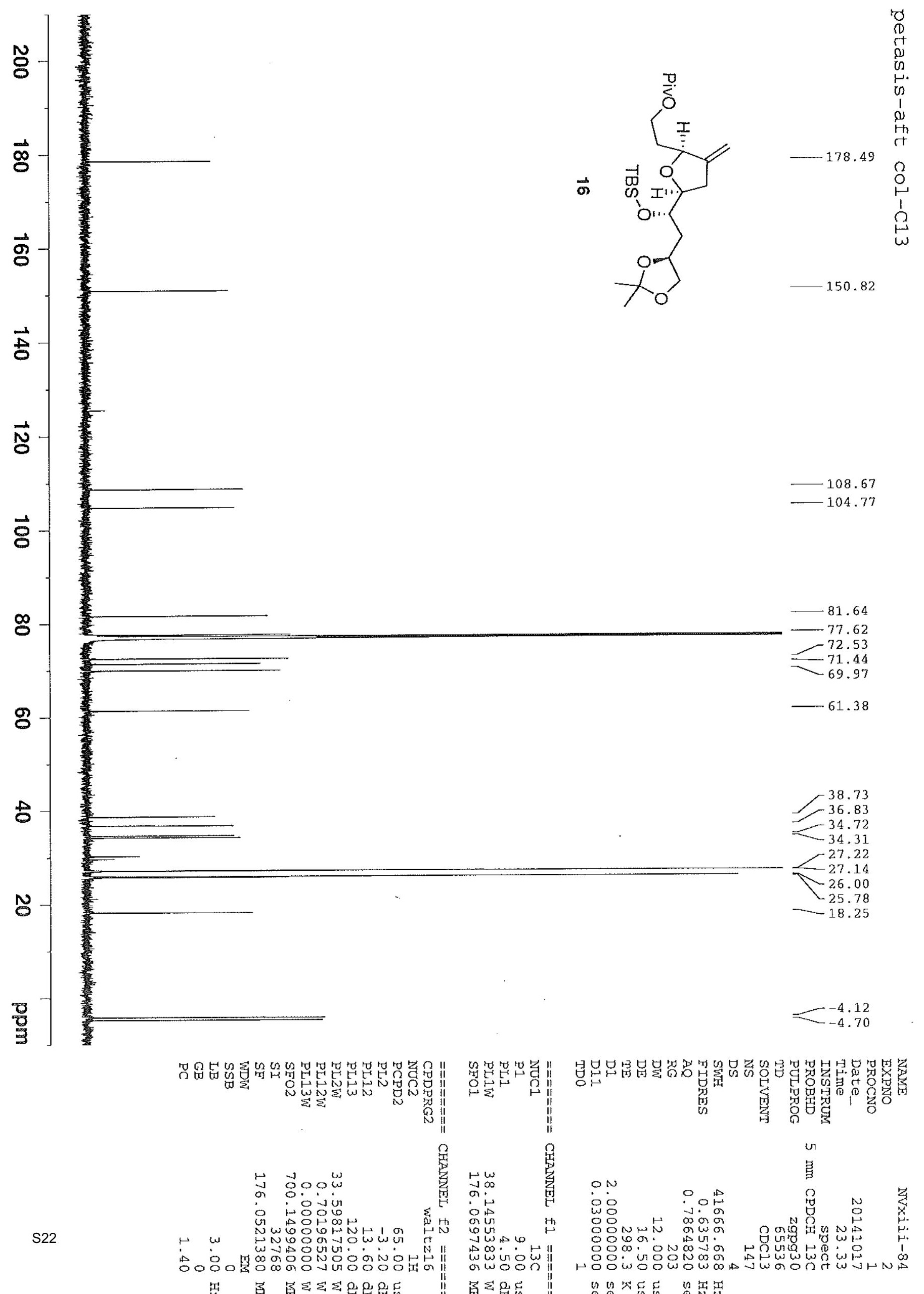




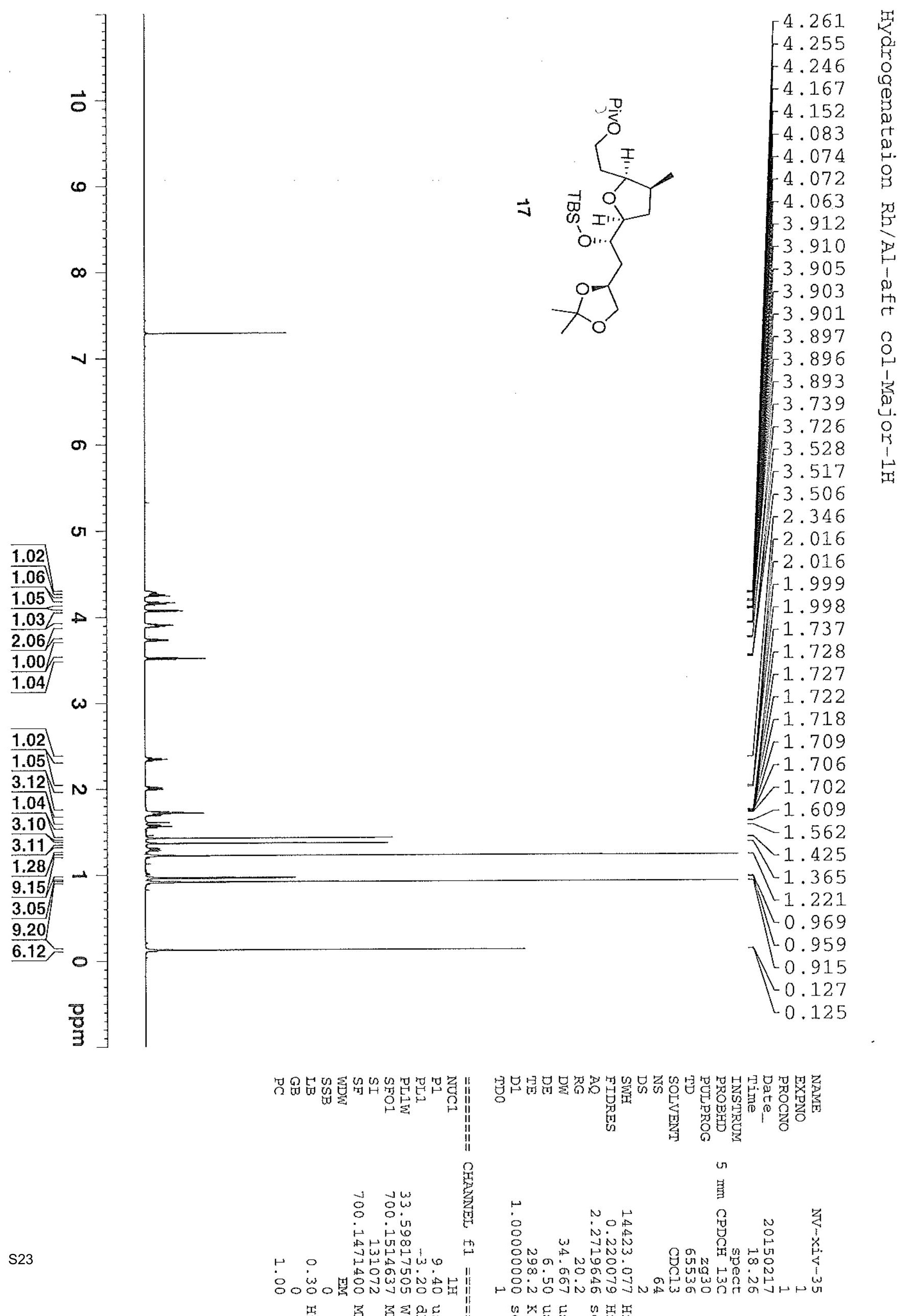




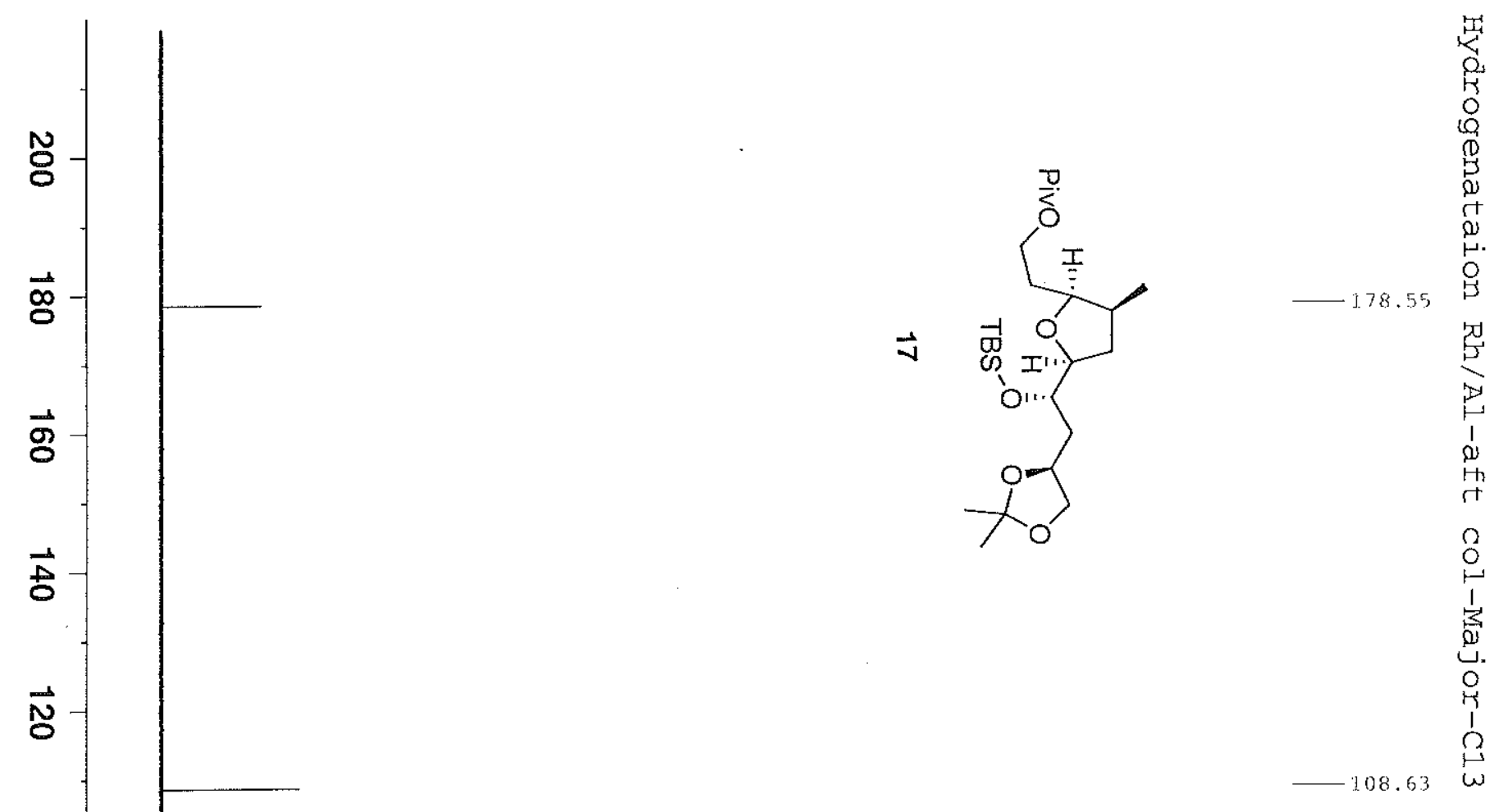

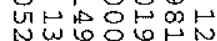

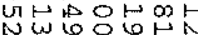

$\vdash \vdash \quad$ H.

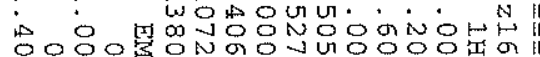

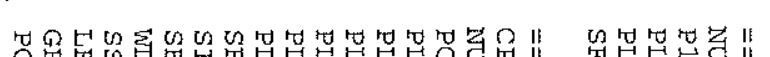
硬

$$
\begin{aligned}
& \mapsto \text { วั0оw } \\
& \text { \% }
\end{aligned}
$$

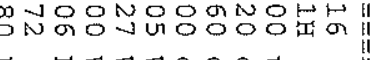

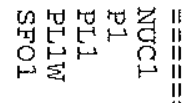

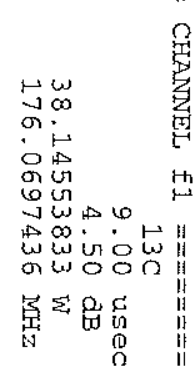

是点

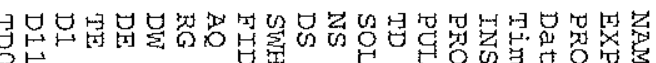
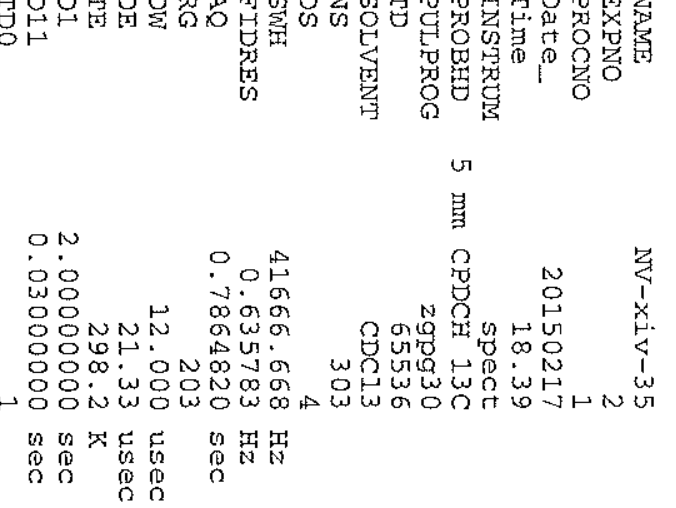


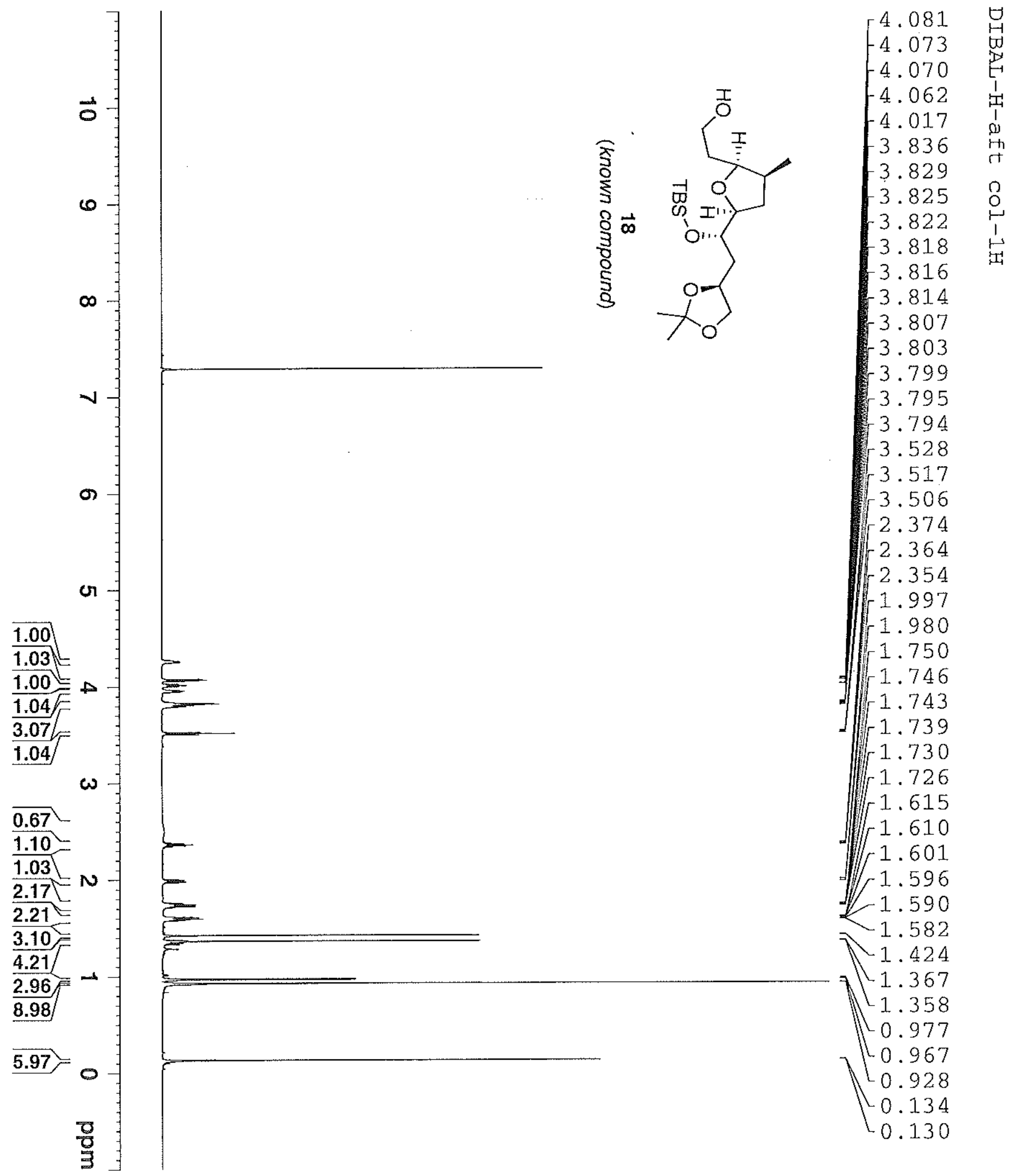

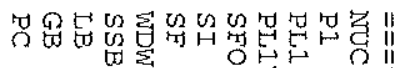
ष是

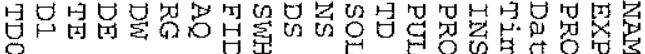

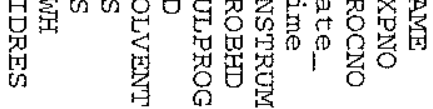

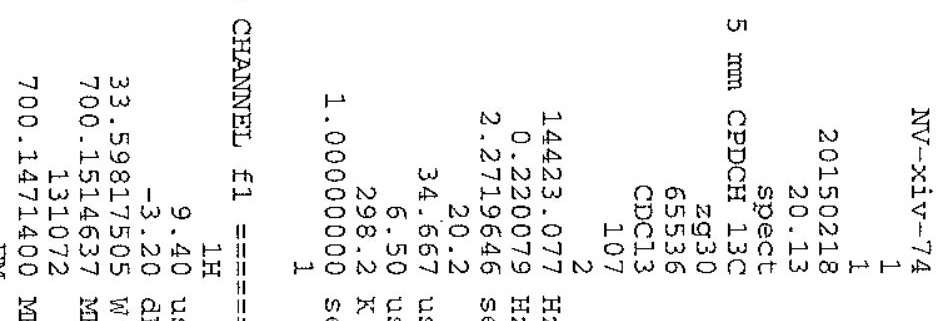




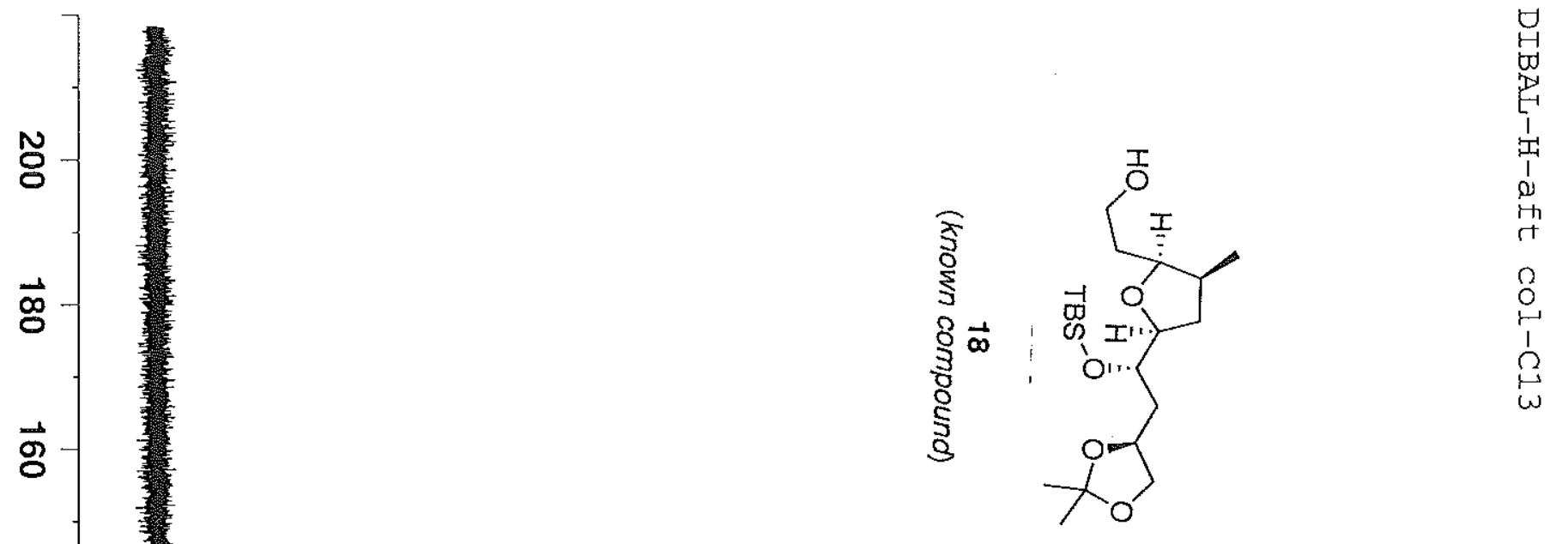

$\overrightarrow{8}$

$\infty$

$\overrightarrow{0}$

$\overrightarrow{\mathrm{O}}$

g

$+$

骂

(

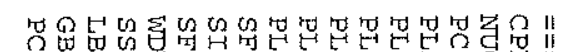

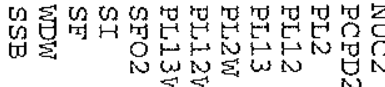

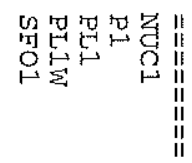

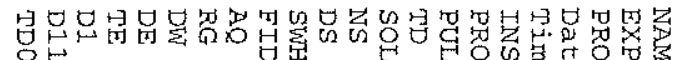

$=-4.05$

37.26
35.75

34.98
-33.12

$-33.12$

$-2.12$

$-2.9 .97$

$-18.20$

$-15.34$

$=-4.60$

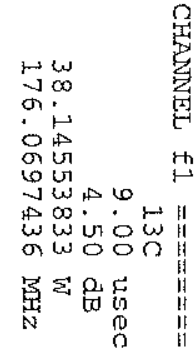

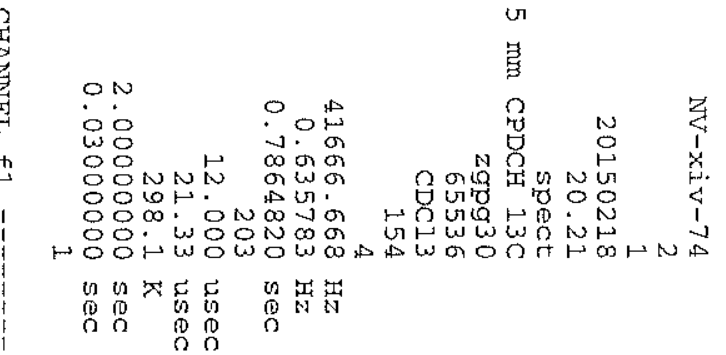

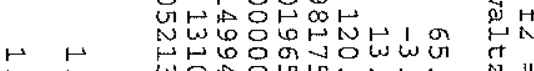

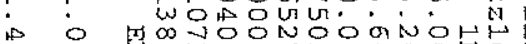




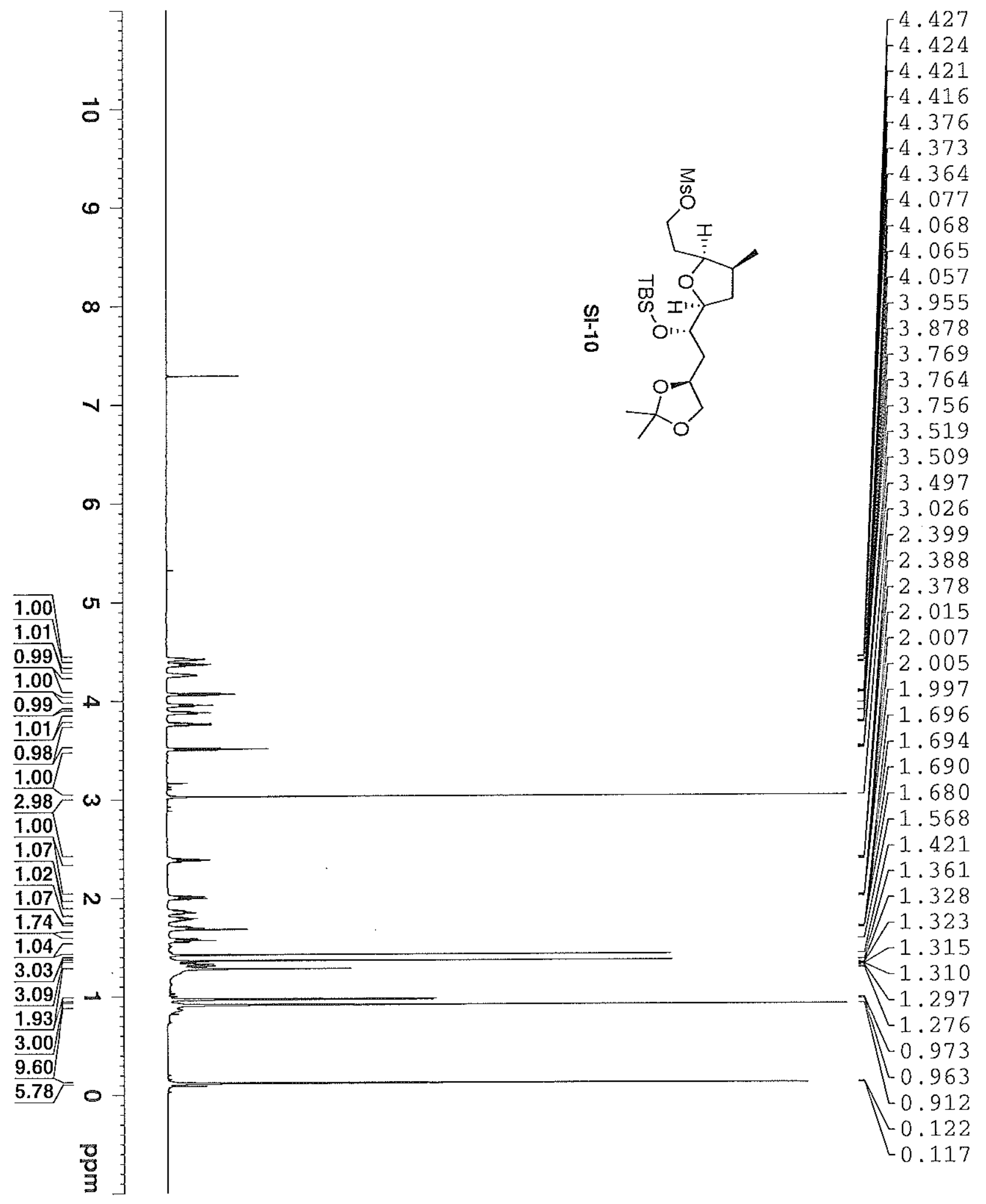

点

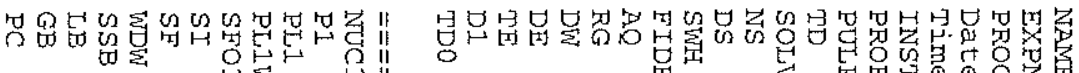

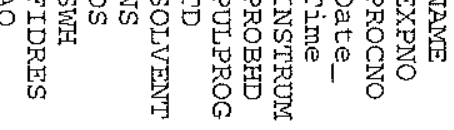

u
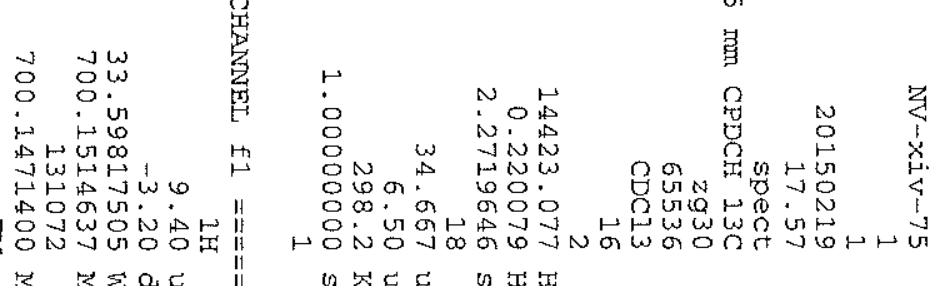


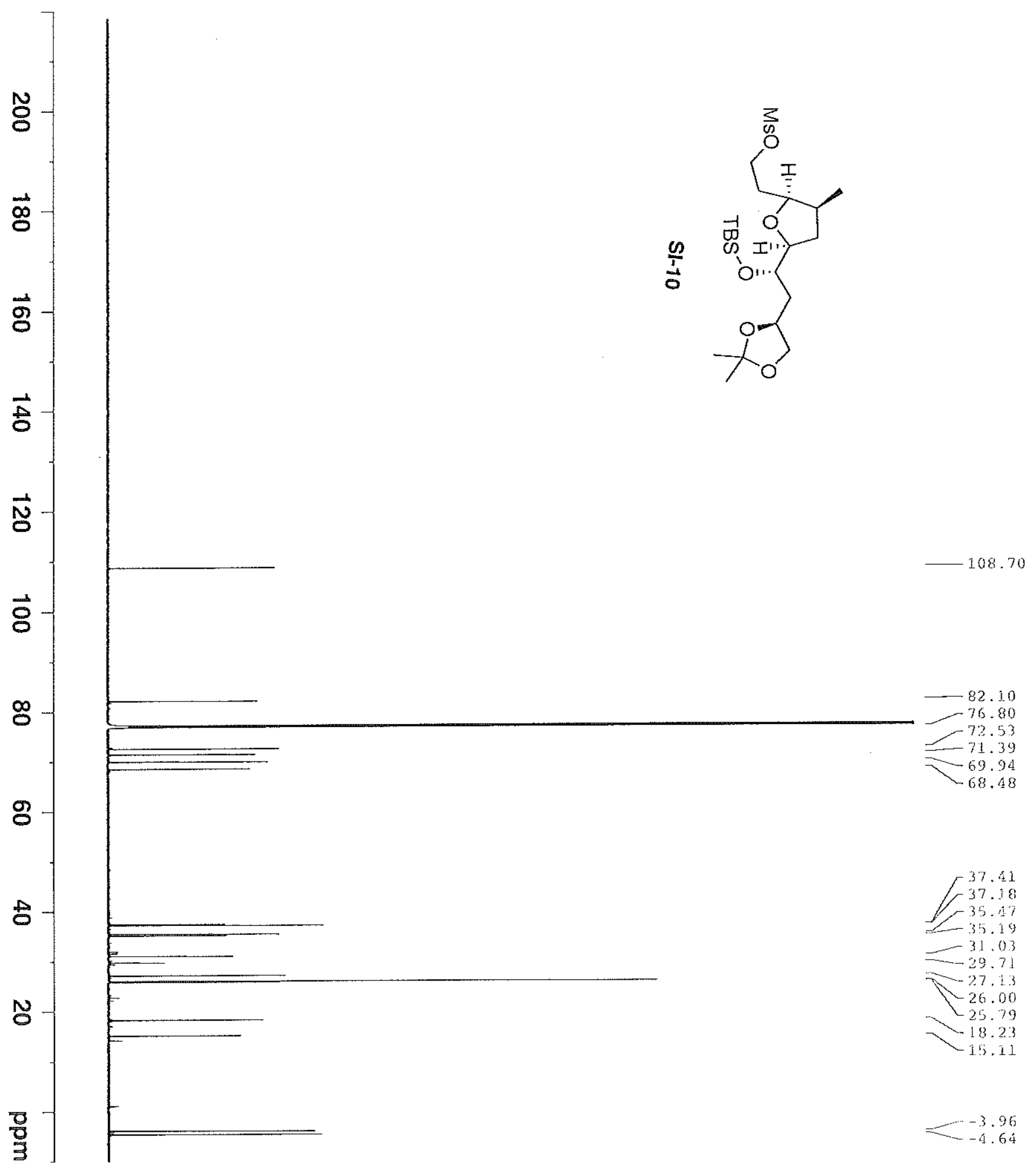

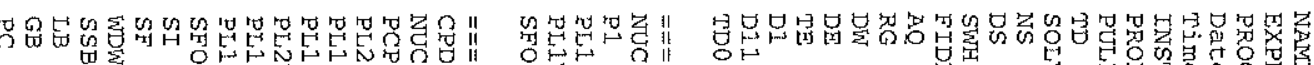

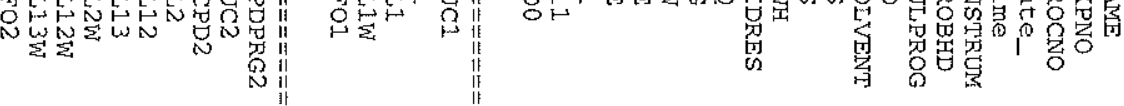

苛 ㅎํㅇㅇํ

م.

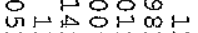

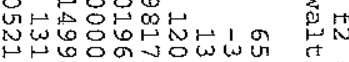

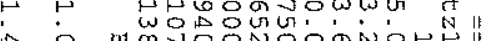

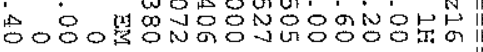

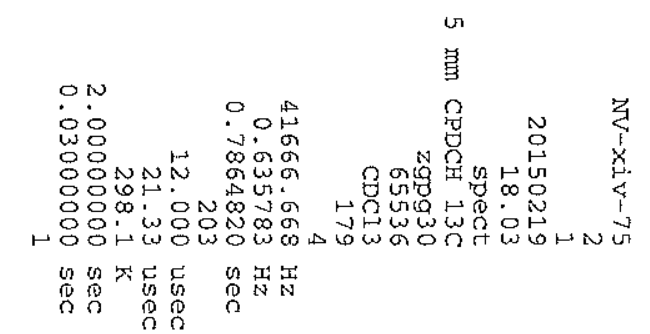




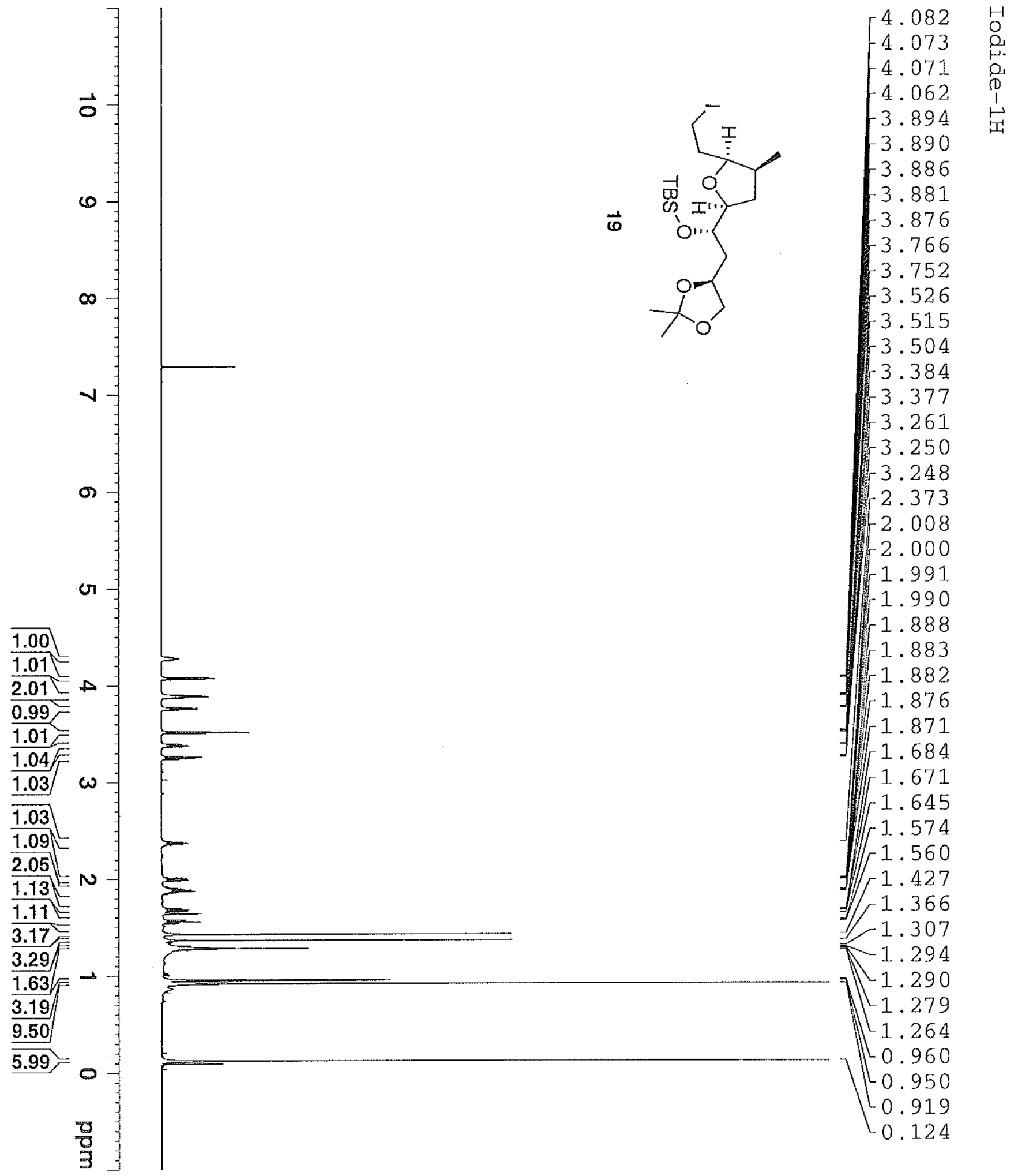

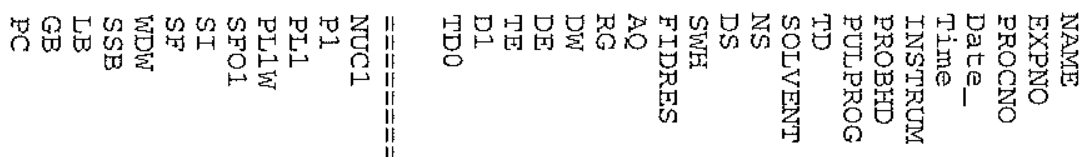

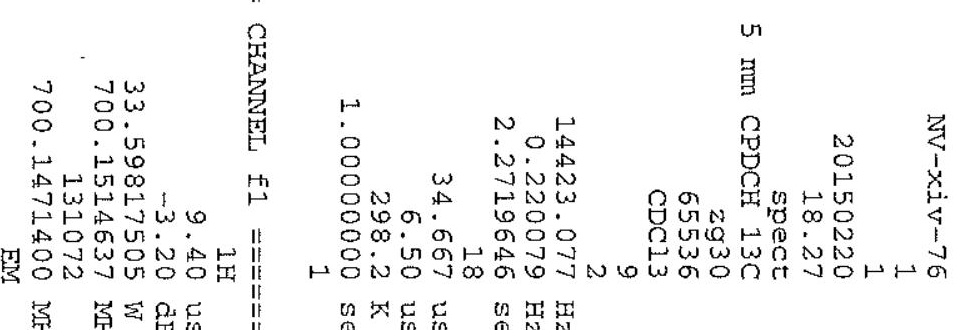




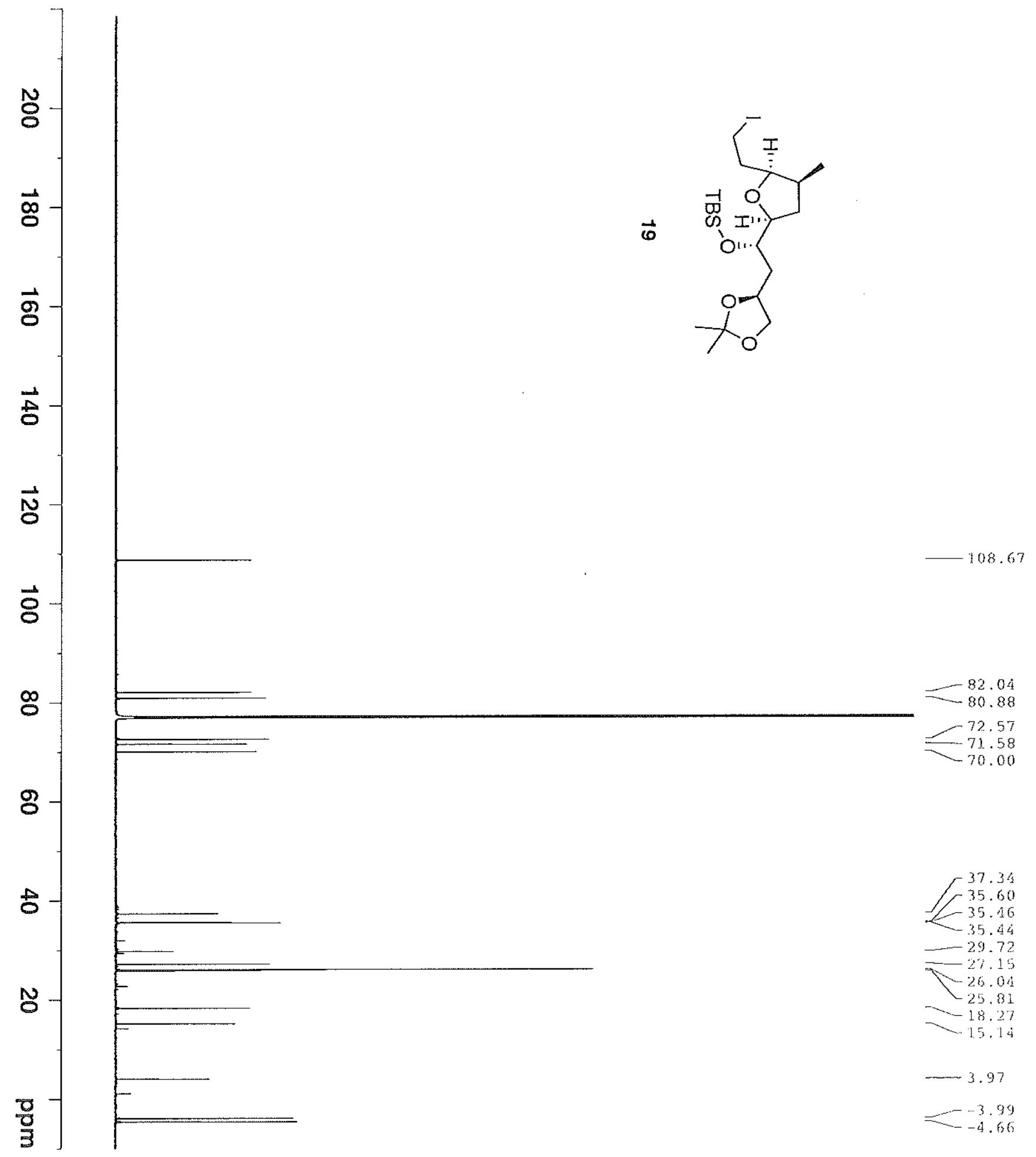

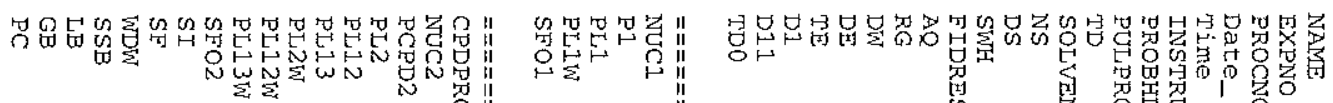

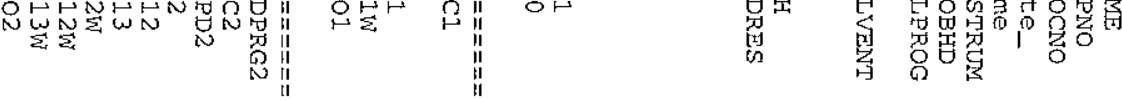

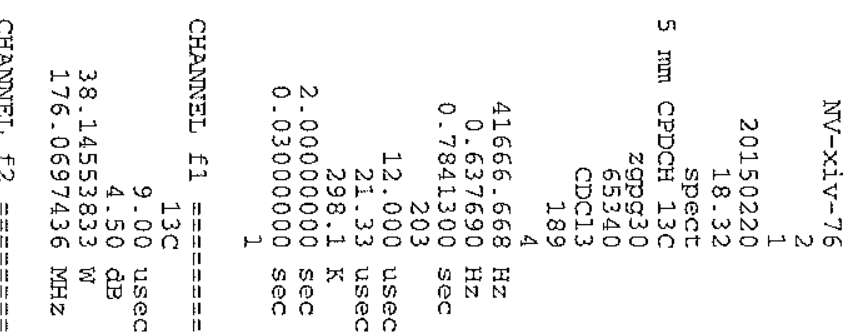




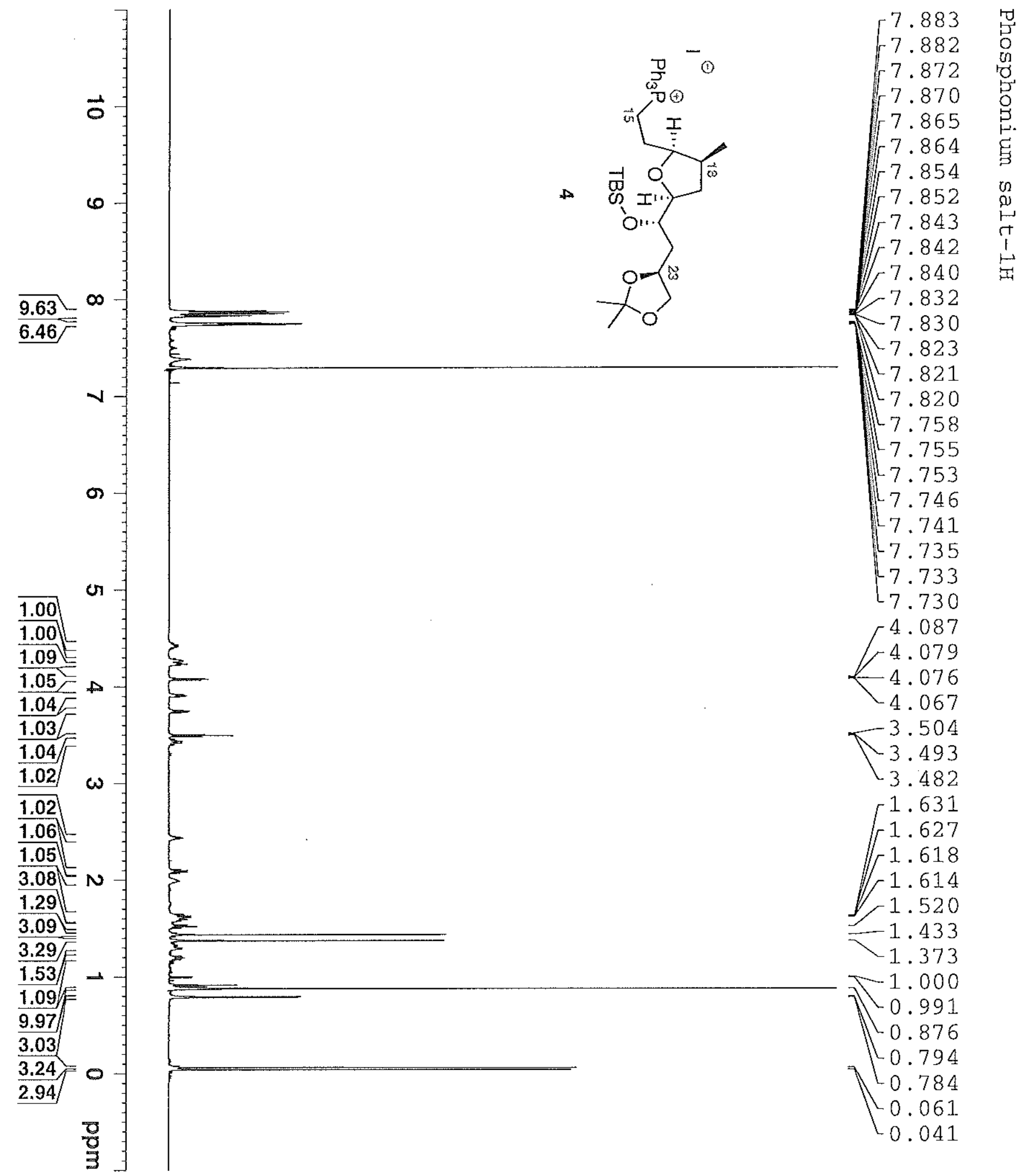

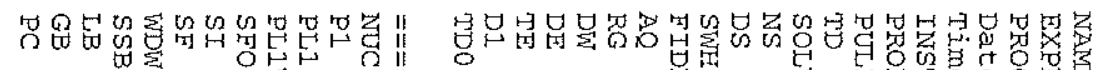




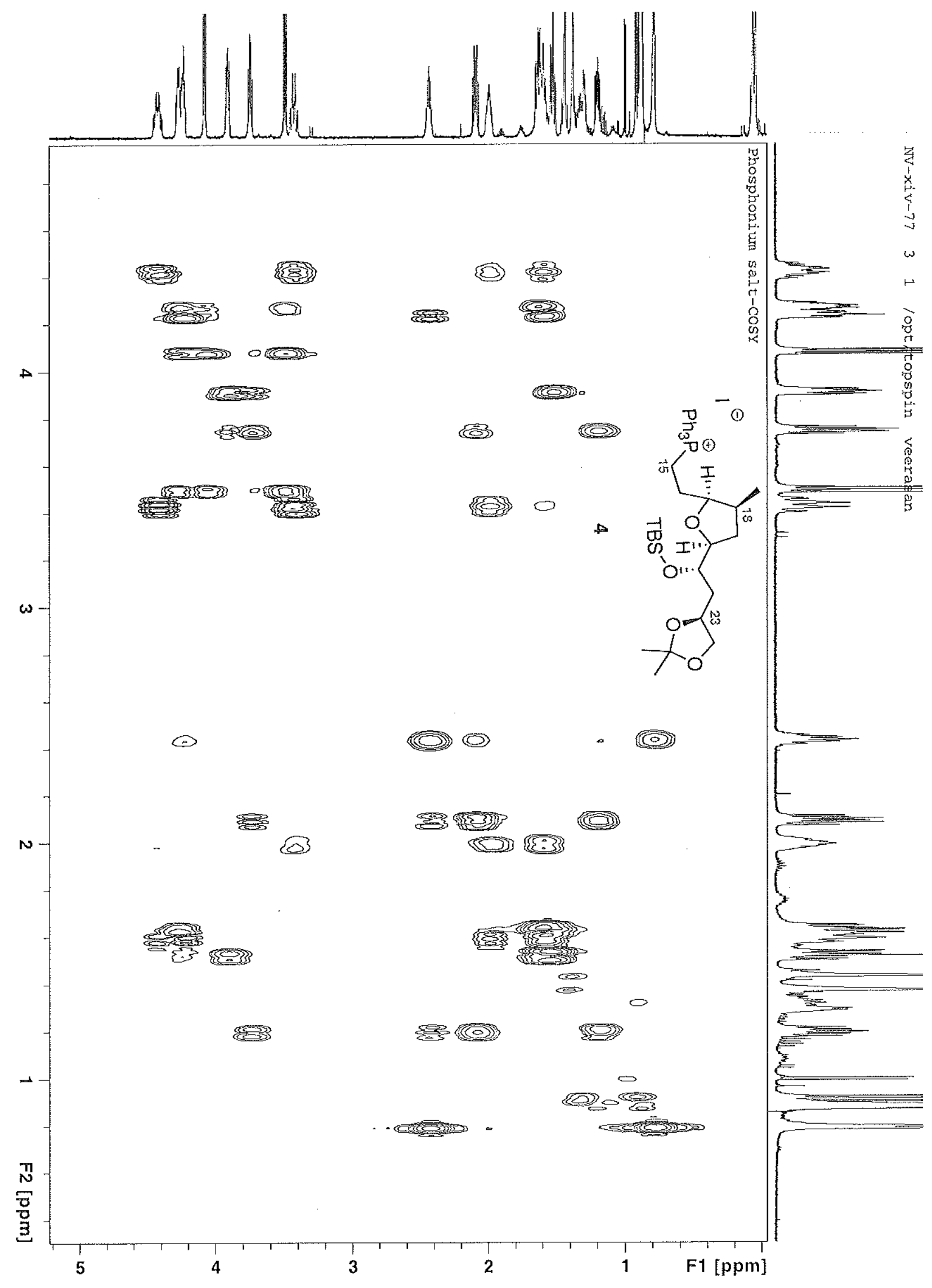




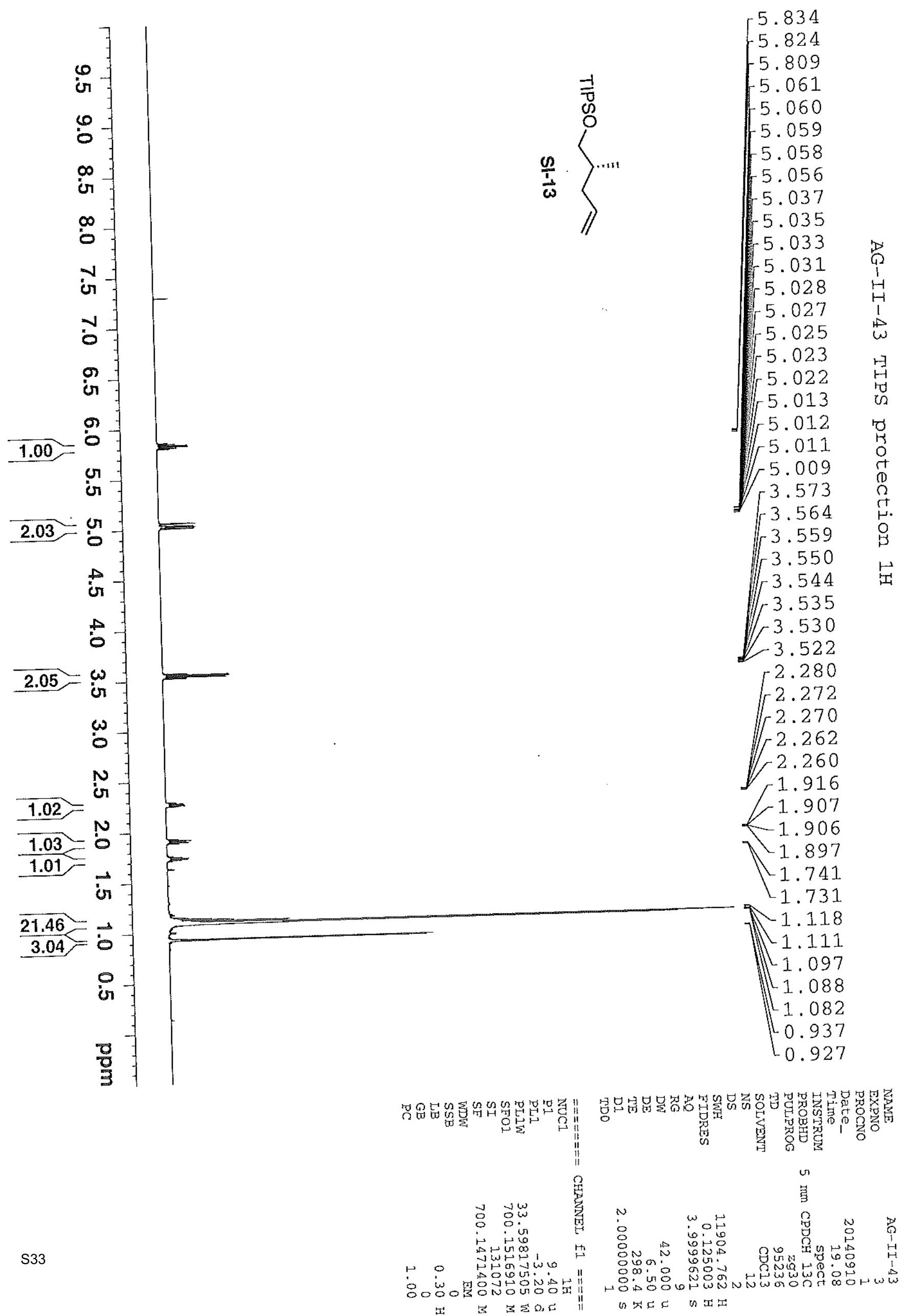




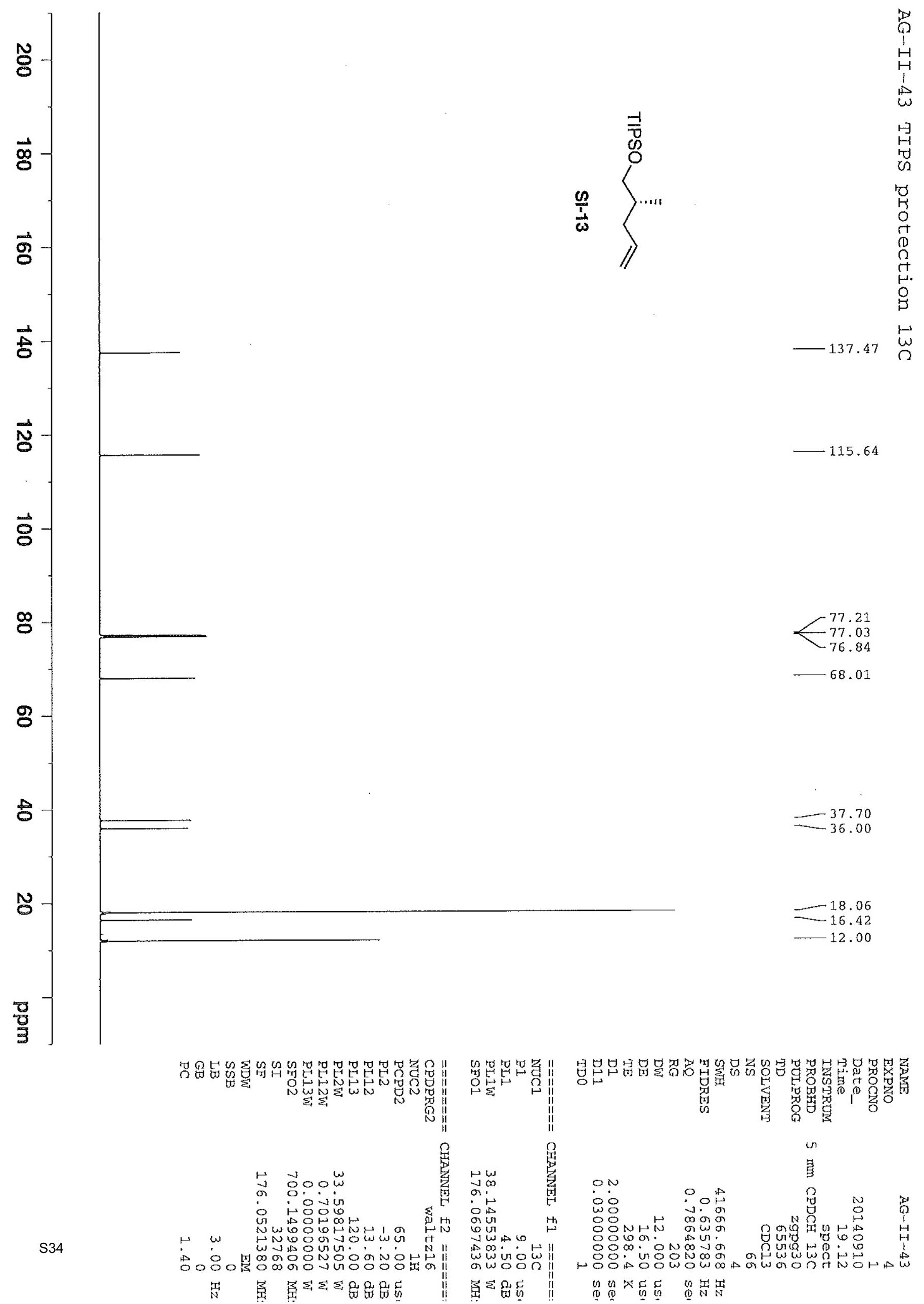



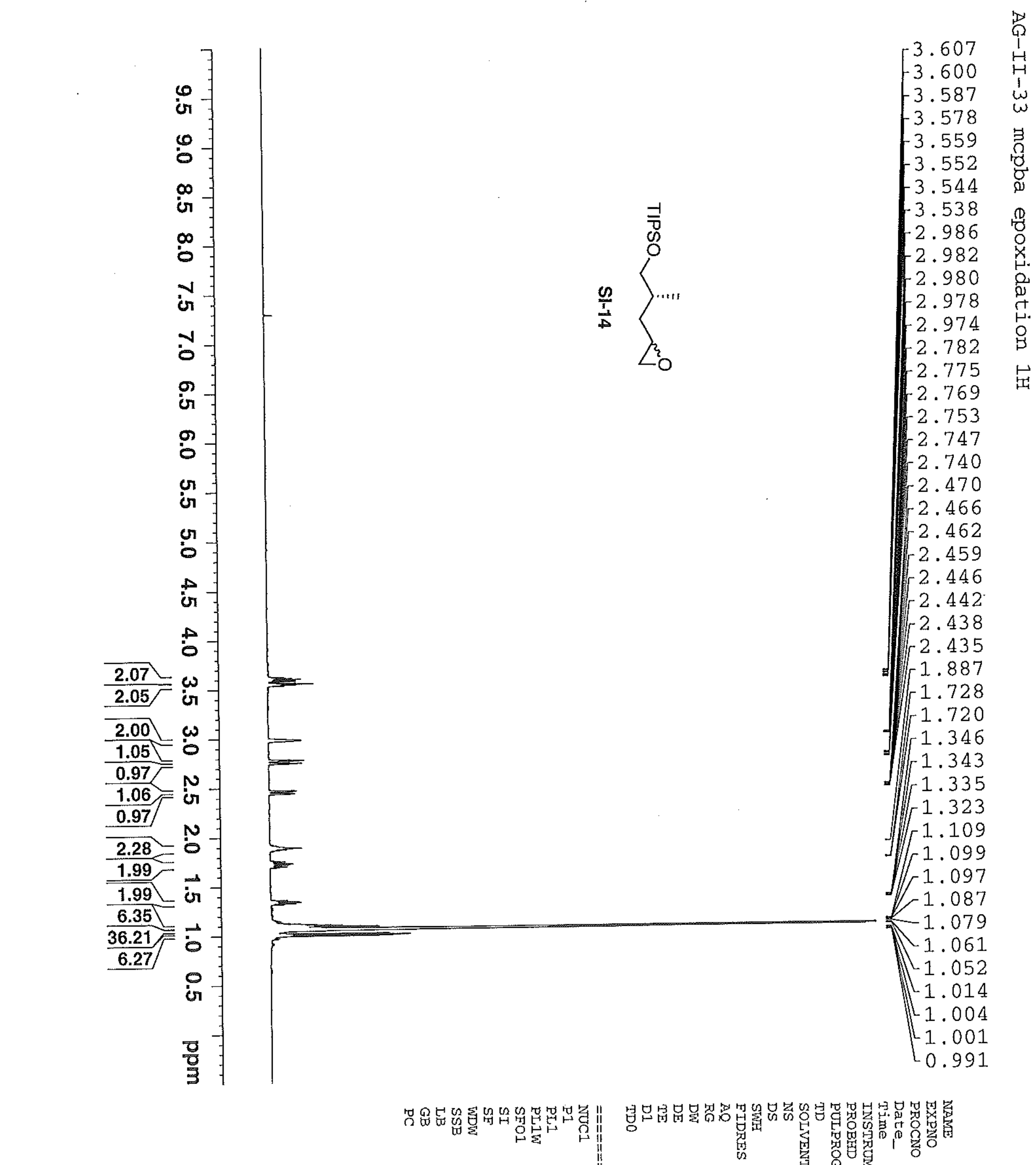

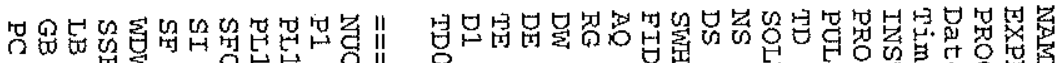
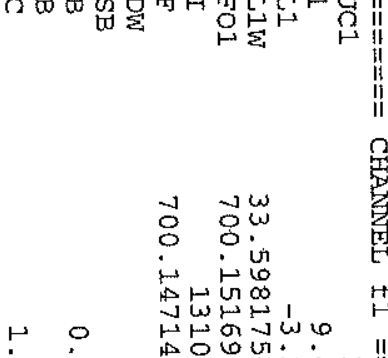

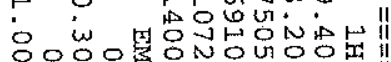

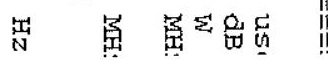

$$
\text { , }
$$




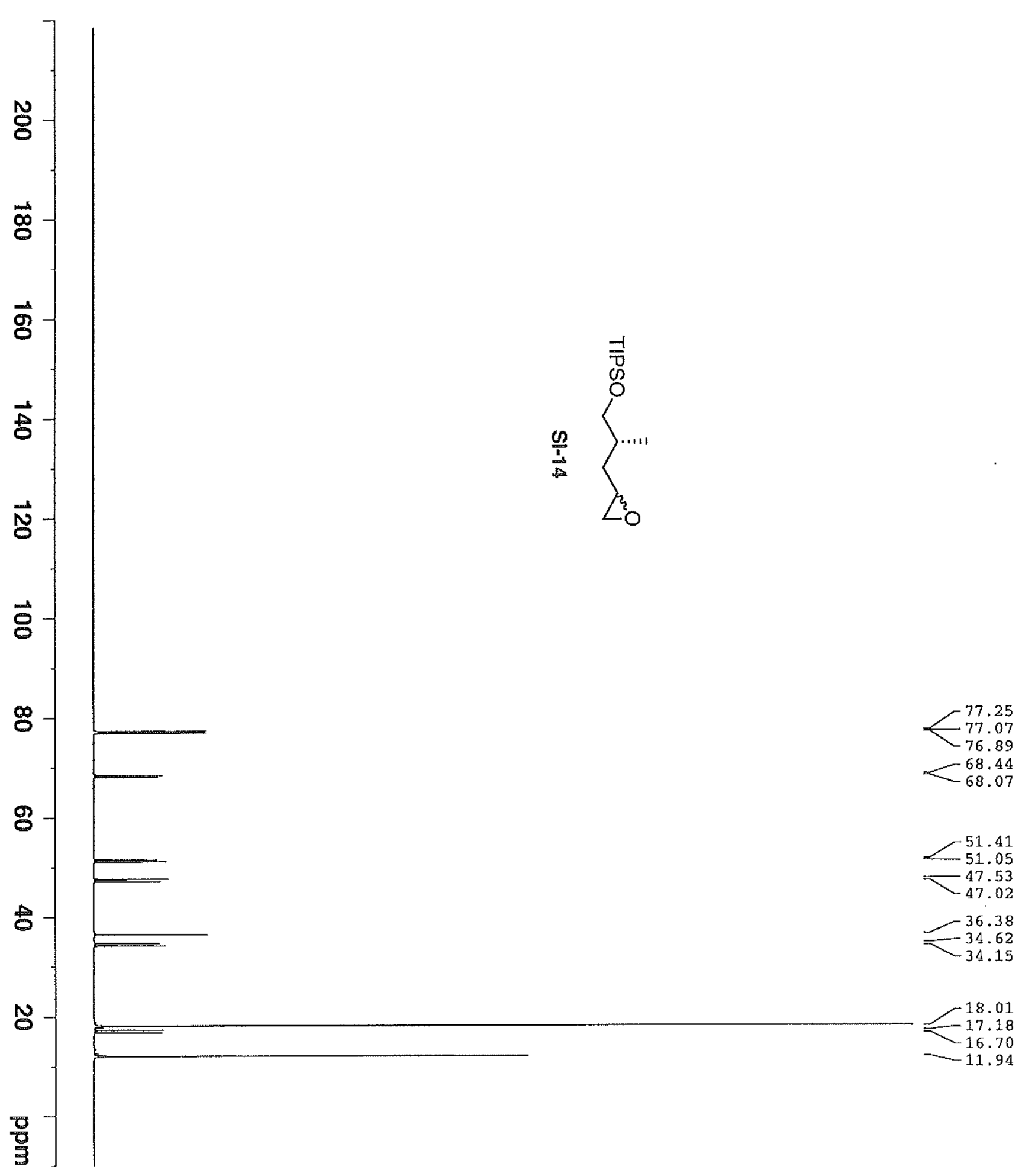

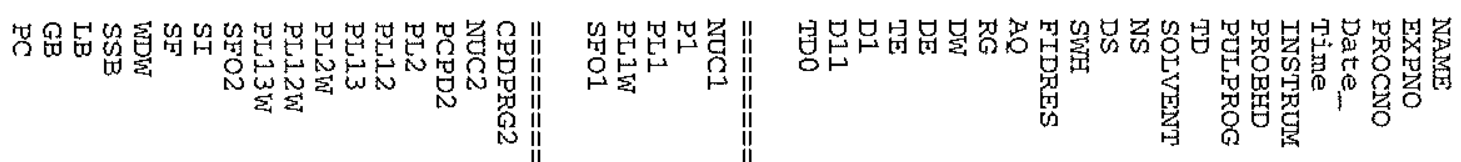




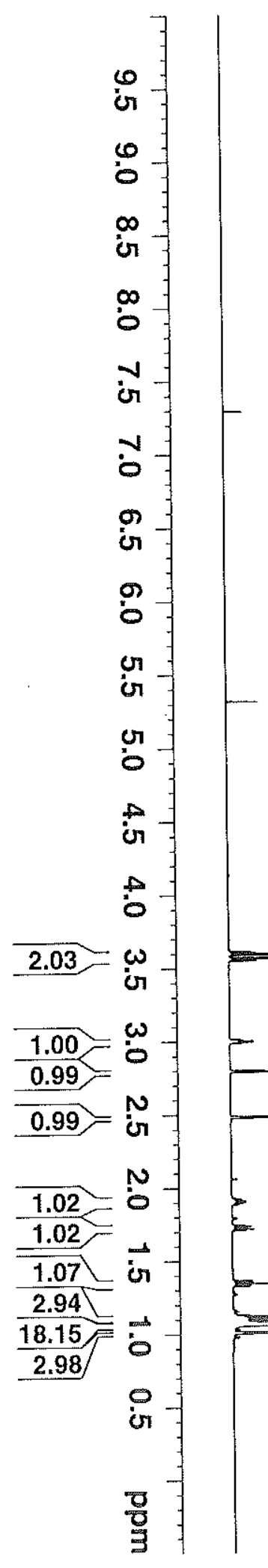

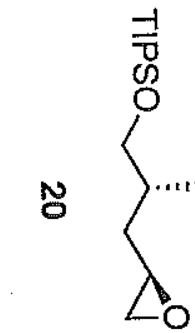

7.290

$-5.314$

$-3.610$

$-3.601$

$-3.596$

$-3.587$

$-3.570$

3.561

3.556

3.548

3.002

2.997

2.993

2.799

2.792

2.787

2.786

2.487

2.483

2.479

2.475

1.900

$-1.735$

$-1.724$

1.715

1.363

1. 355

1.351

1.343

1.335

1.331

1. 323

1. 123

-1.119

-1.115

1.110

1.107

1.105

$-1.098$

$-1.090$

$-1.083$

$-1.071$

$-1.062$

$L_{1.057}$

1.053

1.012

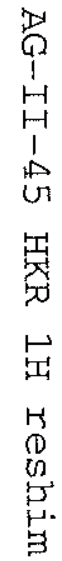

1.002

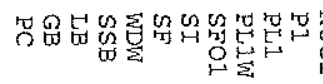

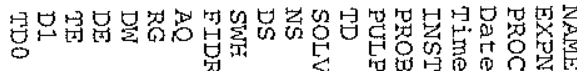

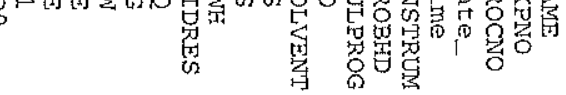

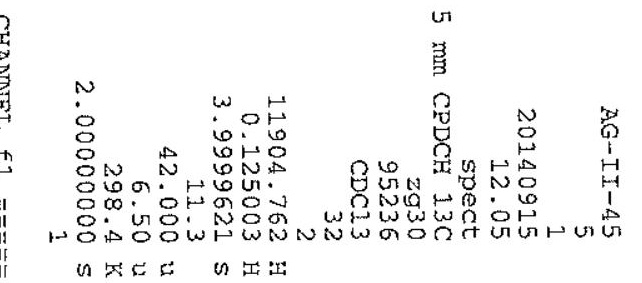




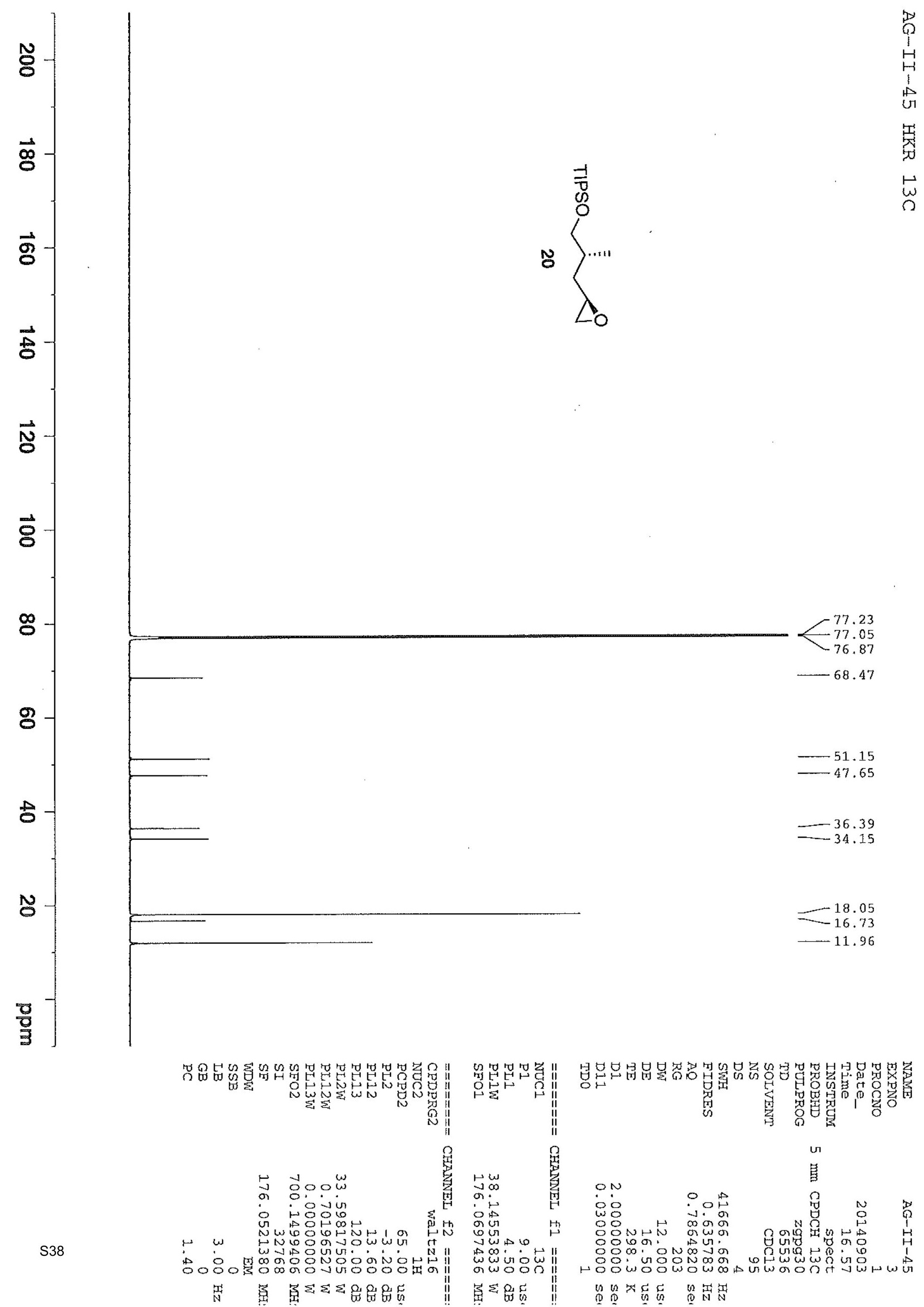




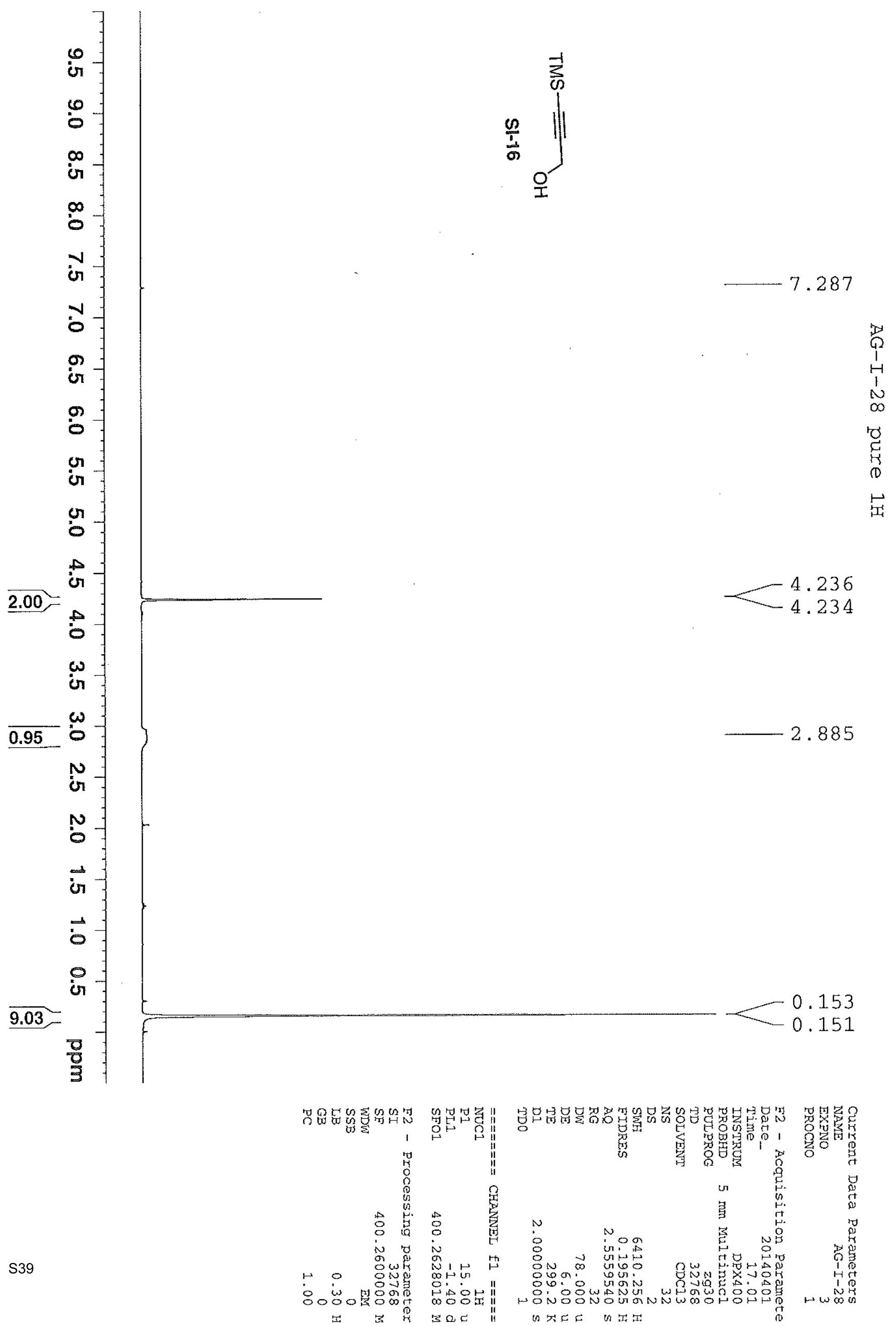




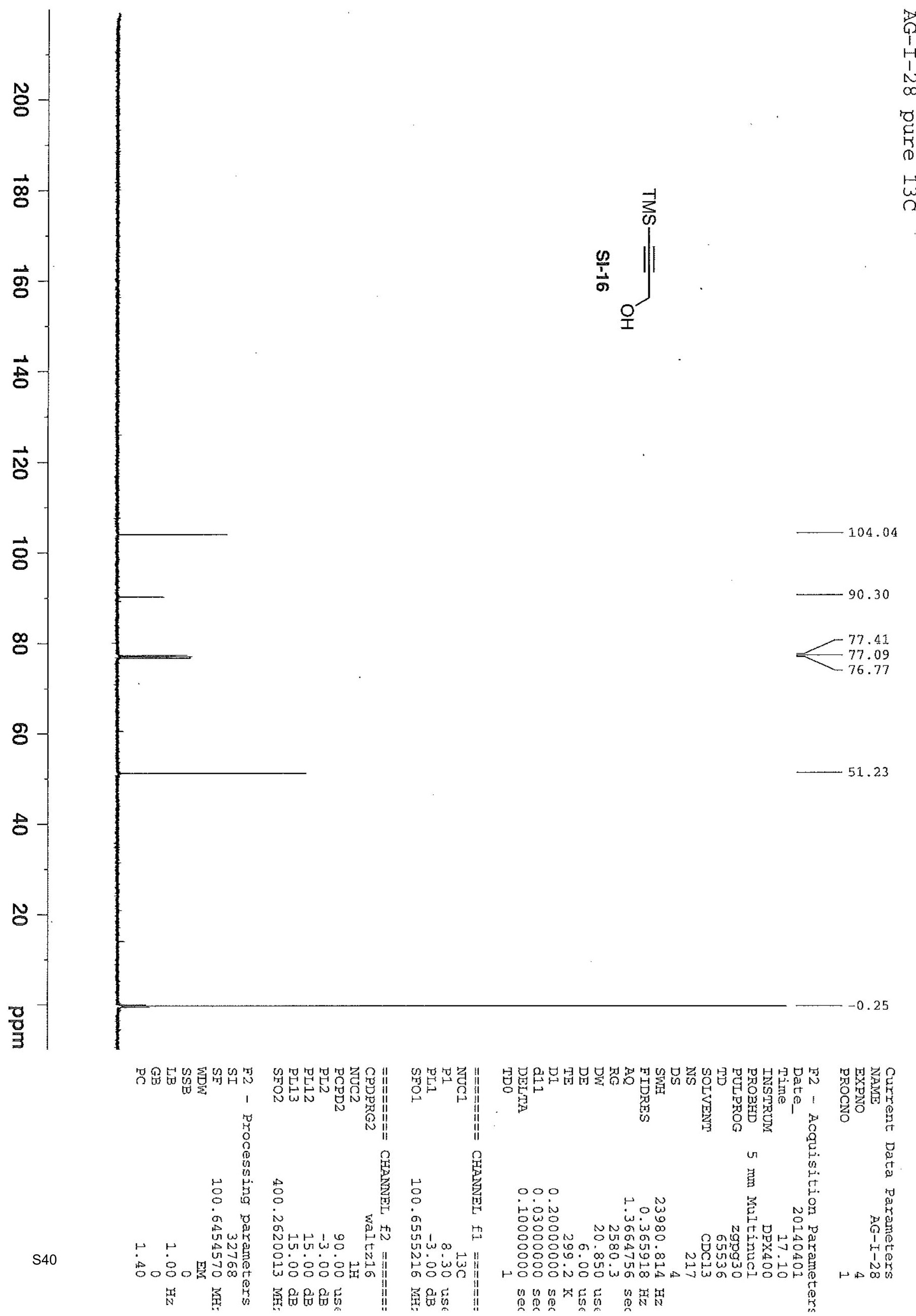



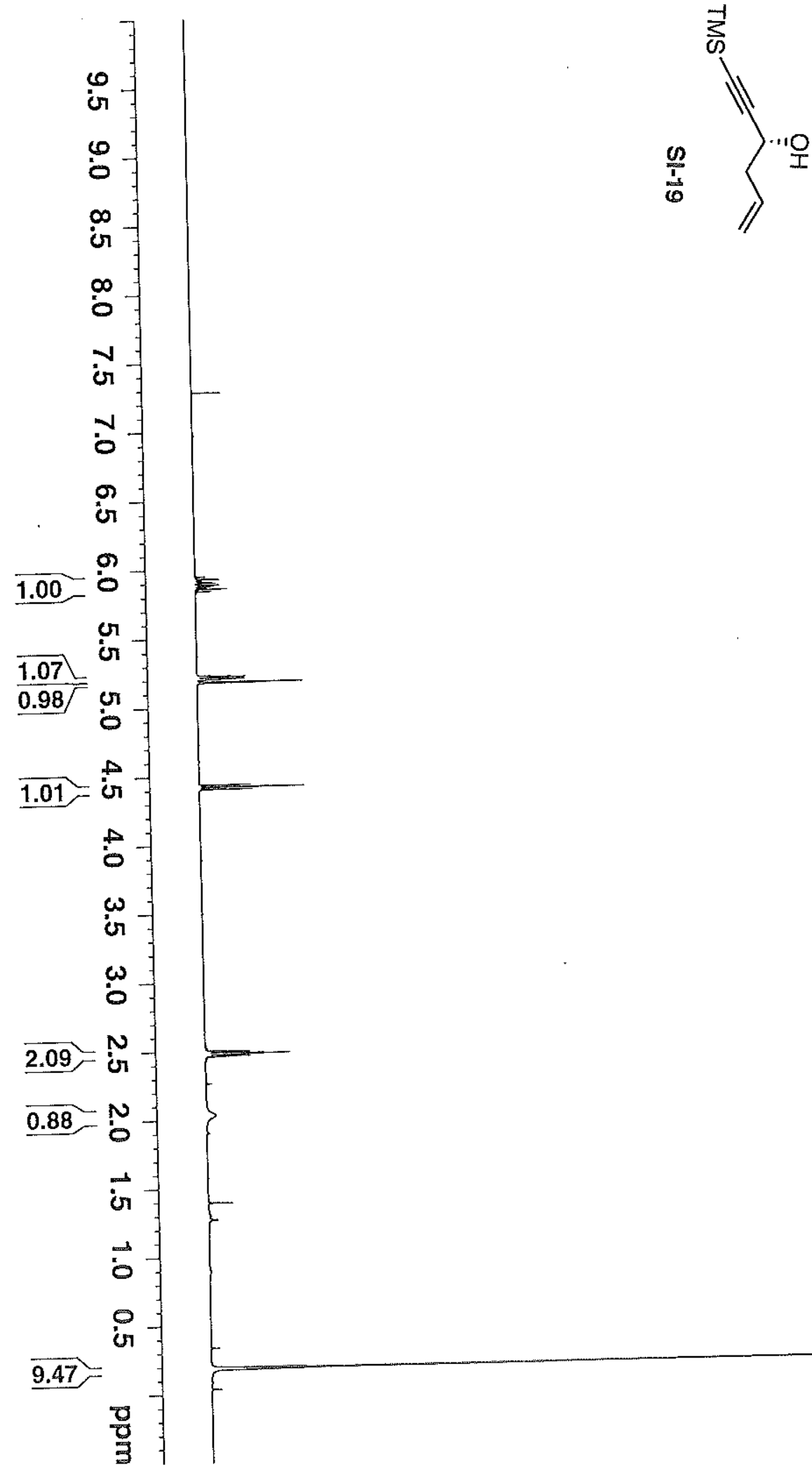

$\left[\begin{array}{l}5.946 \\ 5.928 \\ 5.922\end{array}\right.$

5.918

5.910

$-5.905$

5.901

5.887

5.883

5.878

5.869

5.864

5.860

5.842

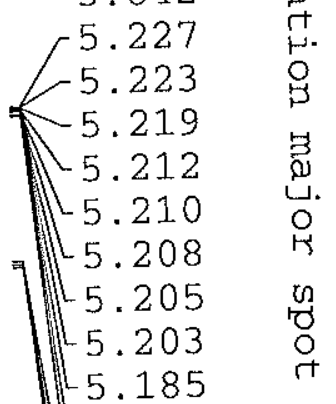

L 5.182

5.179

4.436

4.421

4.406

Q
1
1
1
$\omega$
0

离

त्र

$\stackrel{2}{2}$

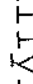

,

.

2.500

$-2.497$

7 -2.485

2. 482

2.479

L2.466

2.464

$\left\lfloor_{2.032}\right.$

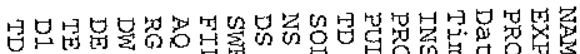

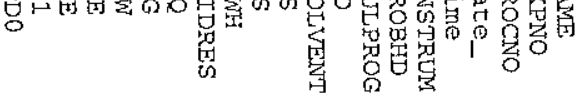

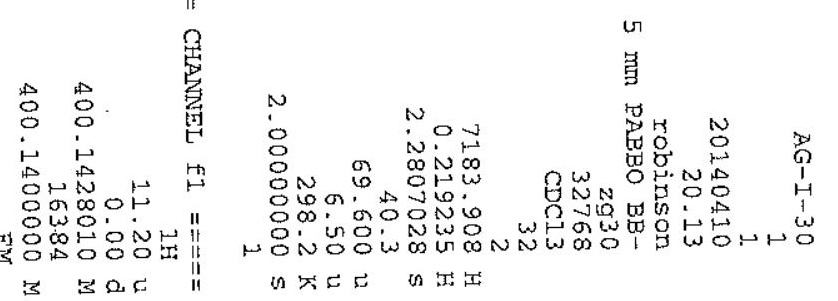




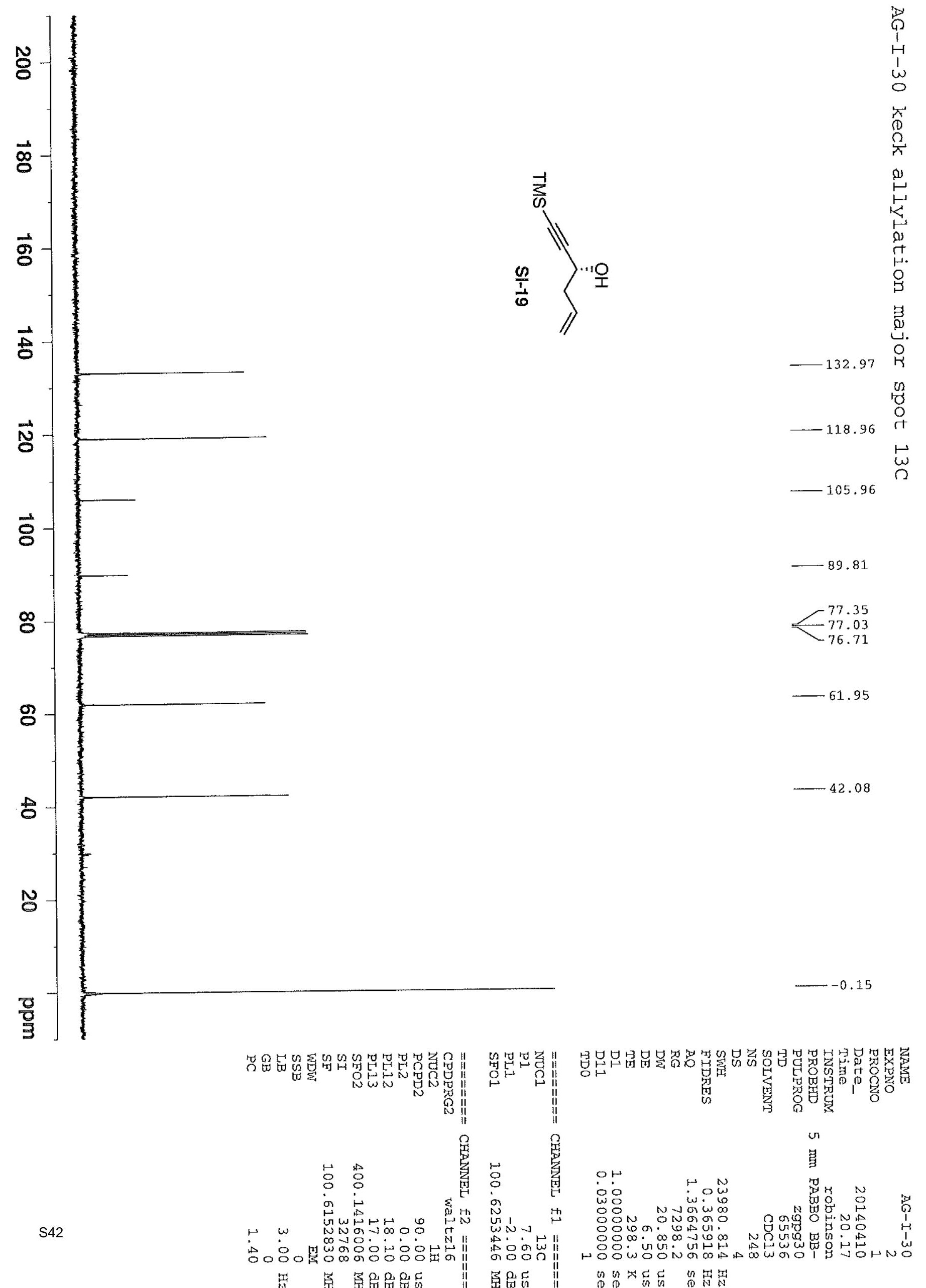



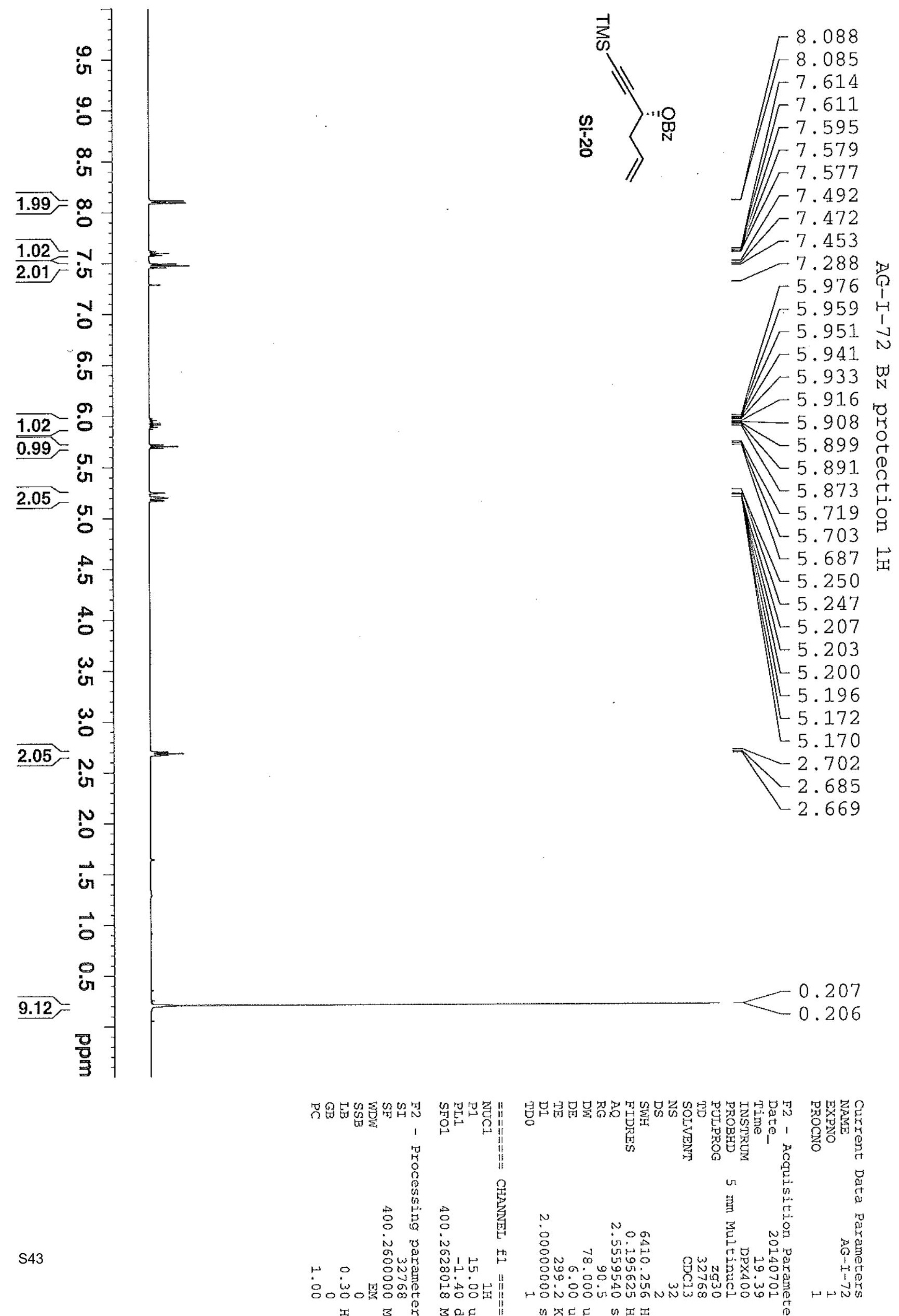


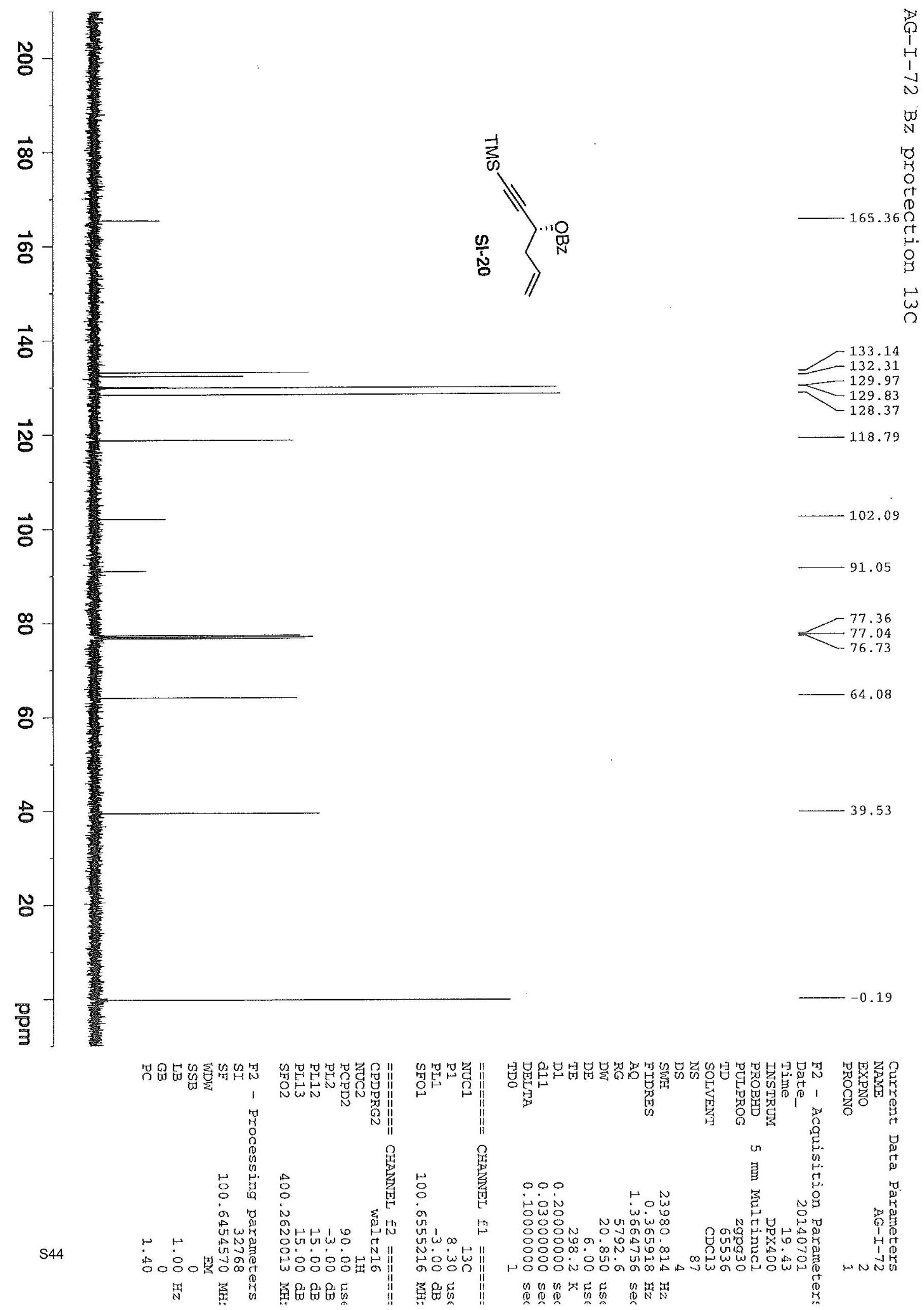



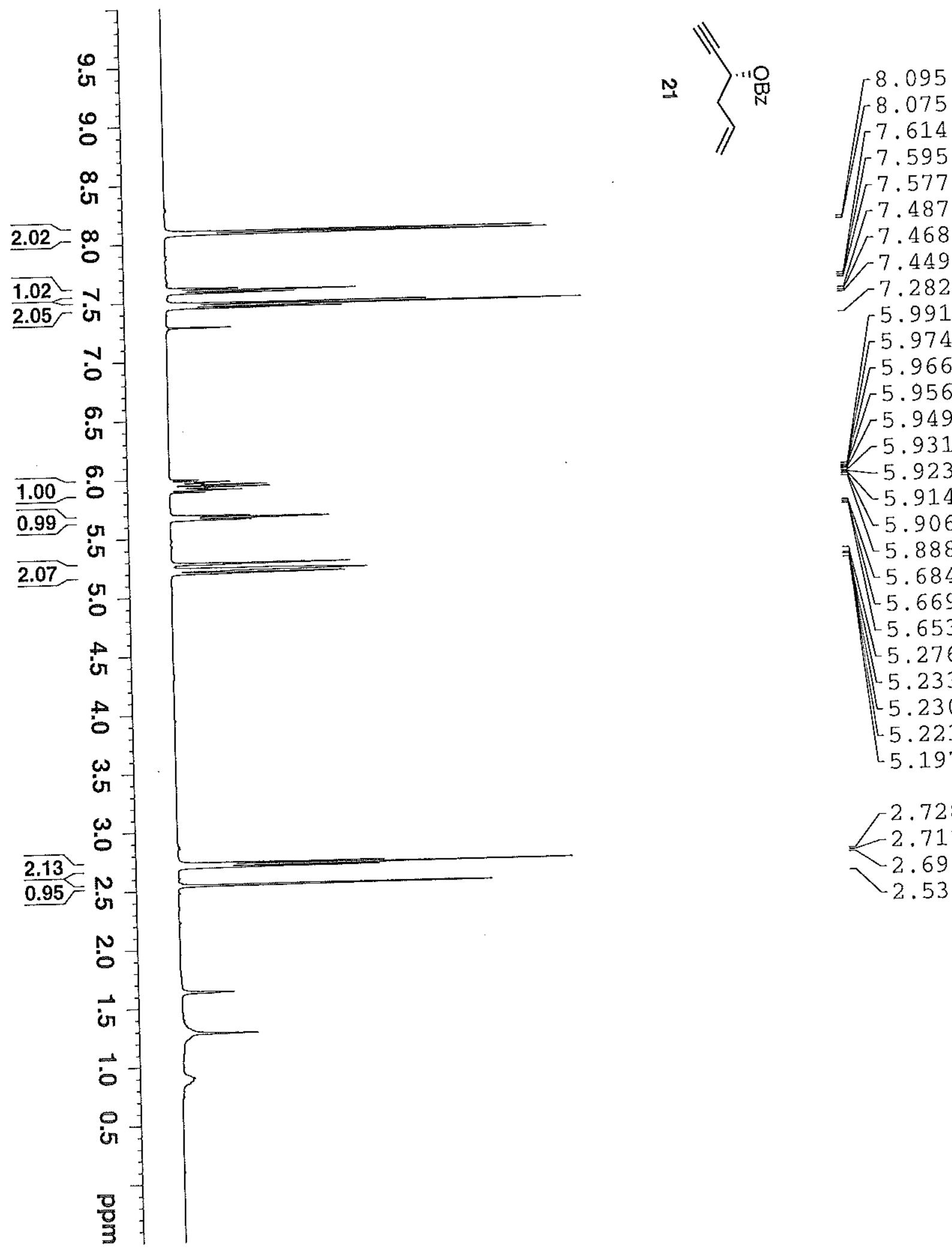

5.991

5.974

5.966

$-5.956$

5.949

$-5.931$

5.923

$=-5.914$

Q
1
H
or
N

$-5.906$

5.888

5.684

5.669

5.653

5.276

5.233

5.230

L. 5.23

โ5.197

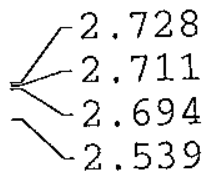

筮

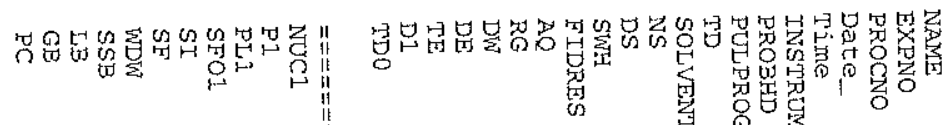

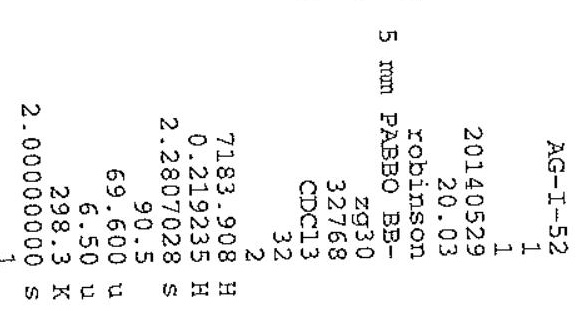




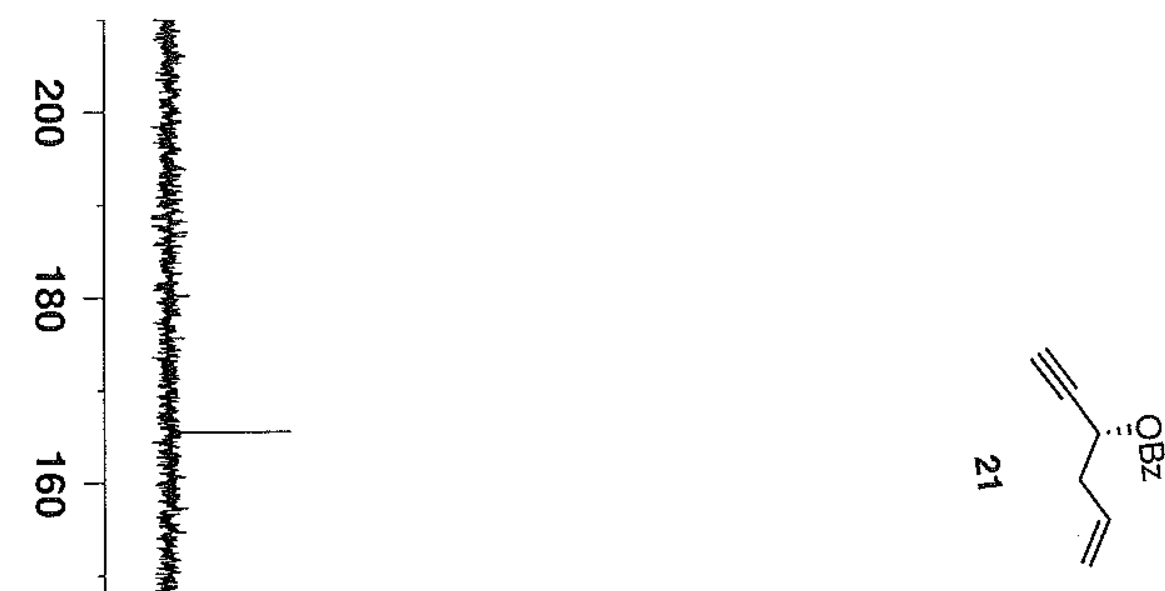

용

$\vec{N}$

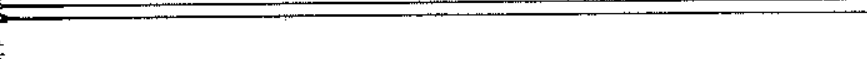

$-131.97$

$-129.80$

$-129.73$

128.42

$-119.05$

$\infty$

8

8

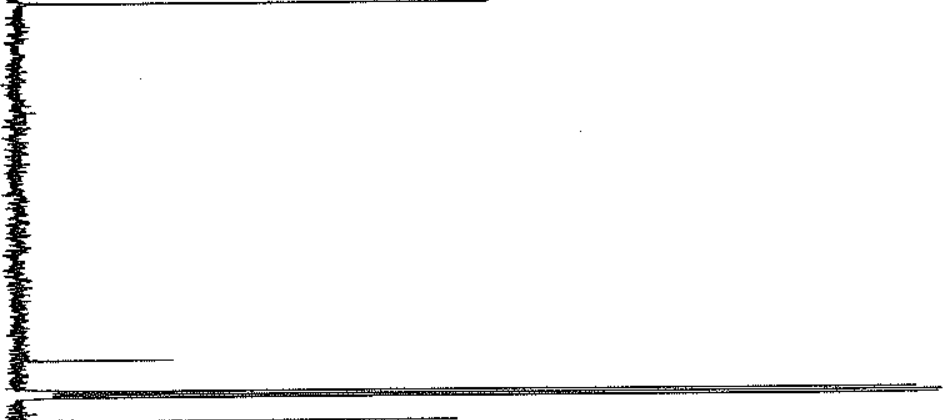

$-80.71$

77.36

-77.04
-76.72

74.14

$-63.53$

$-39.12$

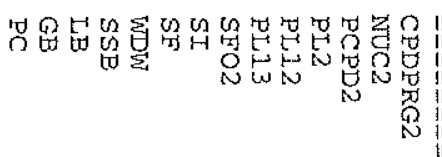

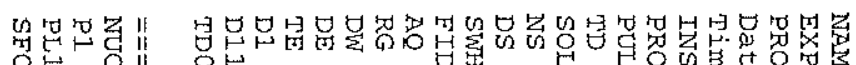

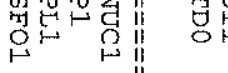

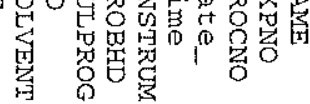

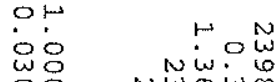

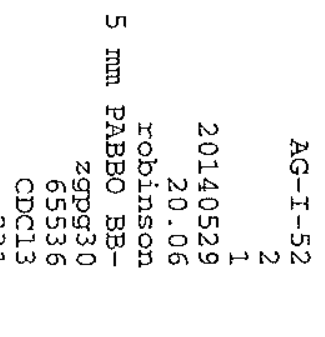



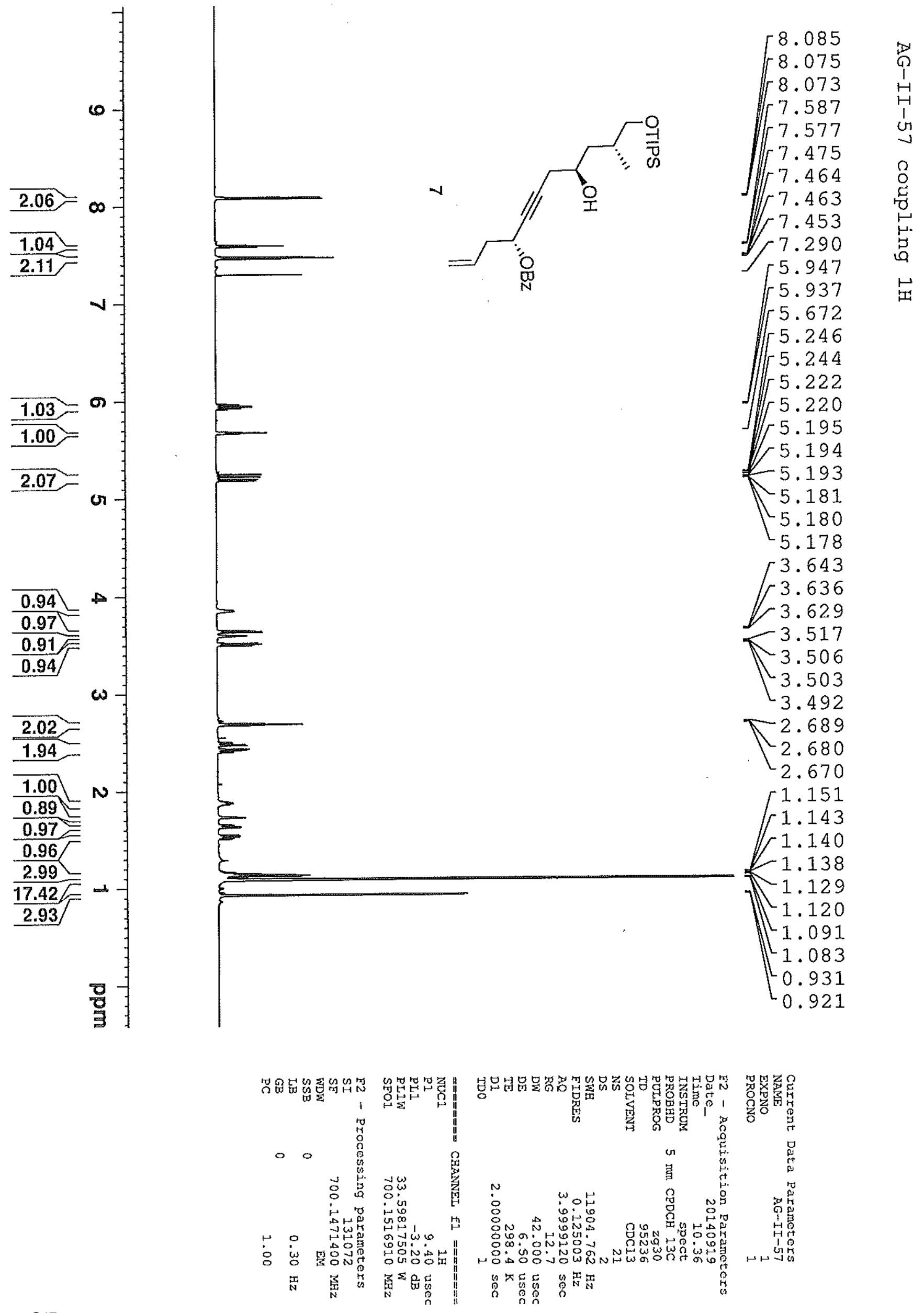

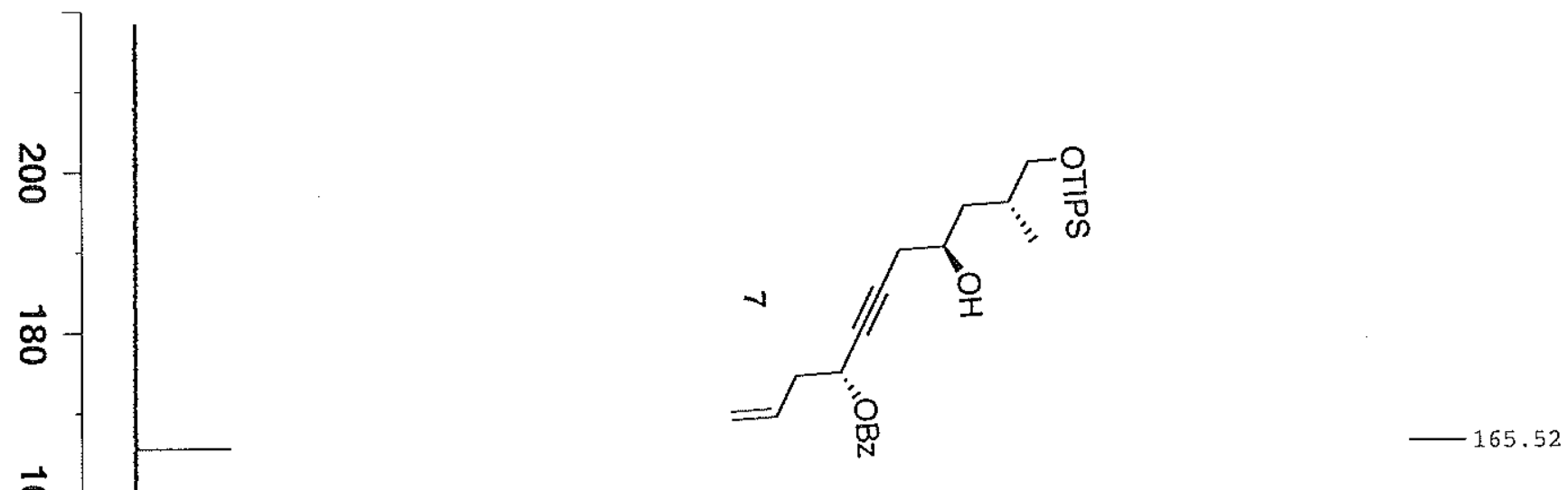

$\overrightarrow{8}$

$\overrightarrow{8}$

$\overrightarrow{\mathrm{f}}$

133.10

$\widehat{N}$
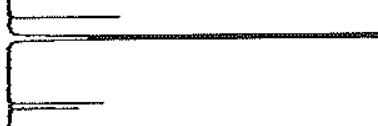

8

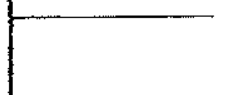

a

$\triangle$

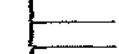

$-42.41$

$-39.61$

$\longrightarrow 34.44$

$-28.13$

N

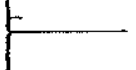

$-17.97$

$<17.82$

$\longrightarrow 11.92$

$\frac{8}{3}$

I

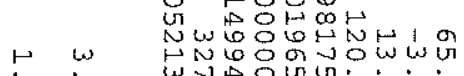

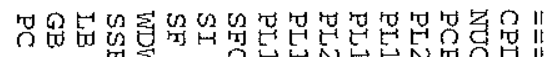
W

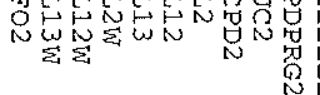

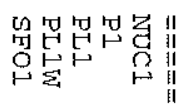

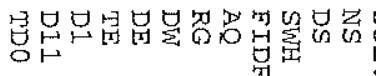

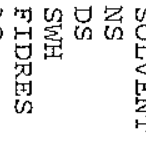

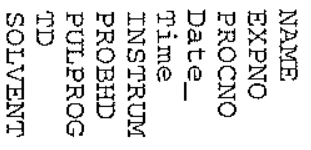

औे

or

is ${ }^{\circ}$ mo

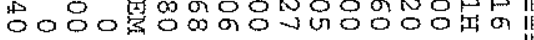

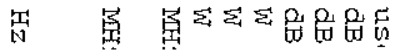

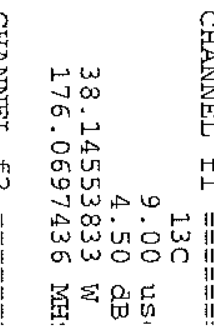

to 

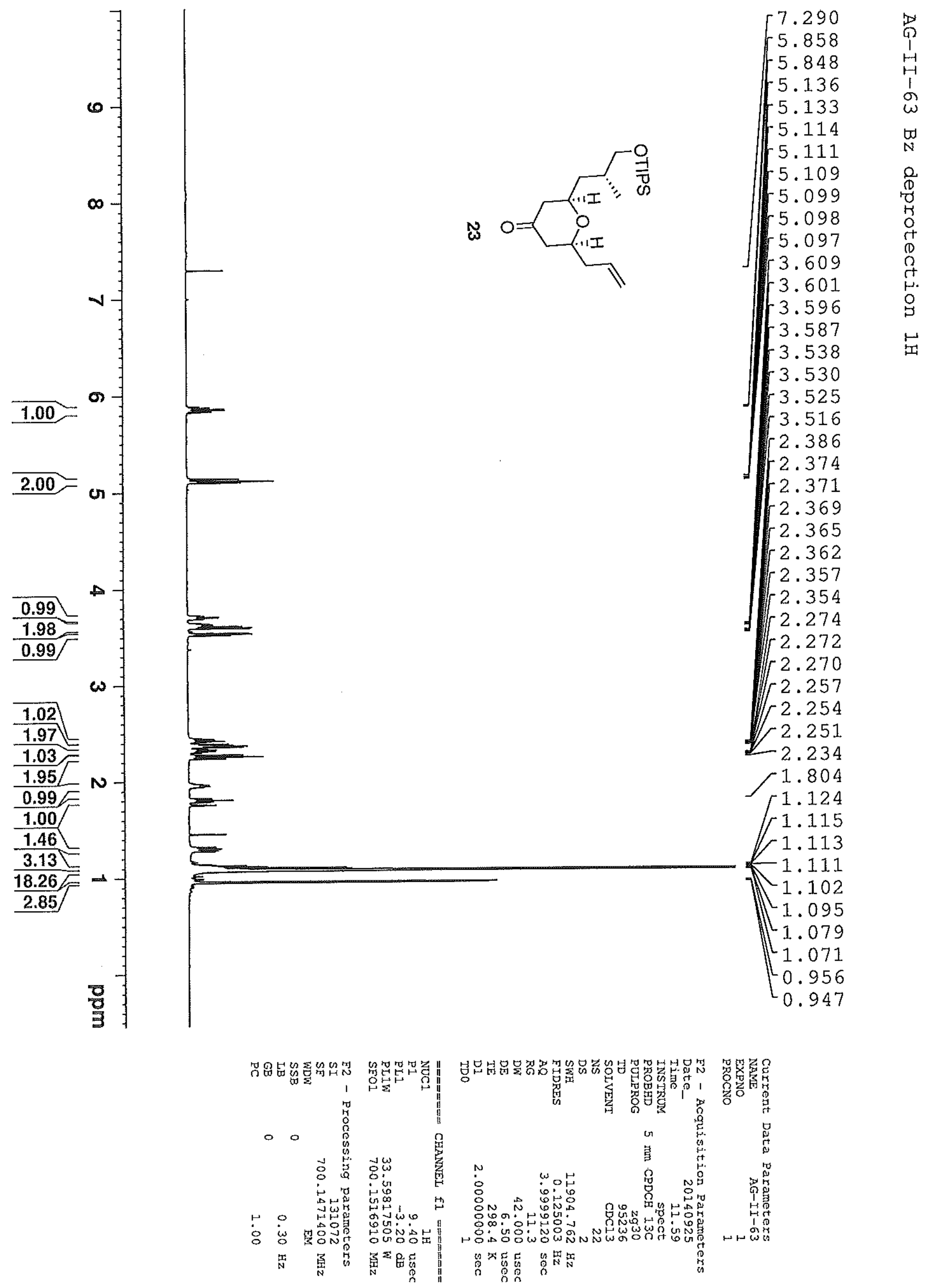


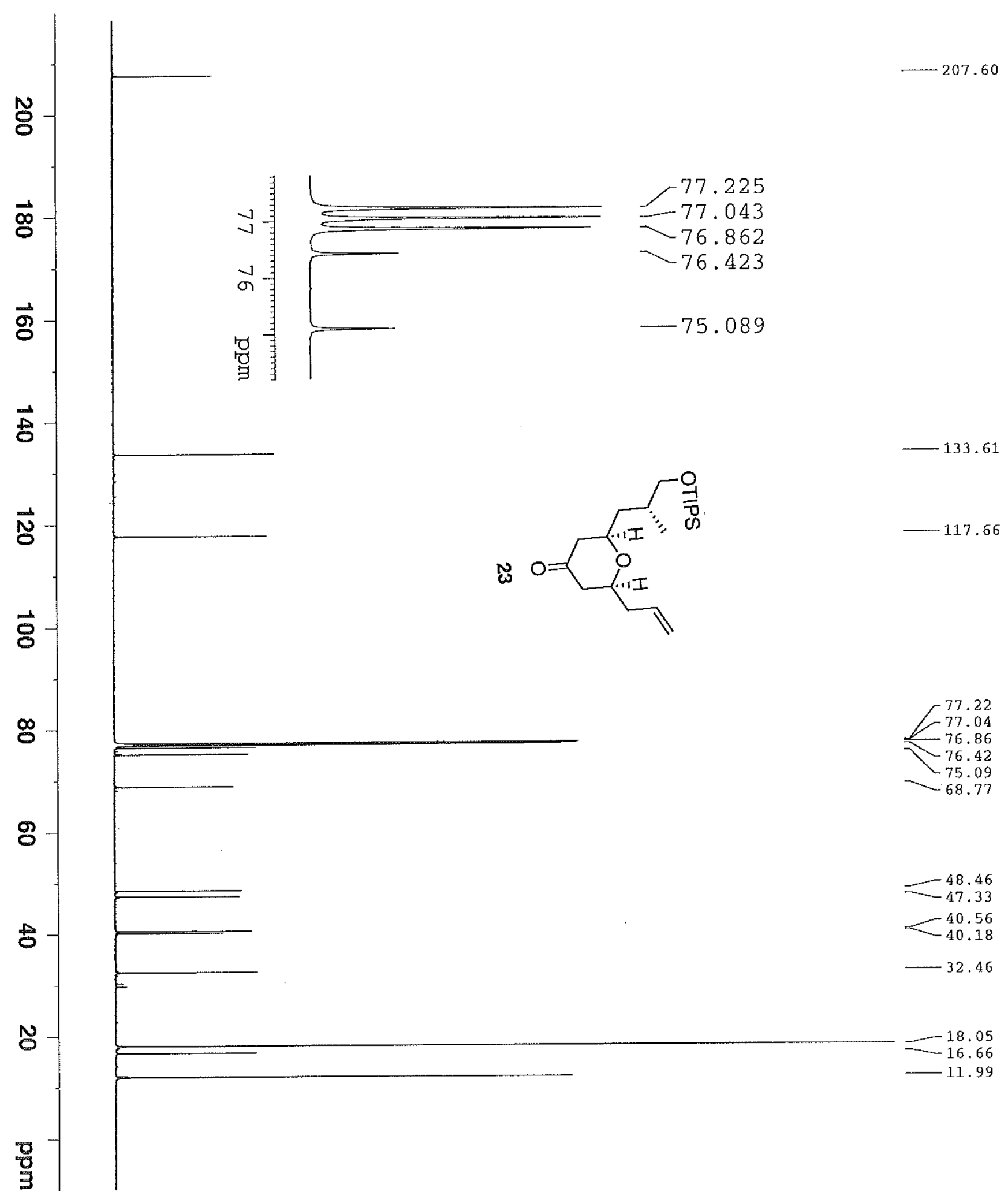

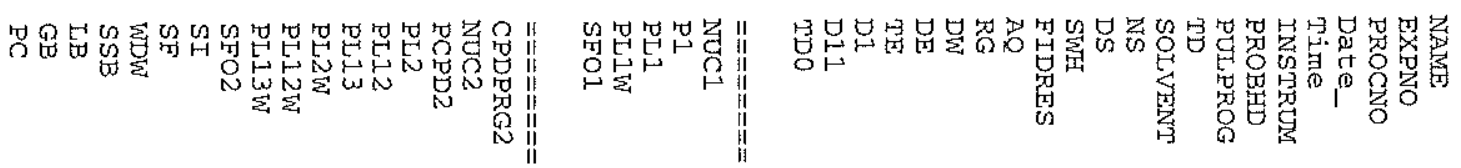



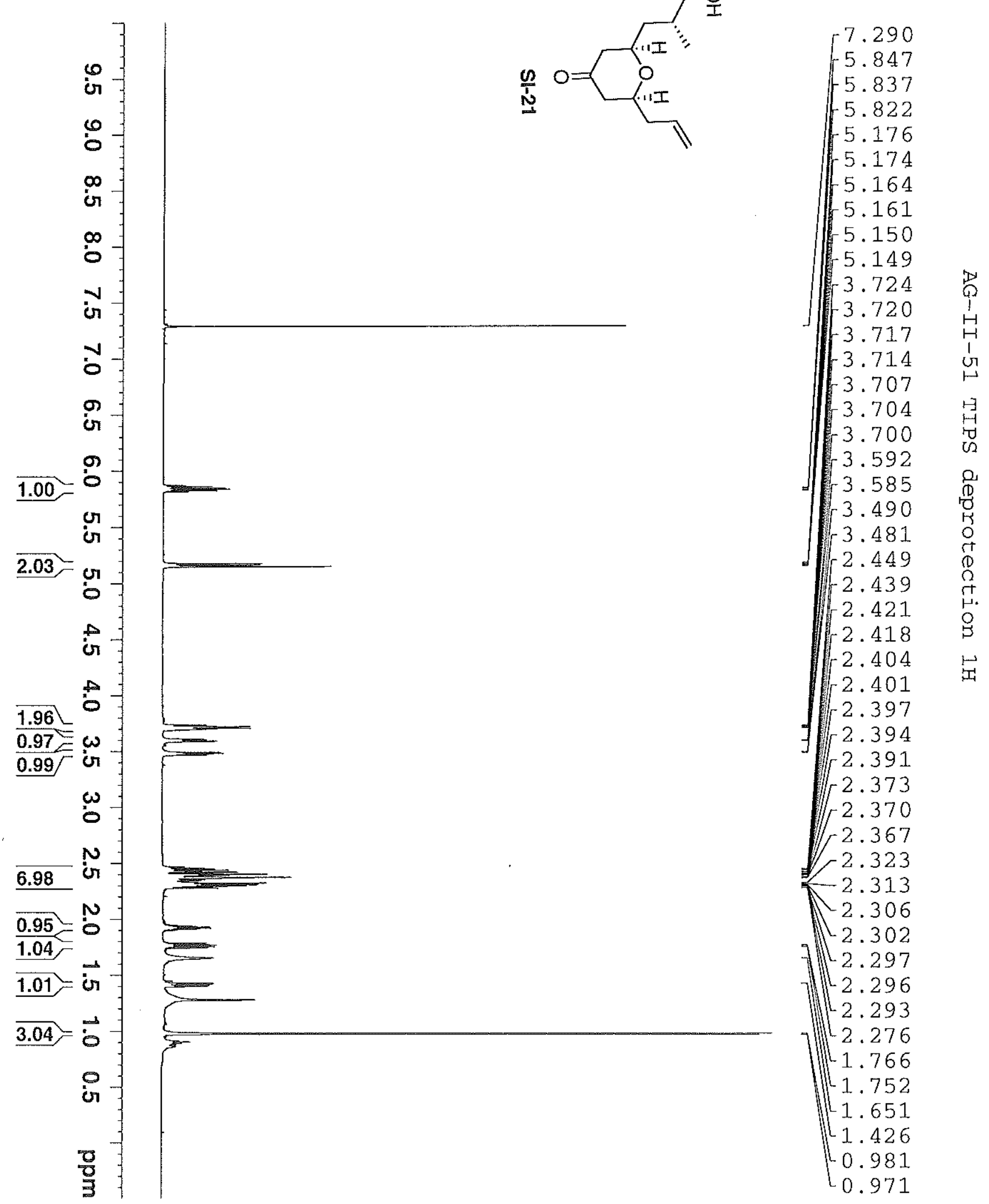

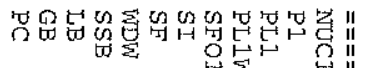




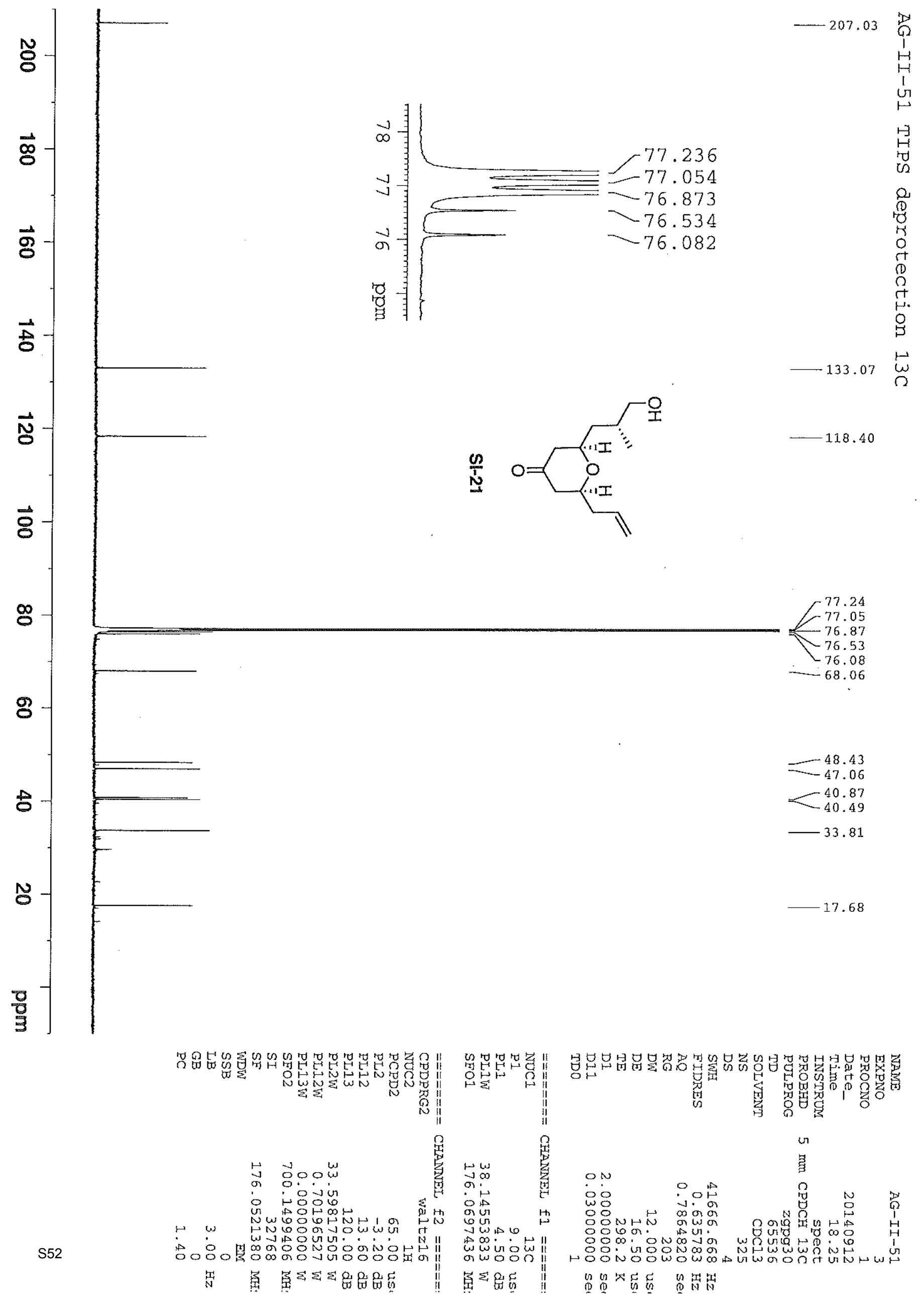



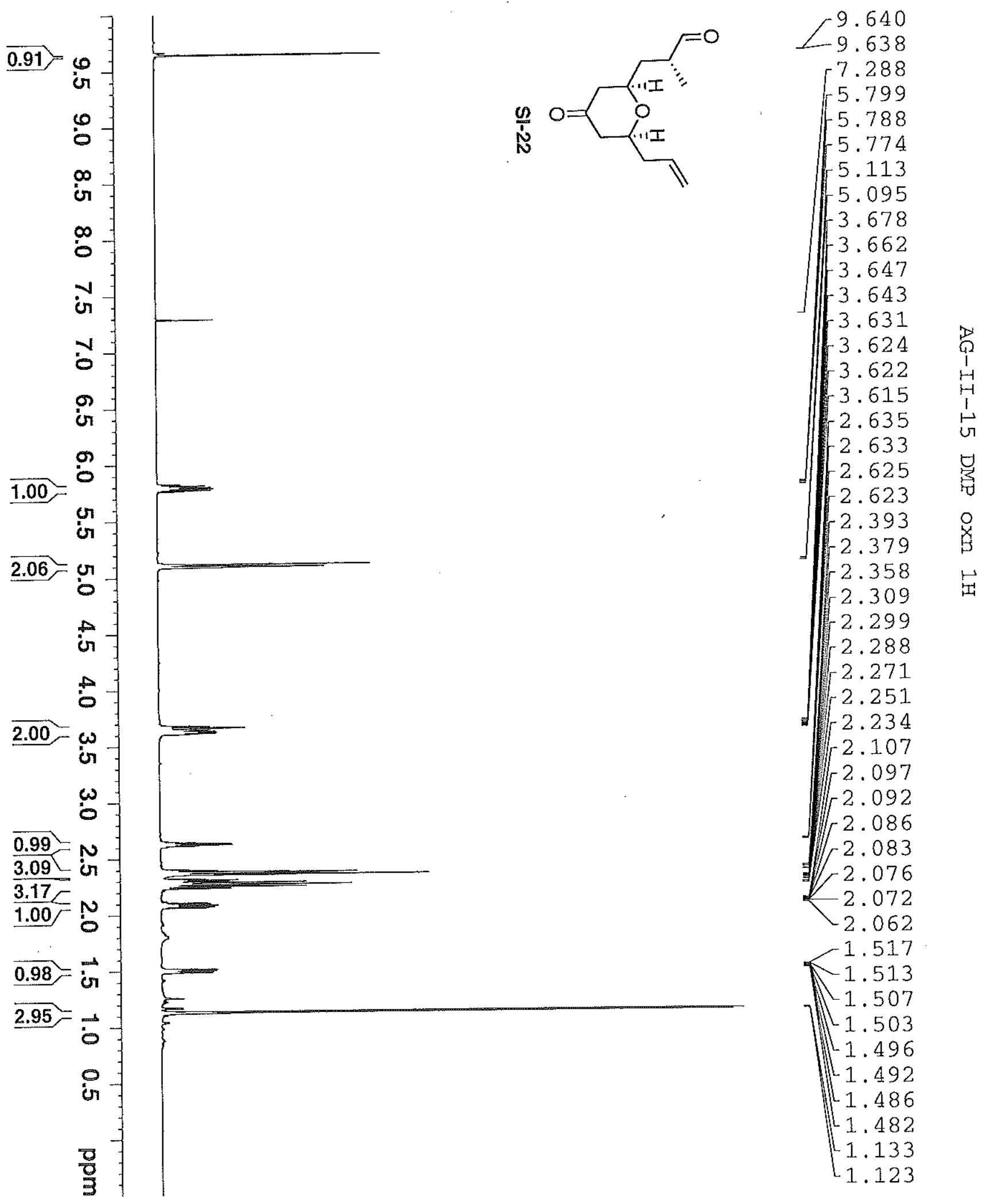

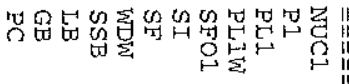

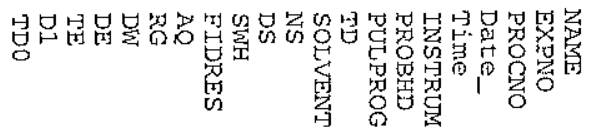

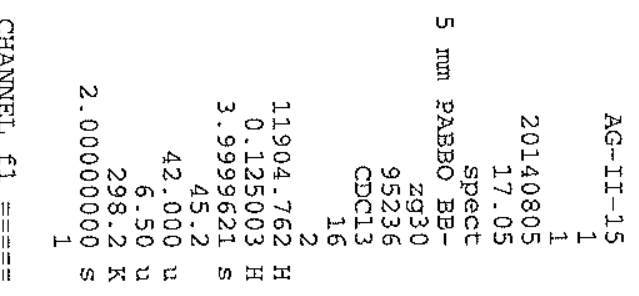




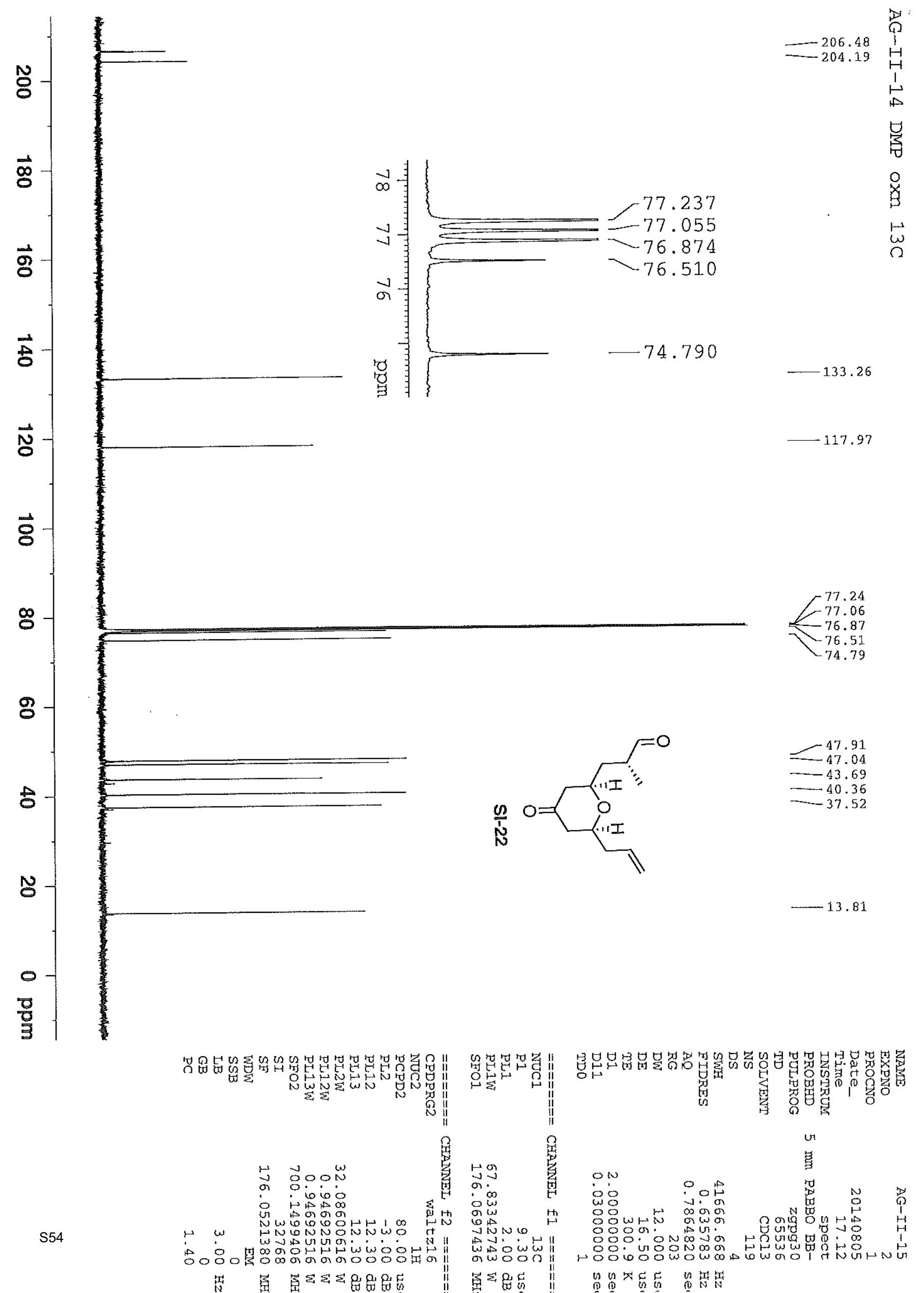



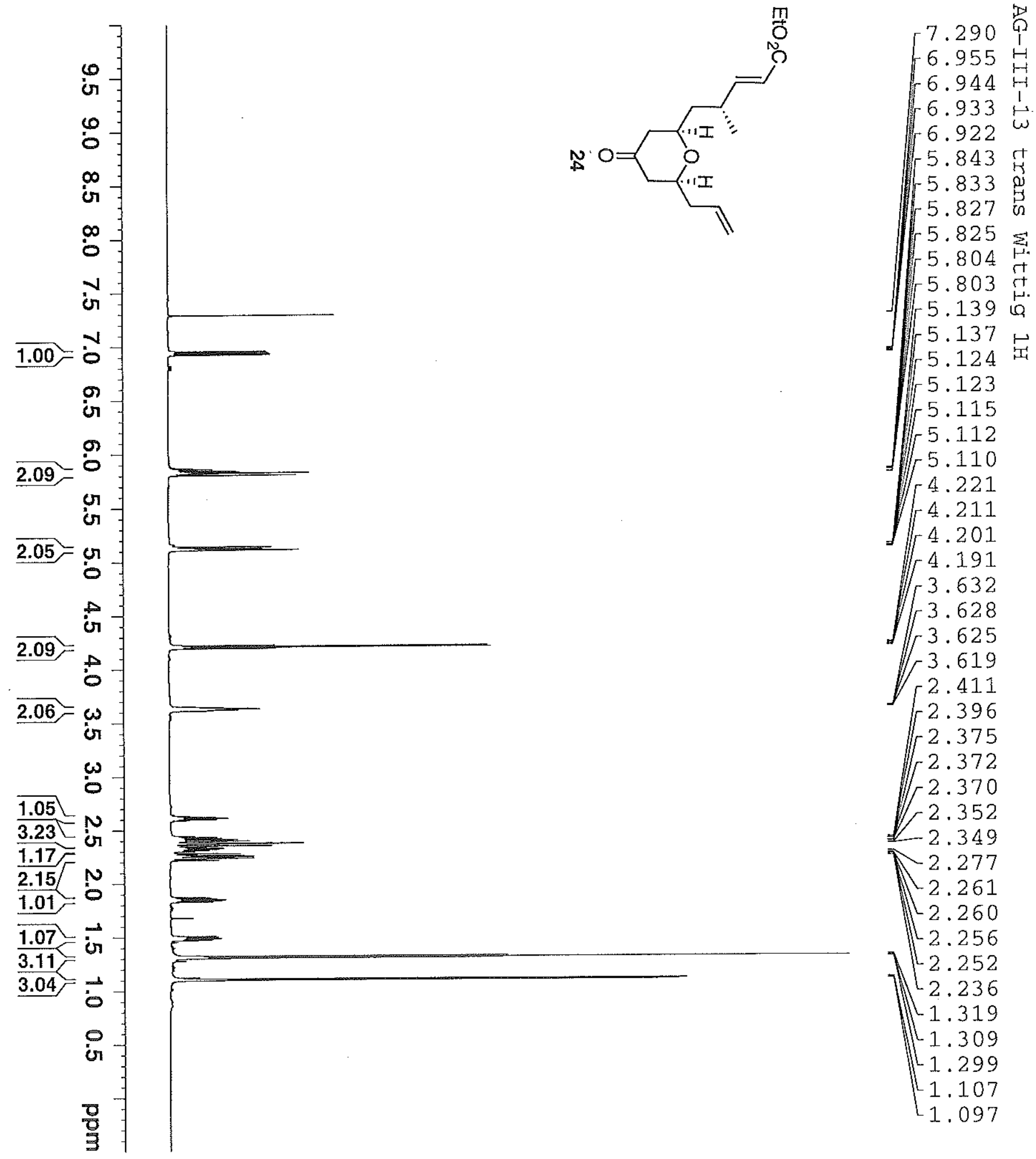

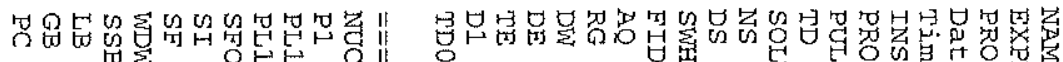




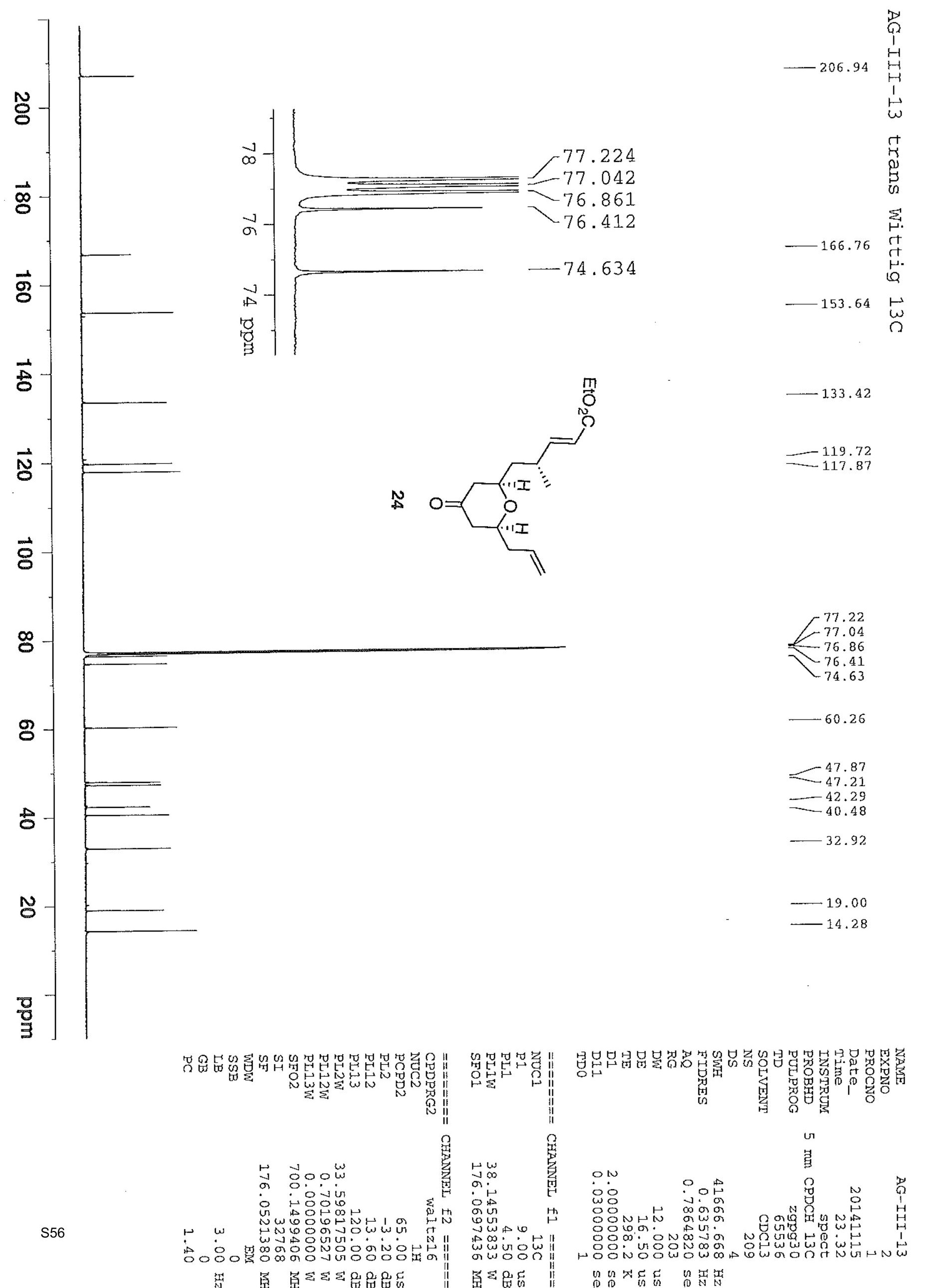



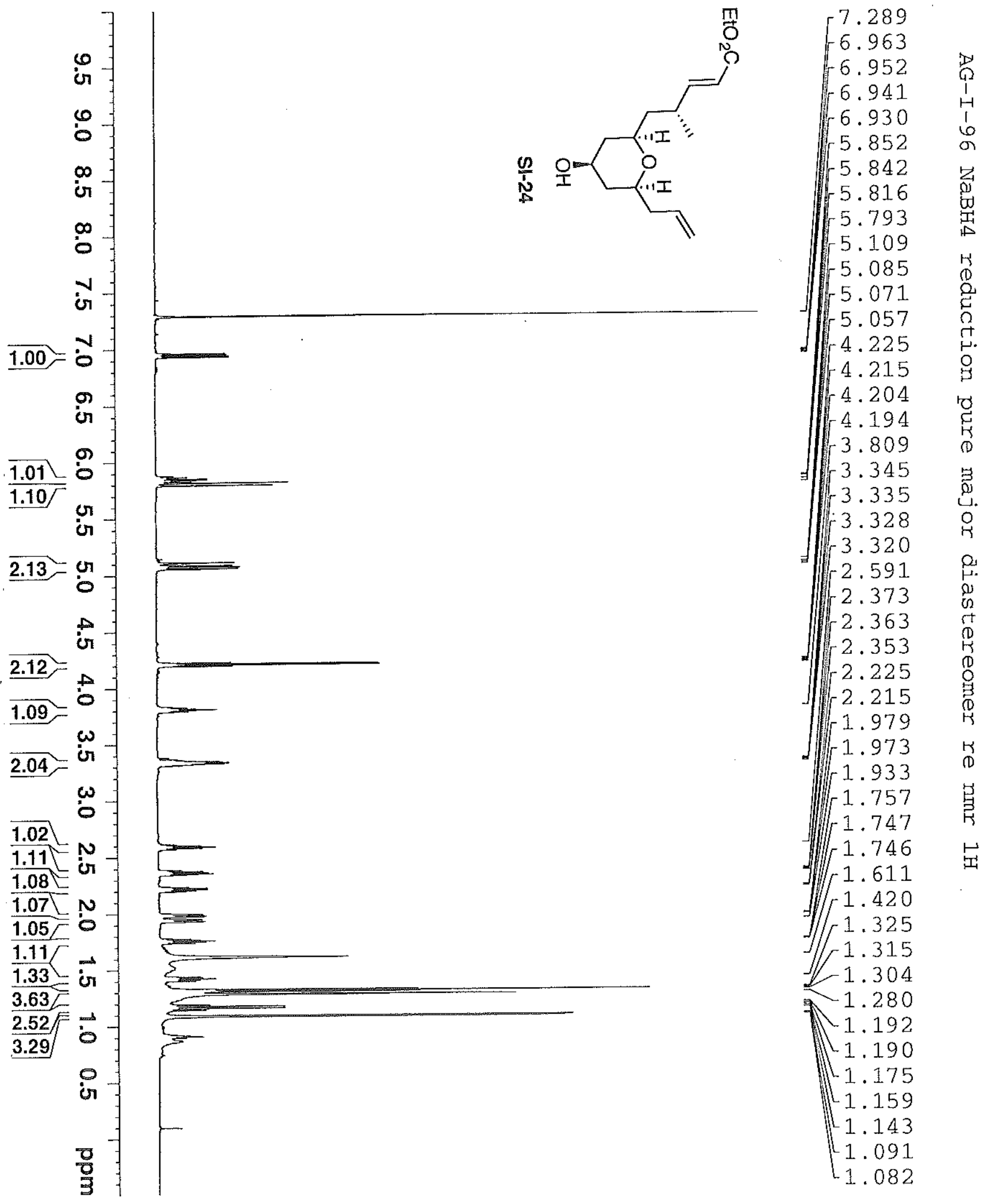

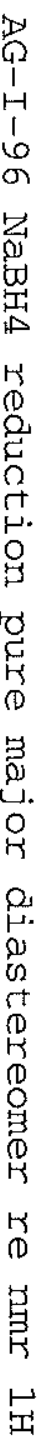

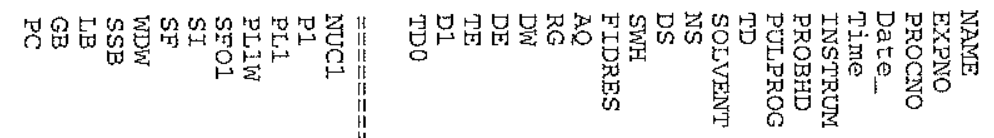

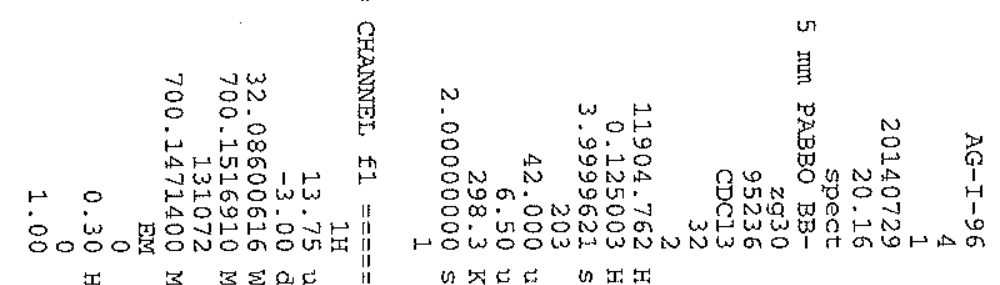




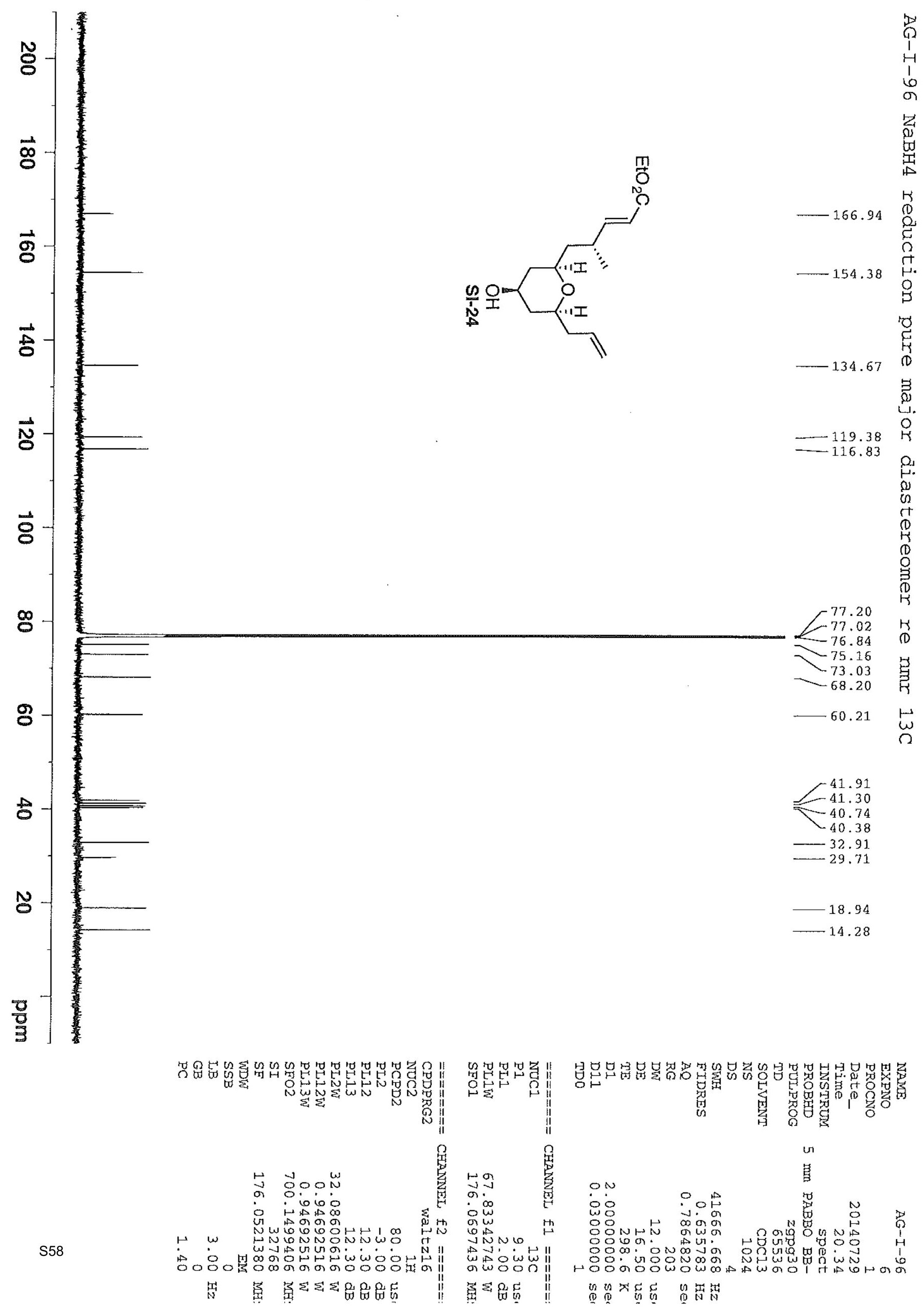




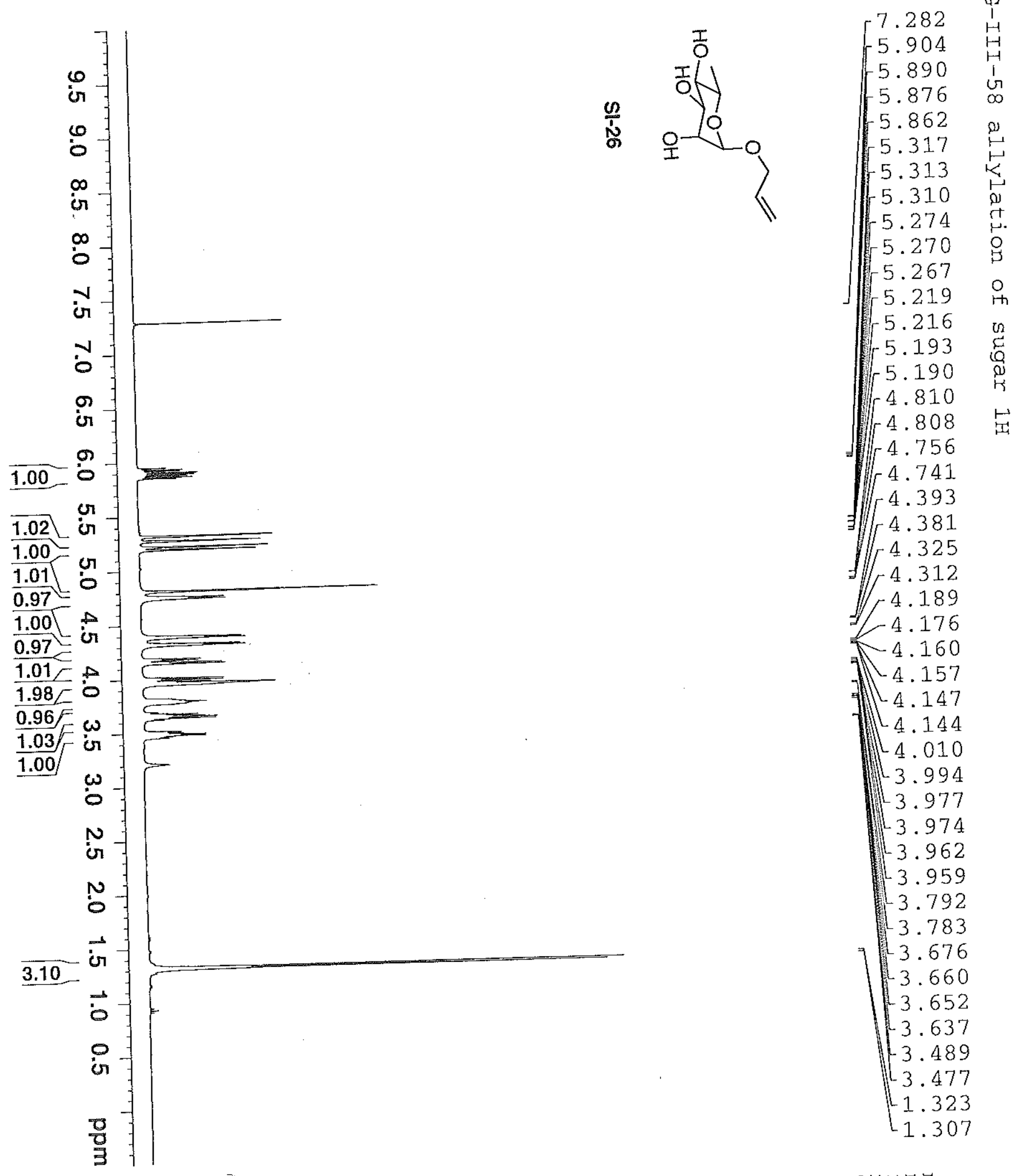

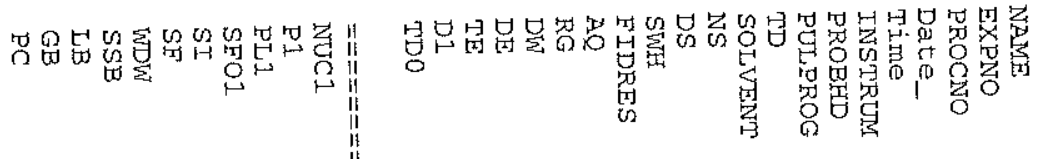

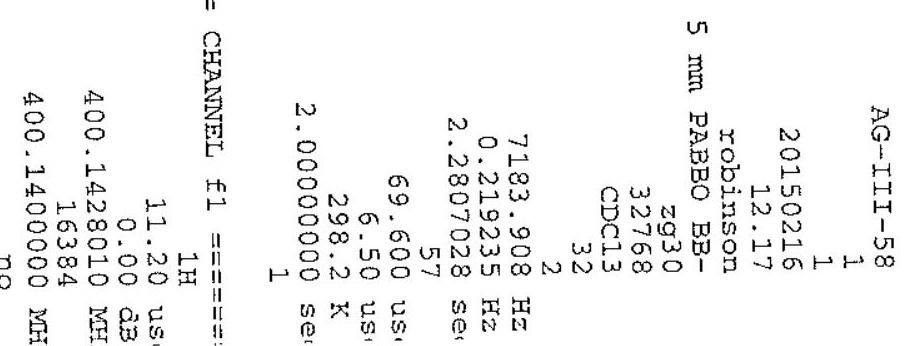




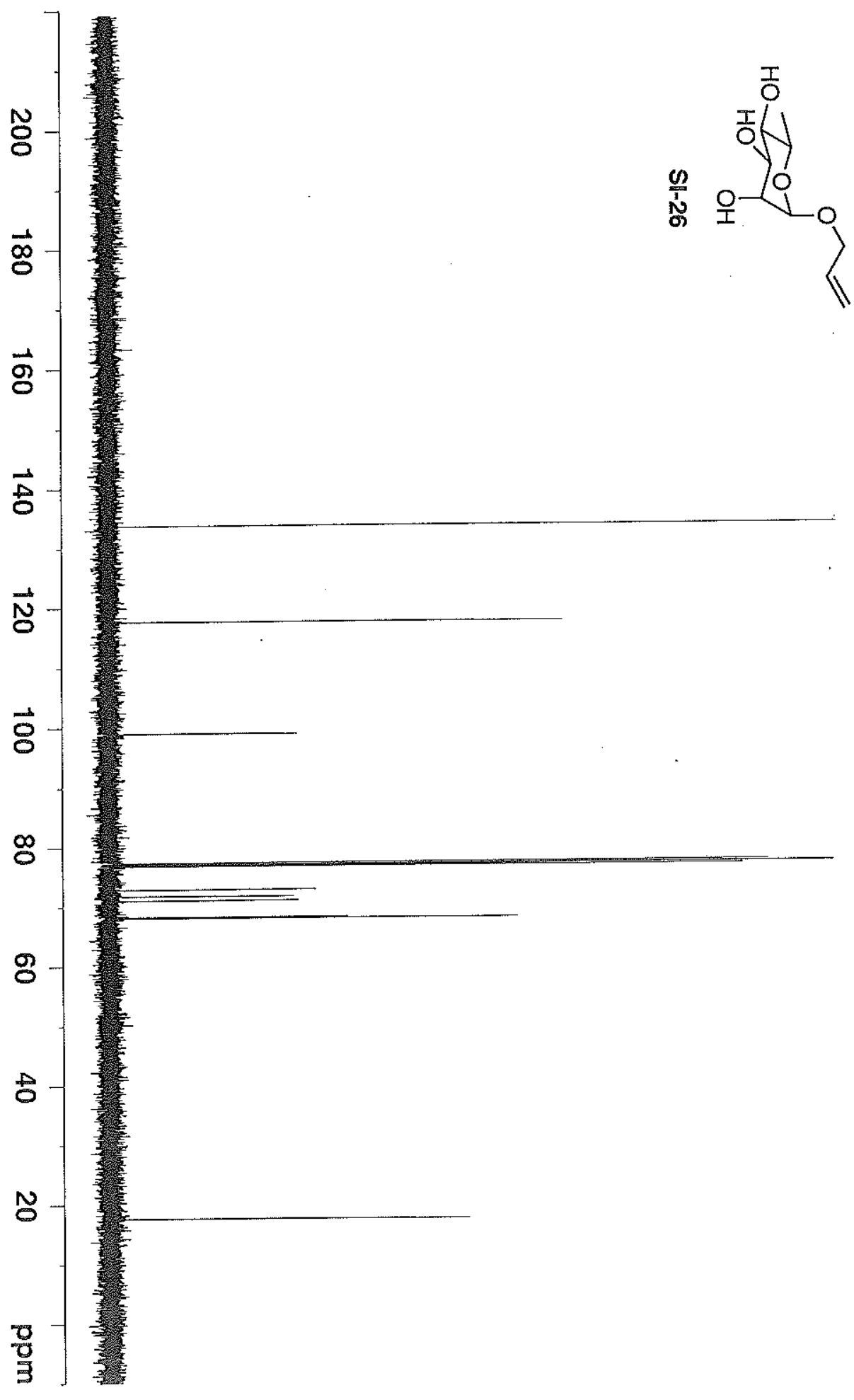

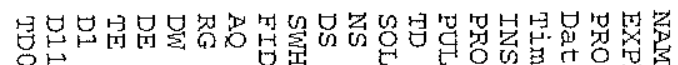

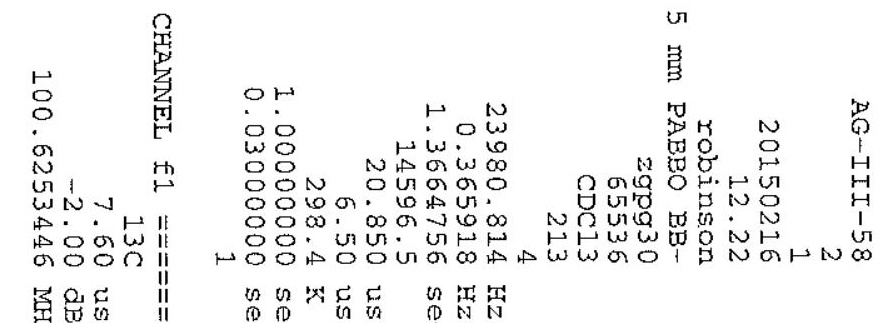



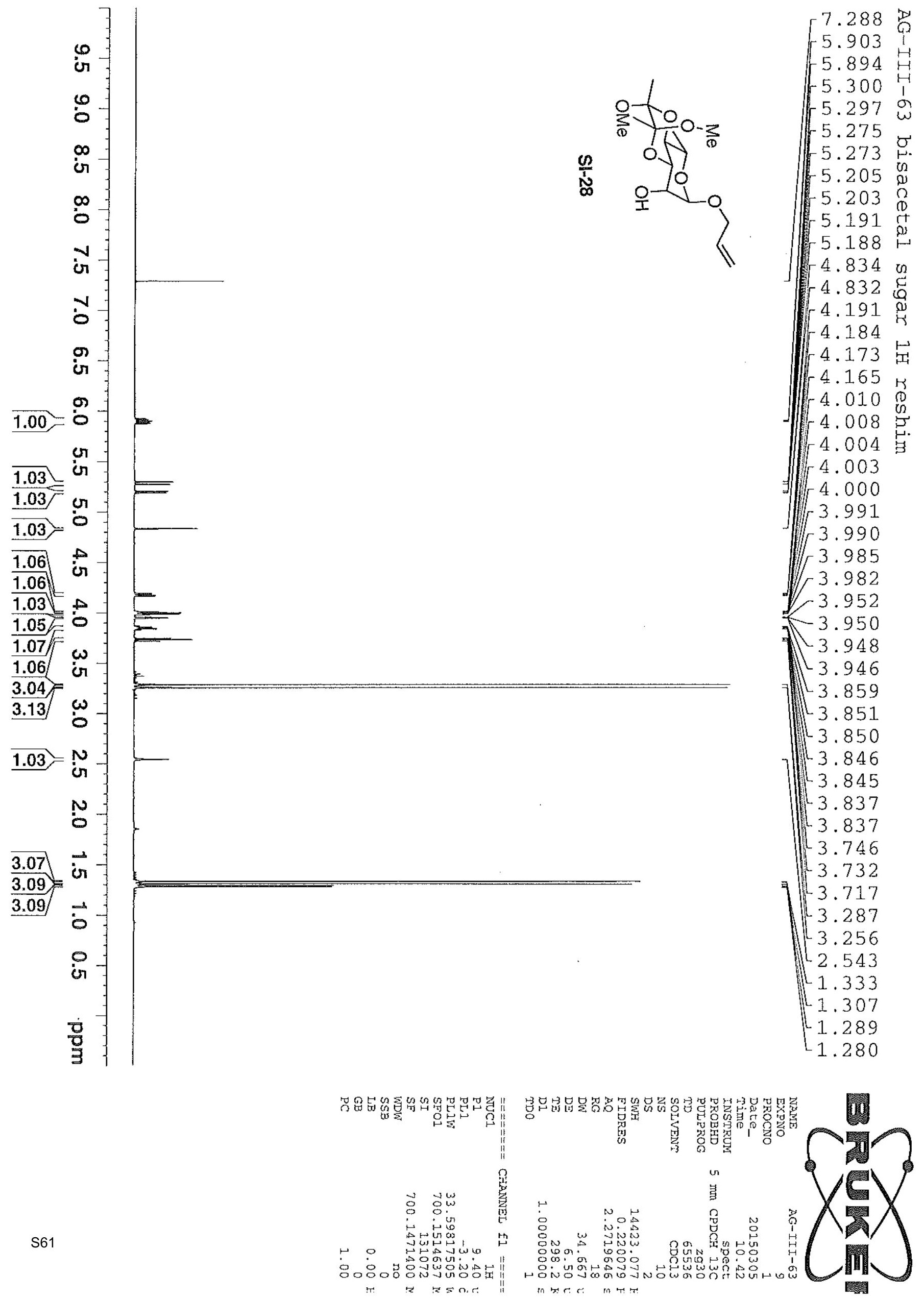


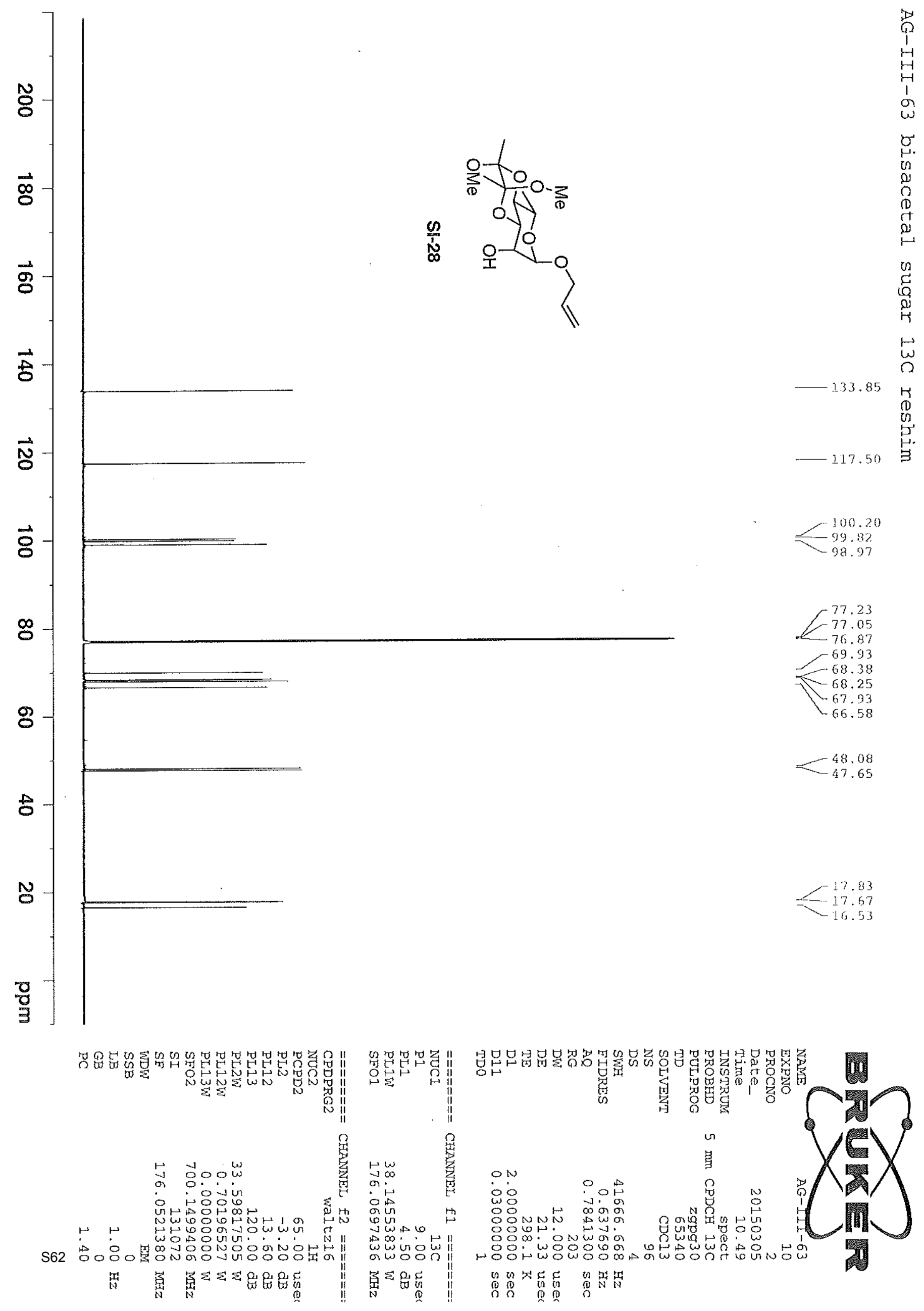




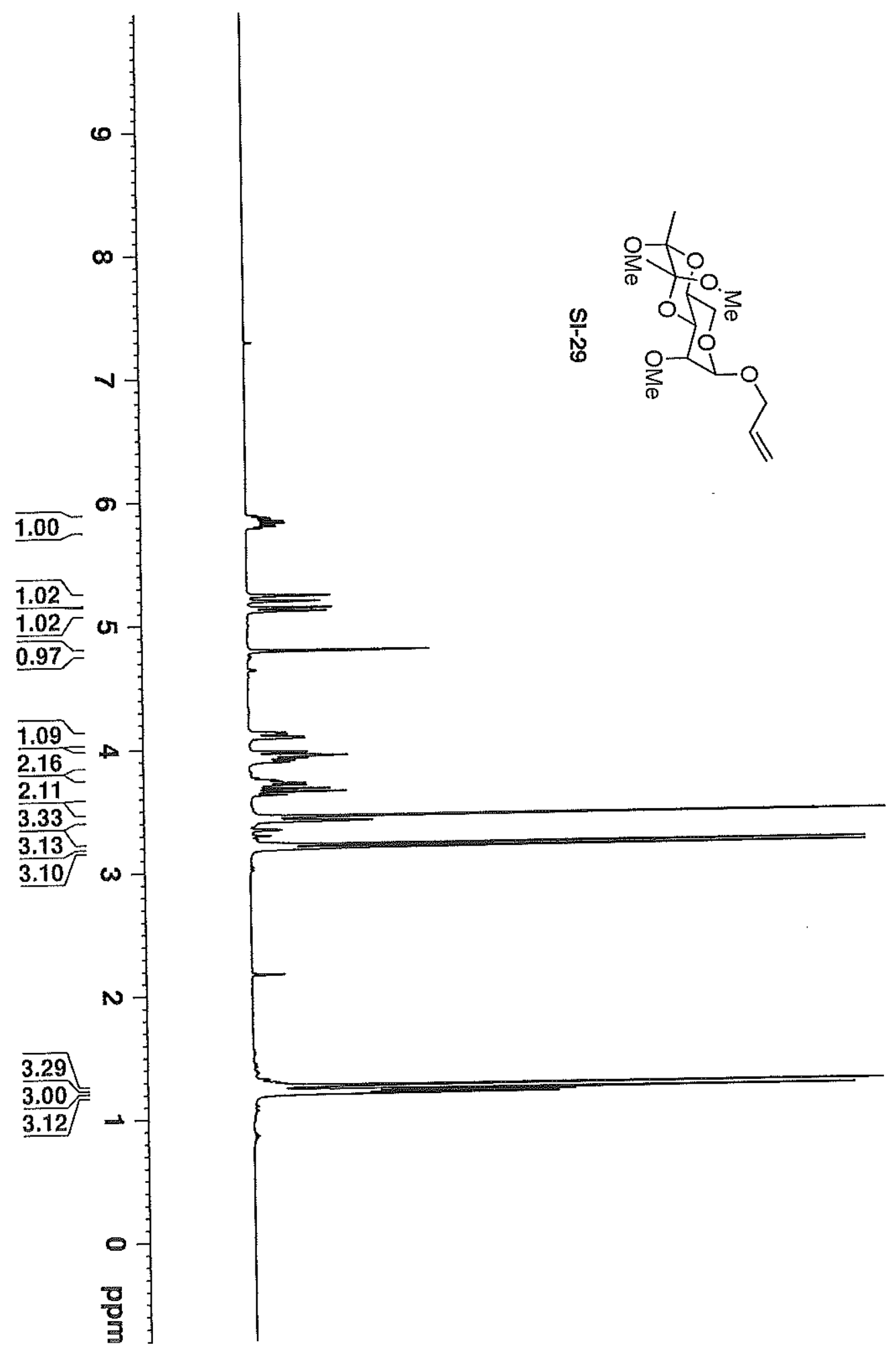

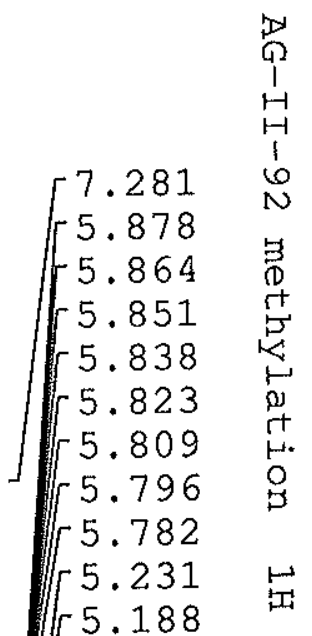

5.134

J 5.108

- 4.785

4.124

- 4.112

4.091

] 4.079

r 3.968

3.962

$=3.942$

3.935

q 3.917

$-3.899$

3.884

3.737

3.723

3.713

3.698

3.683

$-3.668$

3.643

3.619

3.441

$-3.405$

$-3.211$

3.186

1.259

1.223

1.206

1.191

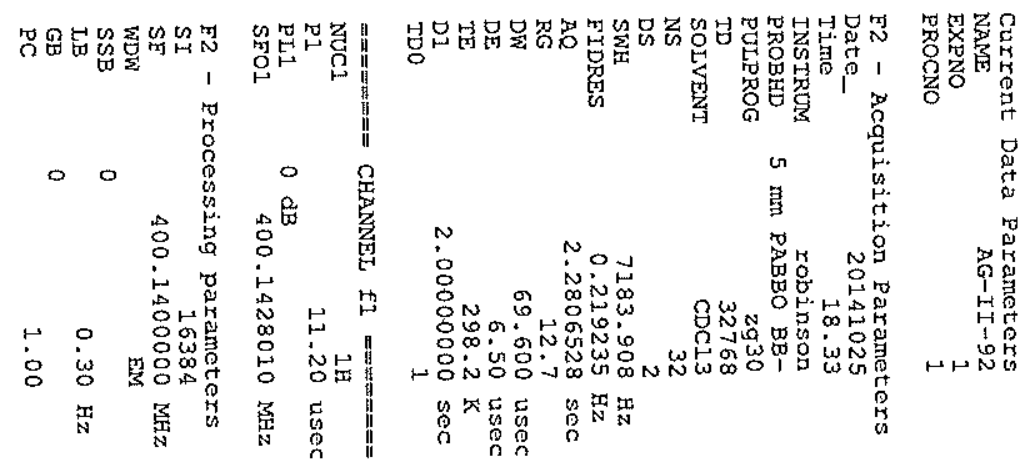




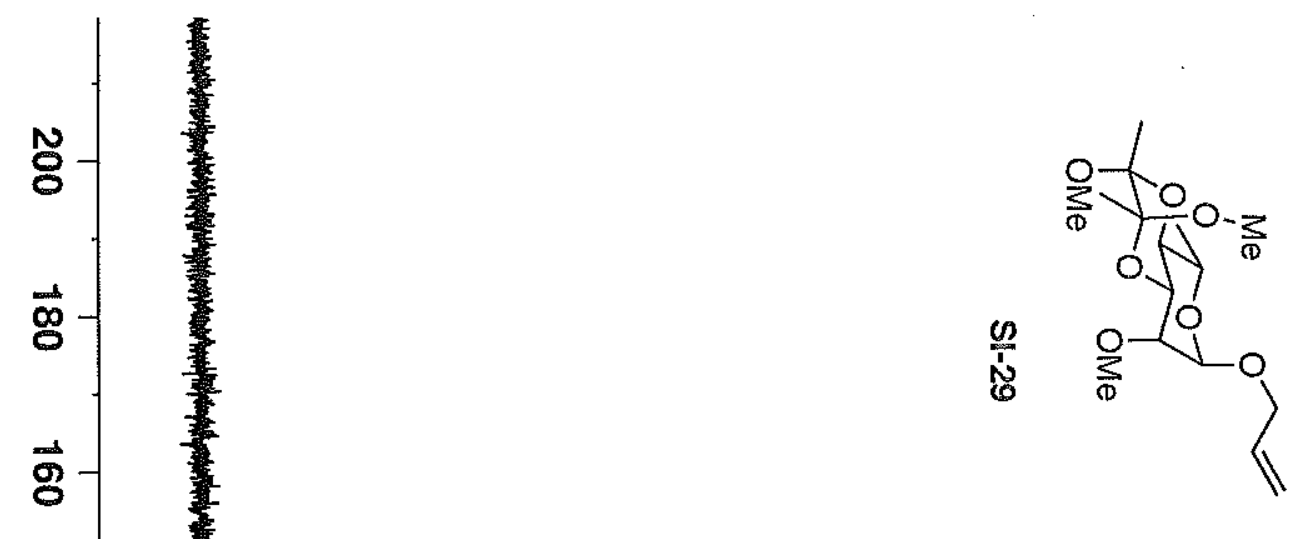

$\overrightarrow{8}$

$\stackrel{\infty}{\circ}$

8

:

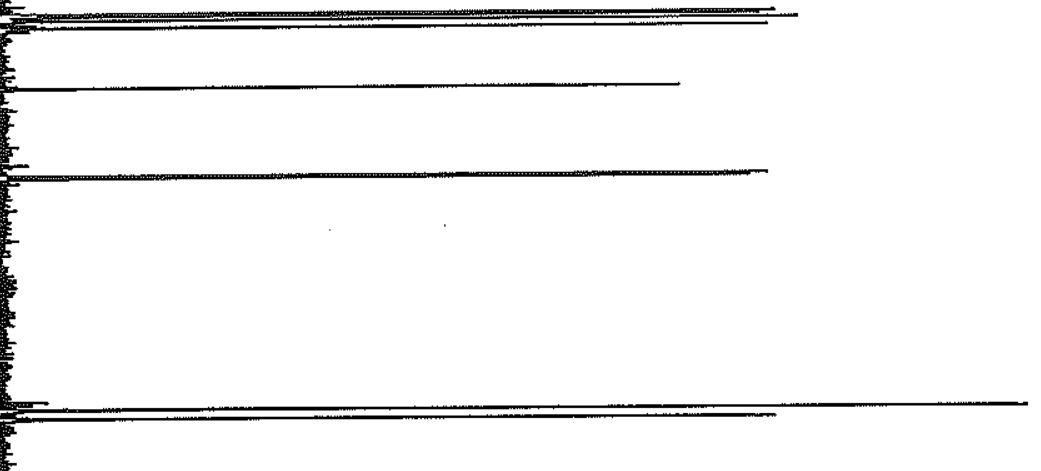

$-133.84$

$\stackrel{\mapsto}{\omega}$

$\longrightarrow 117.24$

$\begin{array}{r}-99.75 \\ \hline\end{array}$

$-99.41$

78.70

77.47

-77.15
-76.83

$-68.35$

$-67.83$

$-66.86$

$-59.09$

47.81

$-47.52$

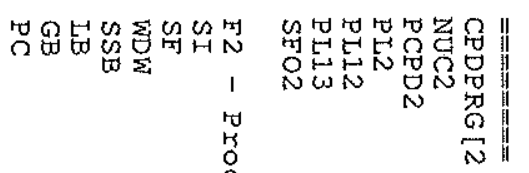

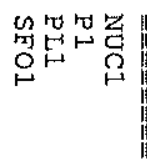

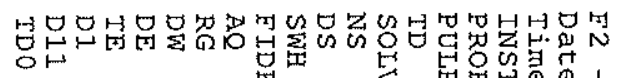

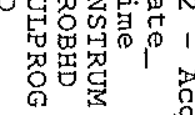

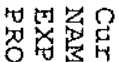

艺神

17,77

17.74
-16.56 مू०ᄋํㅇ

蛋绐点
ㄴ.

$\mapsto N$

onw

oㅇ.

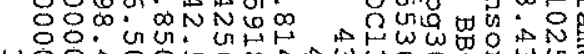

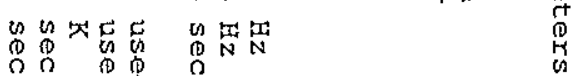




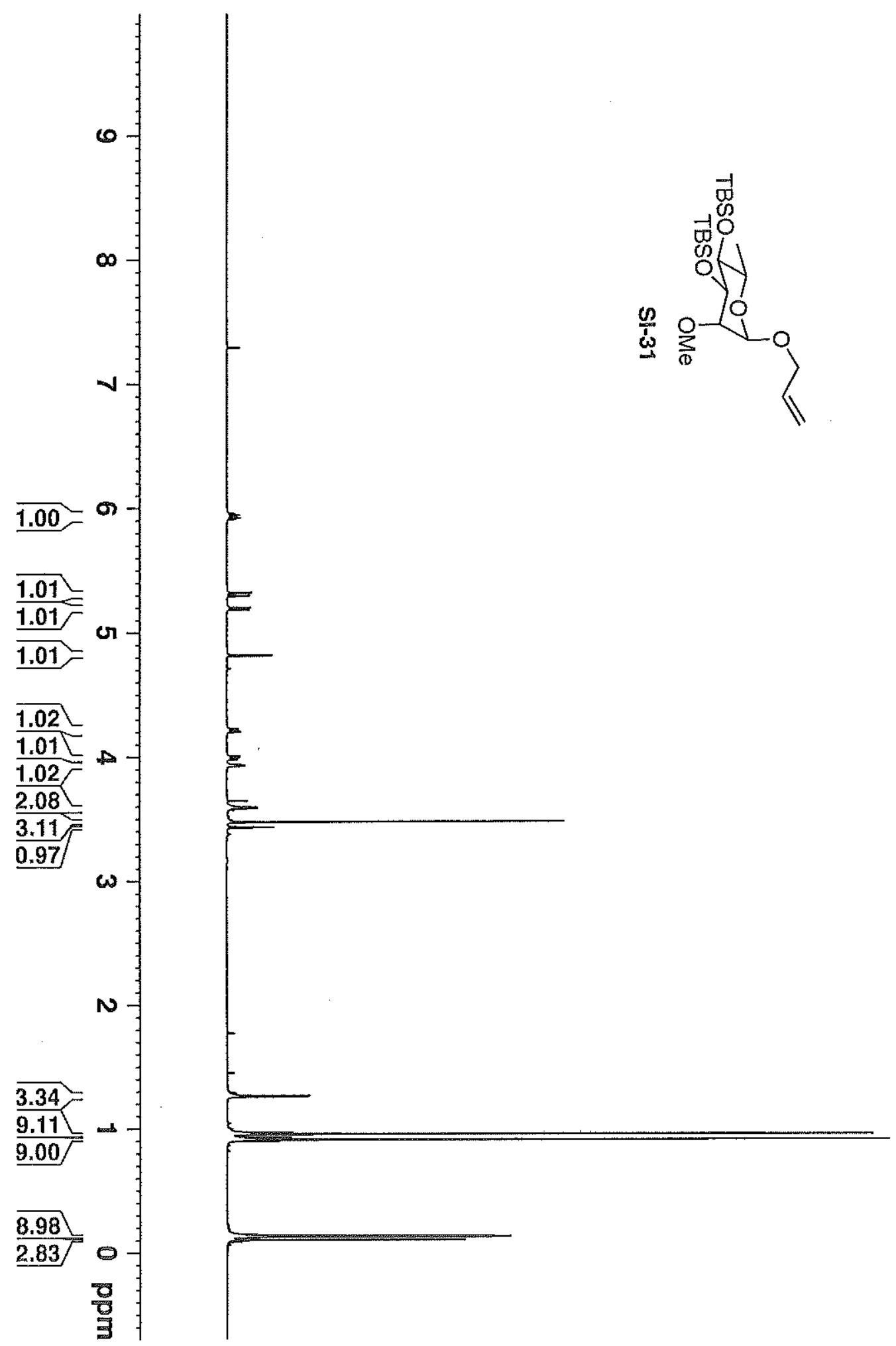

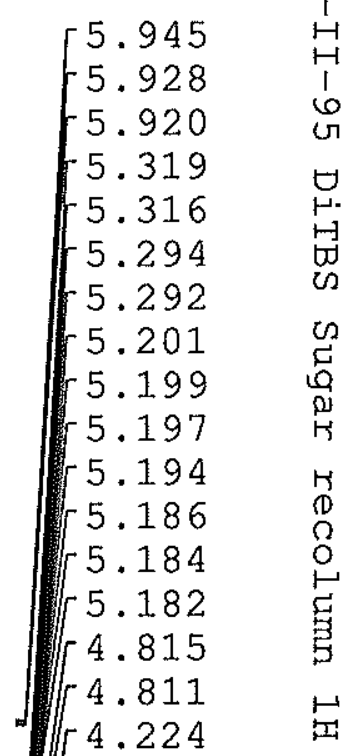

4.217

4.205

4.198

4.003

3.995

3.984

3.976

3.937

$-3.933$

] -3.927

3.922

3.593

3.589

3.585

3.583

3.472

3.433

3.430

3.426

T1.265

1.256

0.956

0.911

0.139

0.133

0.129

0.104

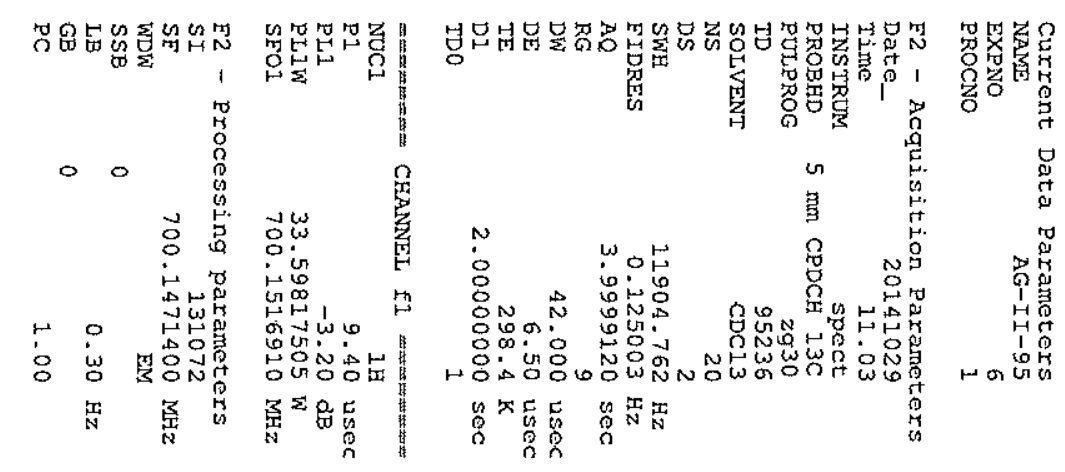




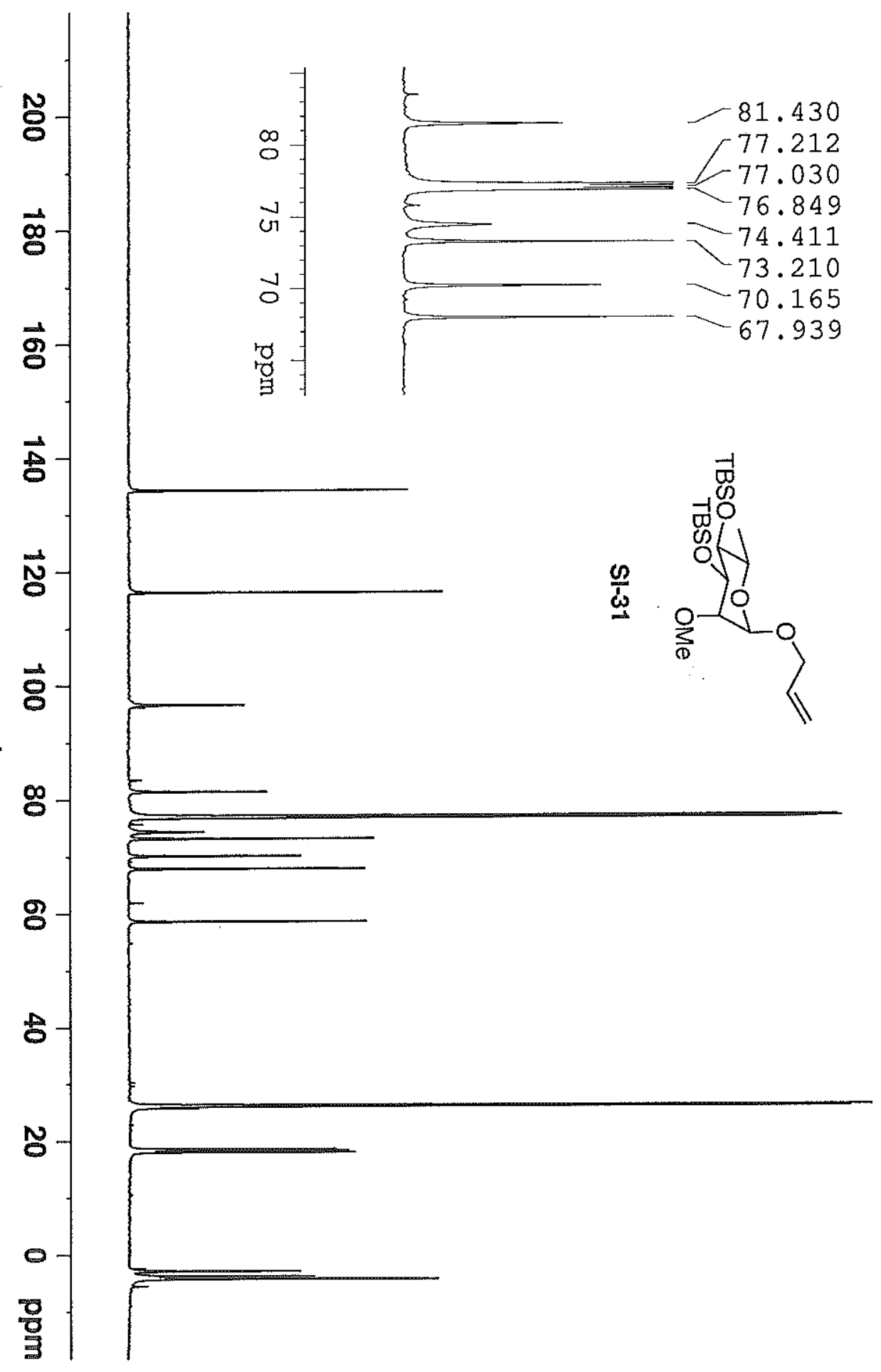

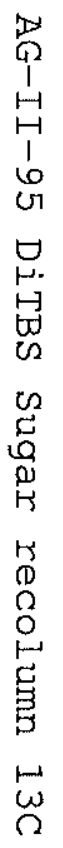
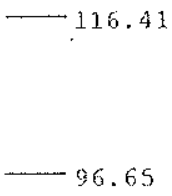

81.43

C 77.21

76.85

74.41

$-73.21$

70,16
67.94

$-58.68$

$-26.33$

$-26.11$

18.63

18.40
-18.06

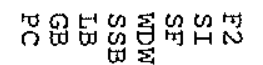

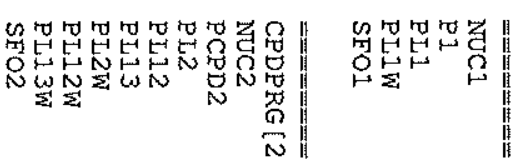

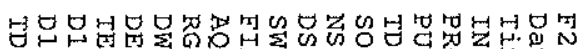

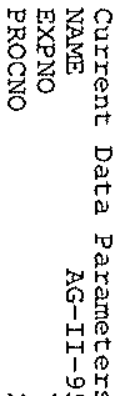

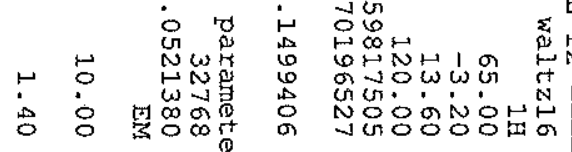

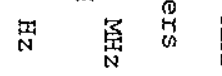

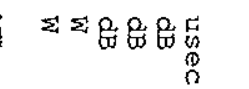

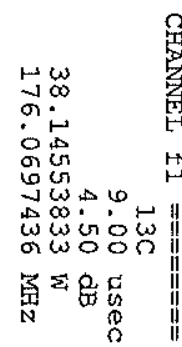

ON

家

NㅐN O०. ONw 世

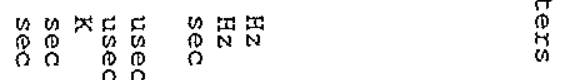

ND战 


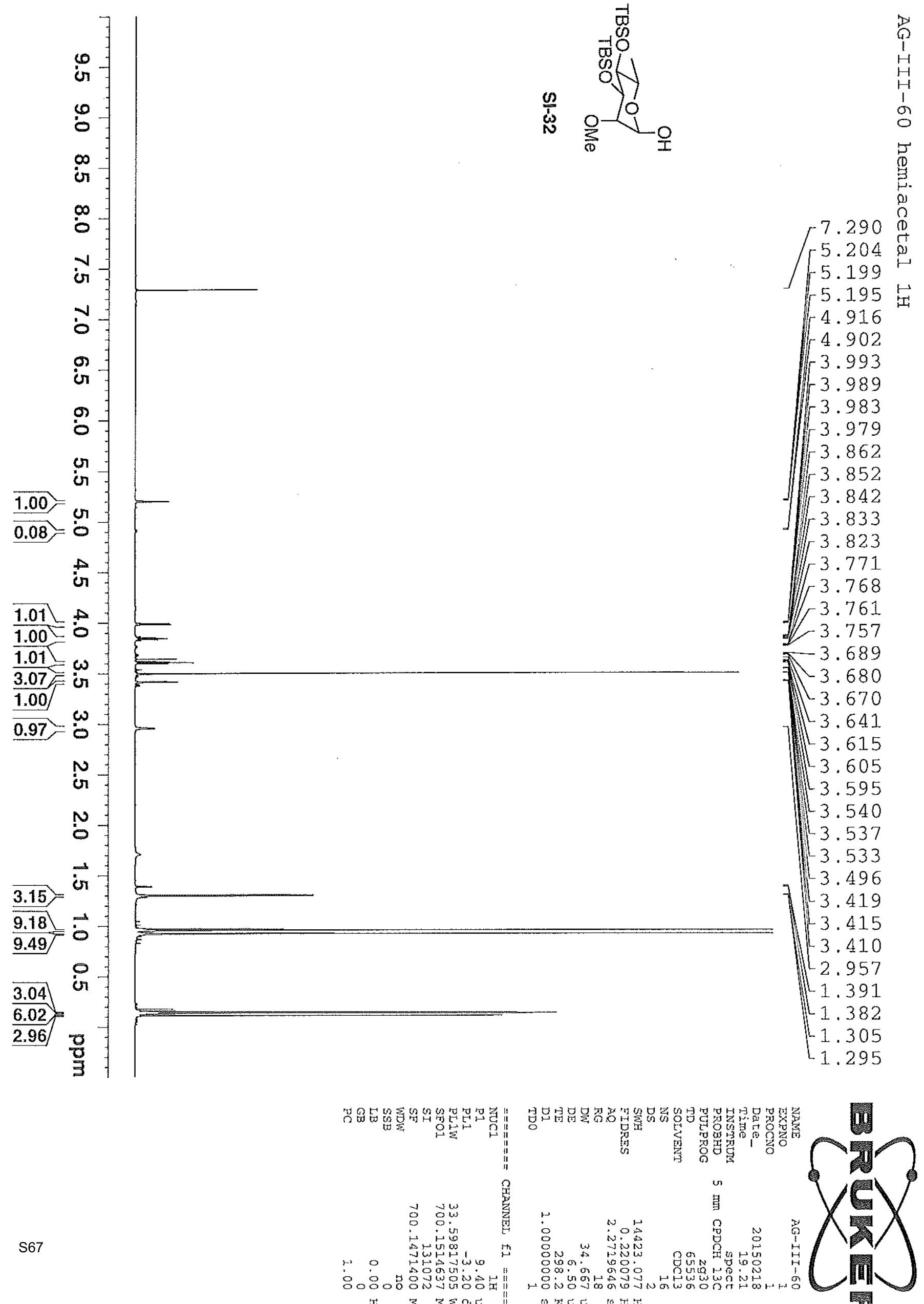



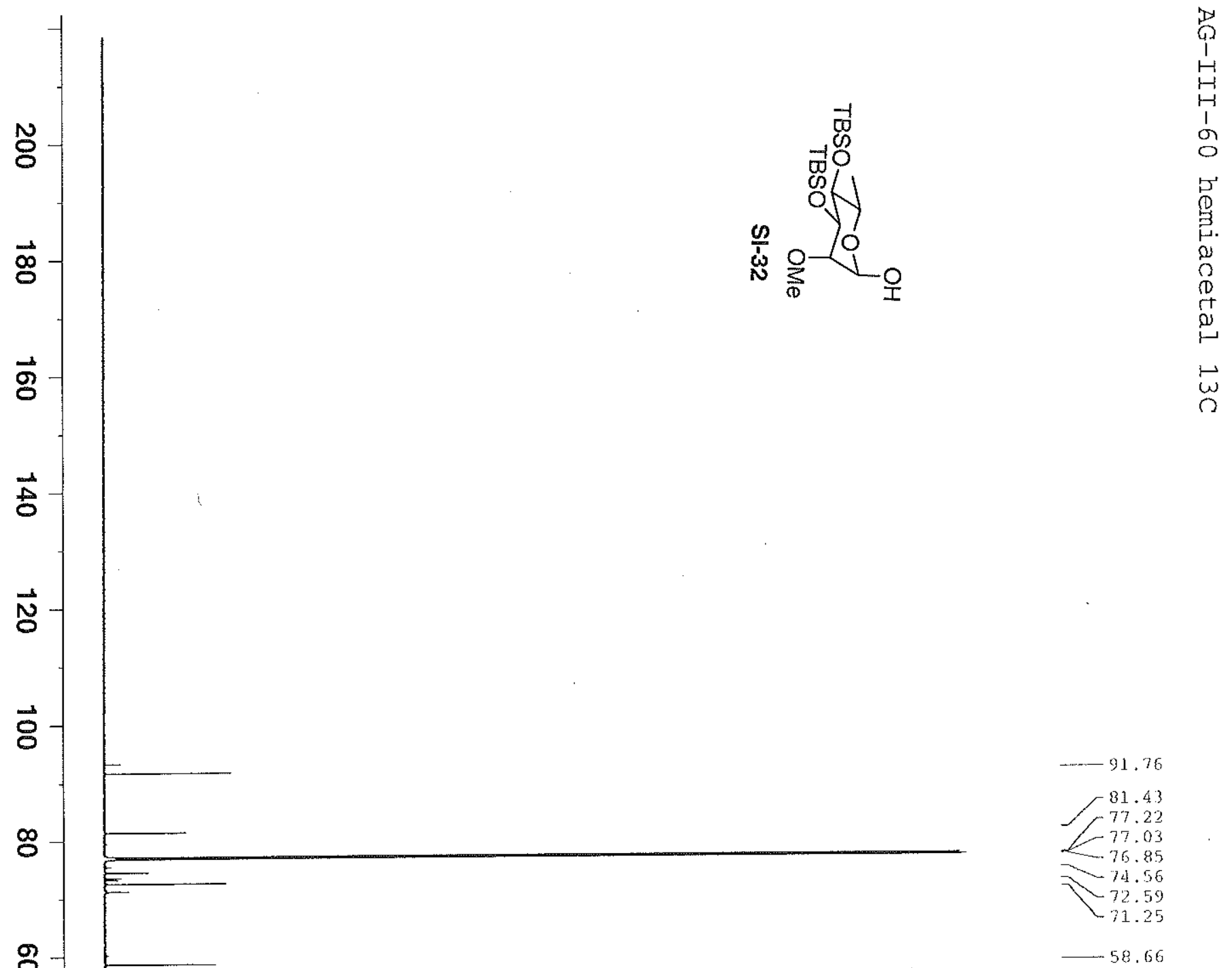

g

$\overrightarrow{8}$

$\overrightarrow{\mathrm{s}}$

$\overrightarrow{\tilde{O}}$

ø

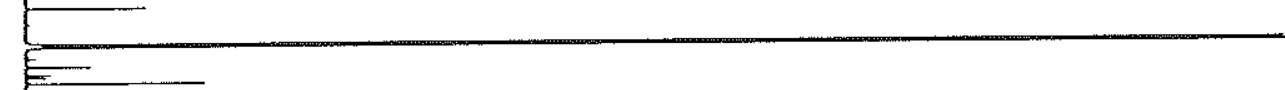

$<-26.04$

18.58

居

8

$-16.07$

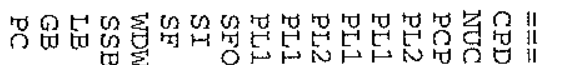

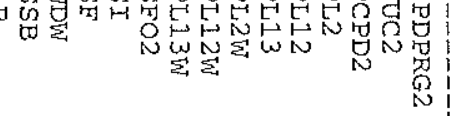

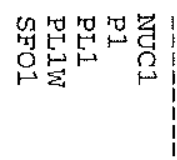

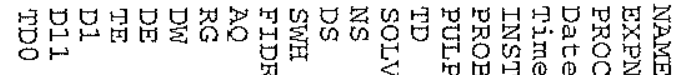

龸 忽出

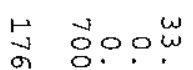

a 0.0 is

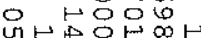

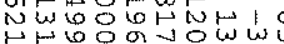

? WOAOUf

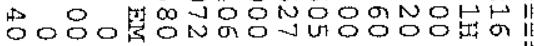

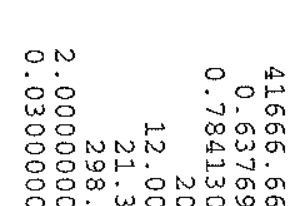



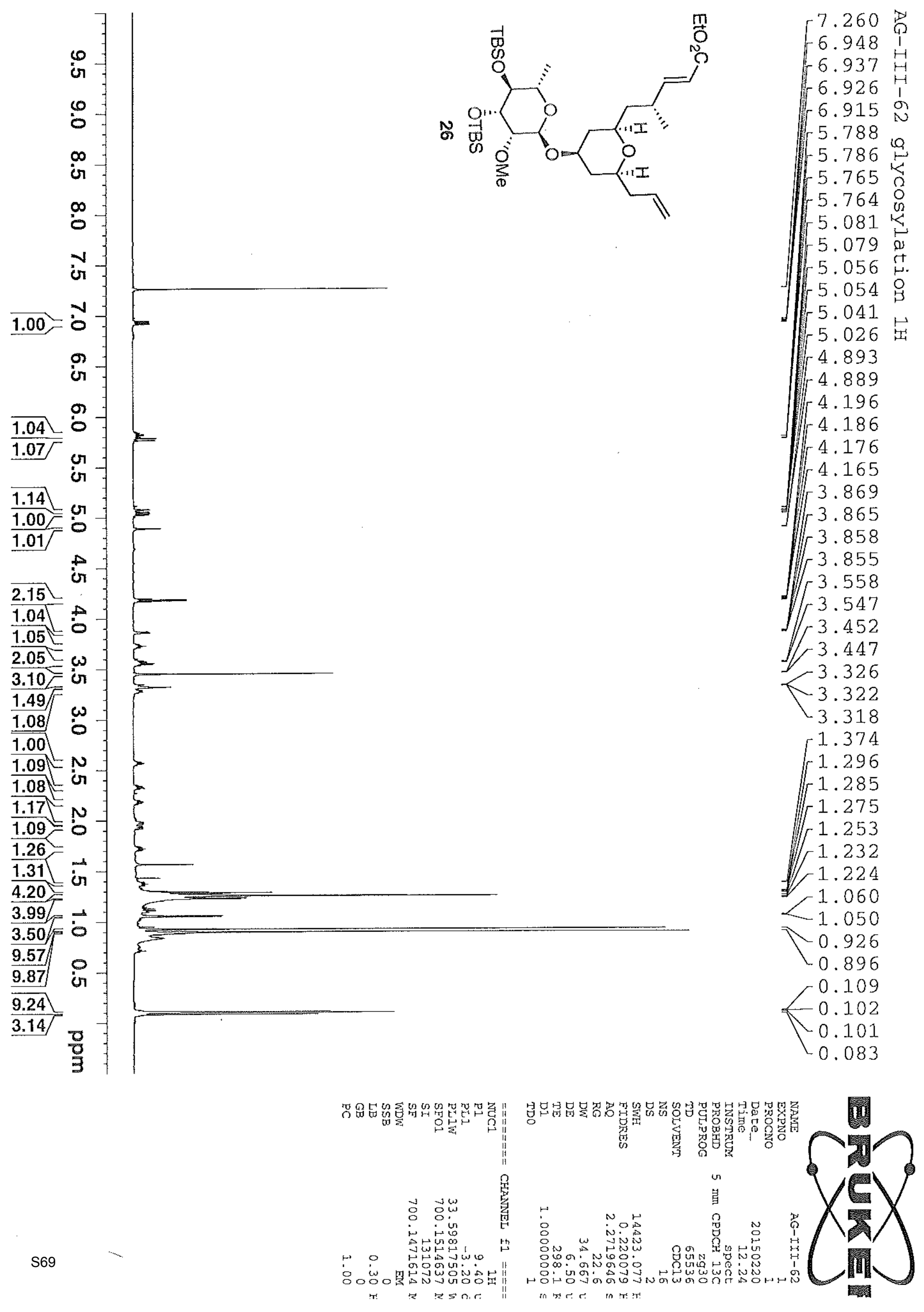


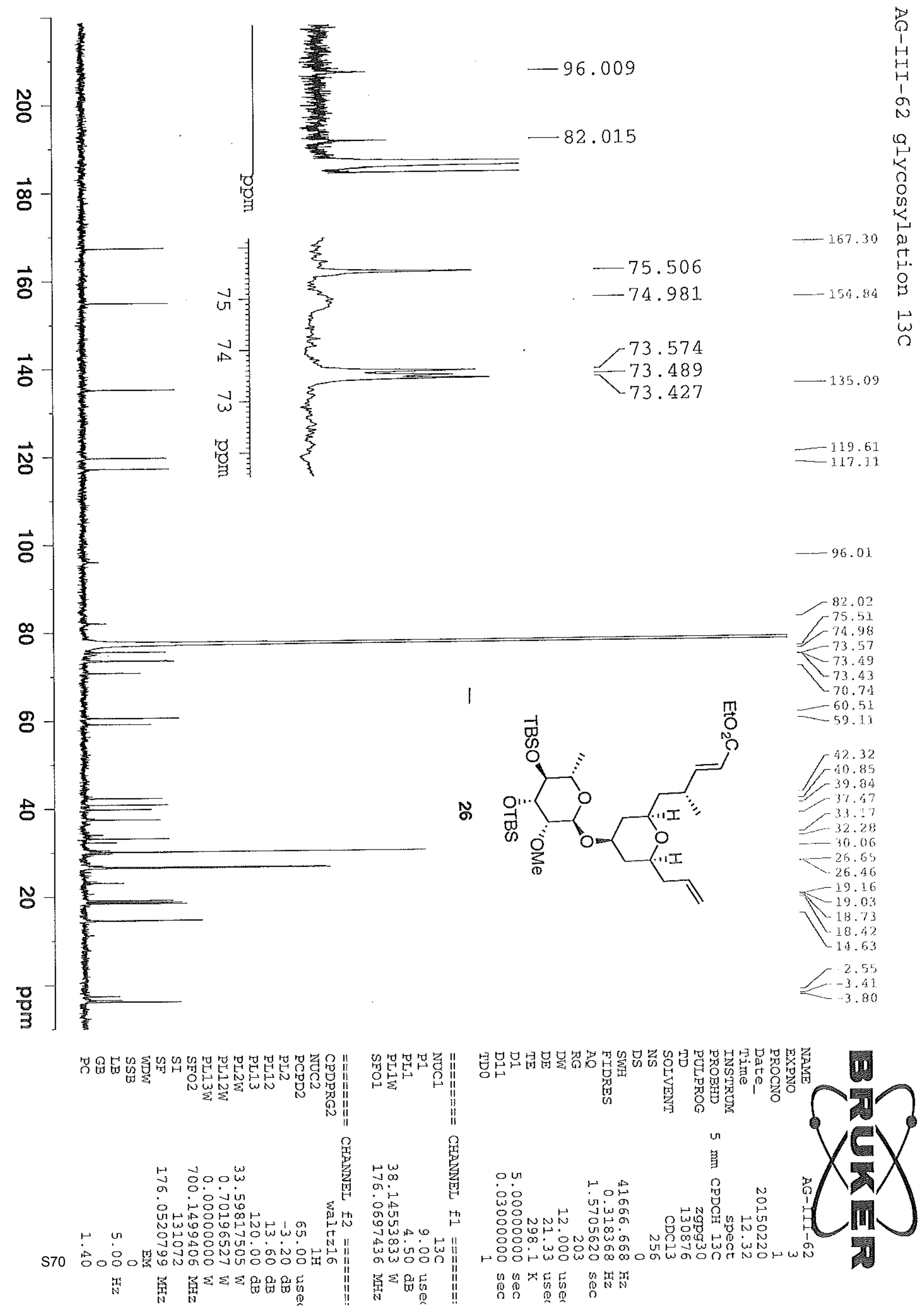




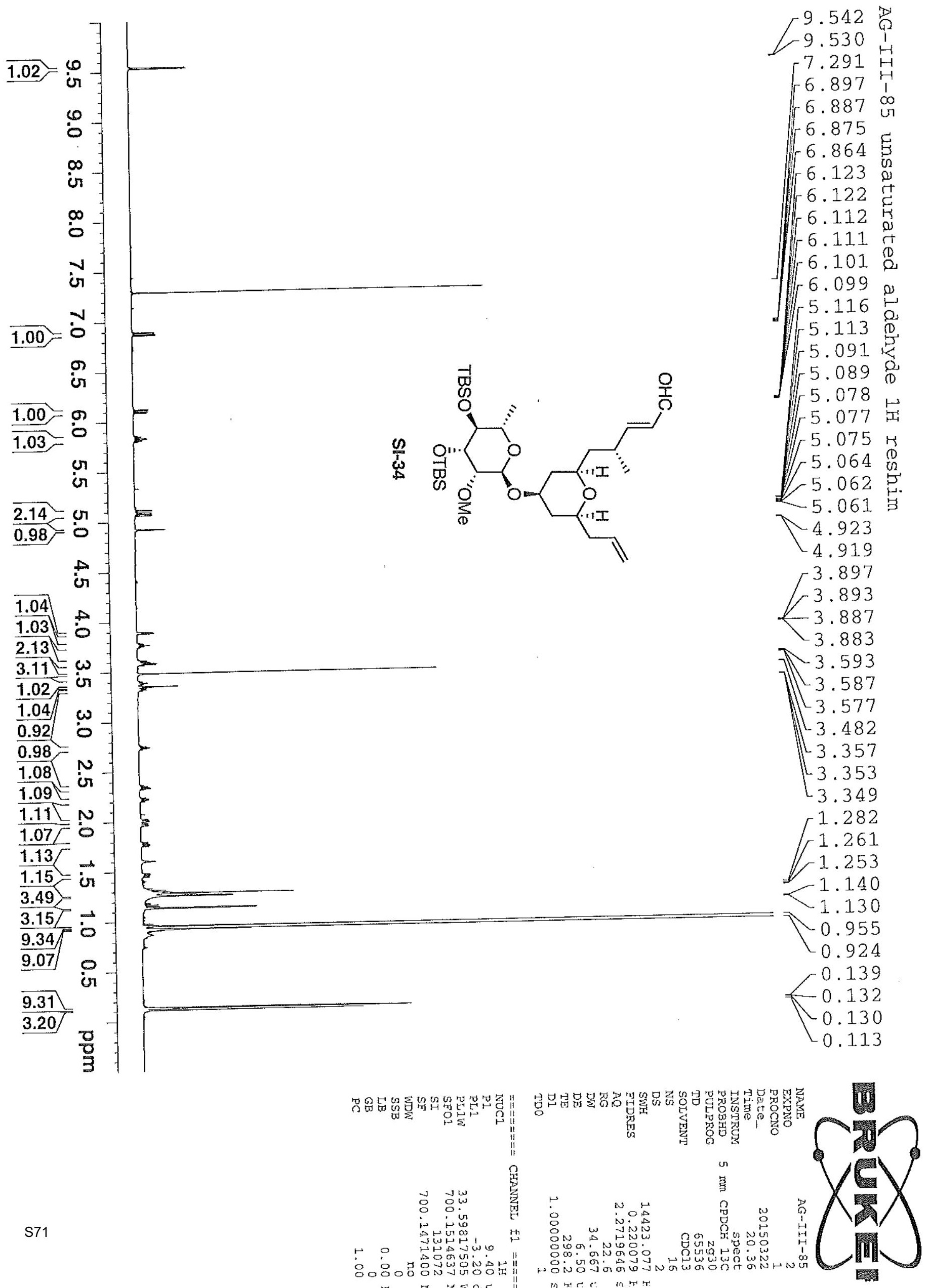



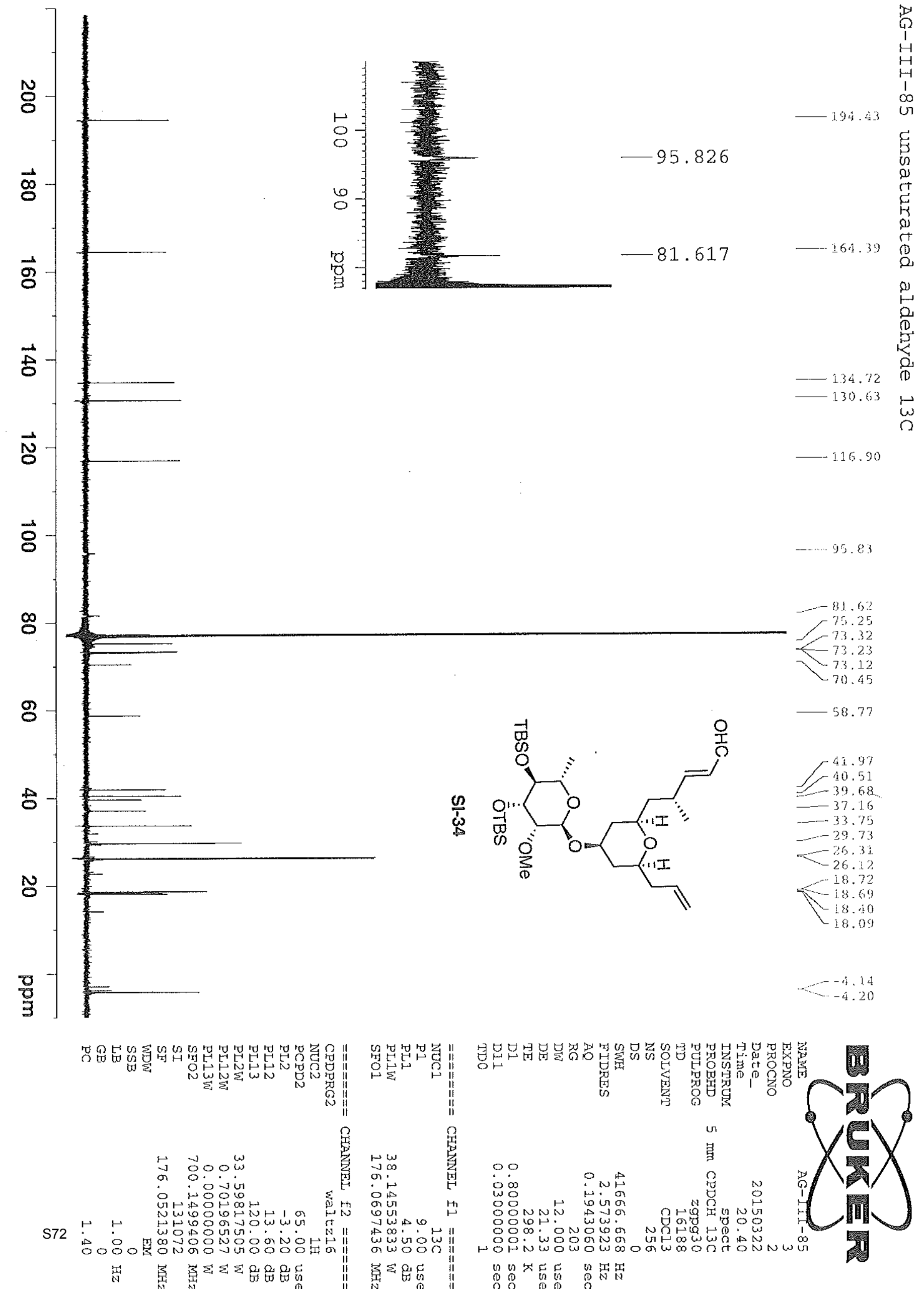


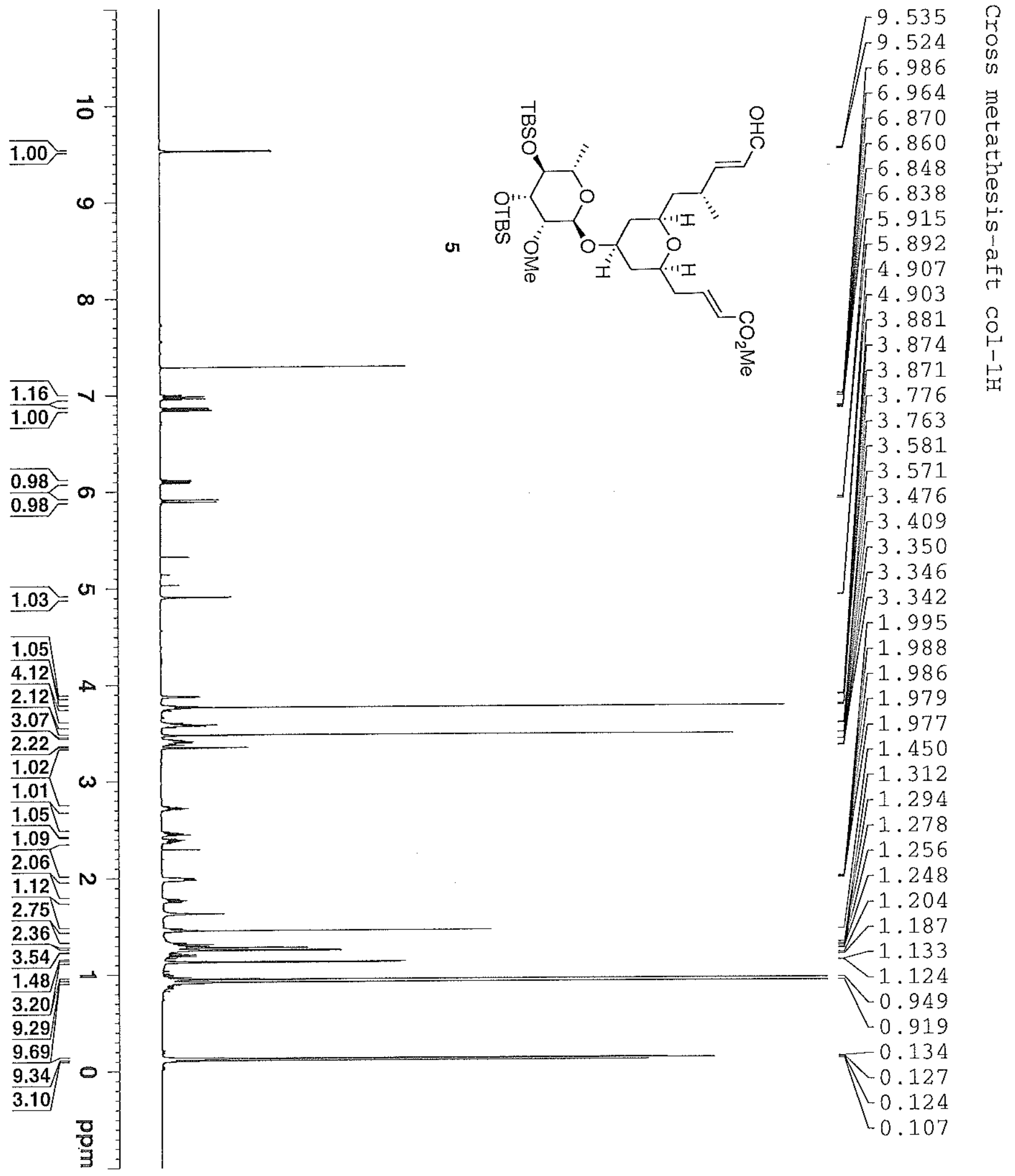

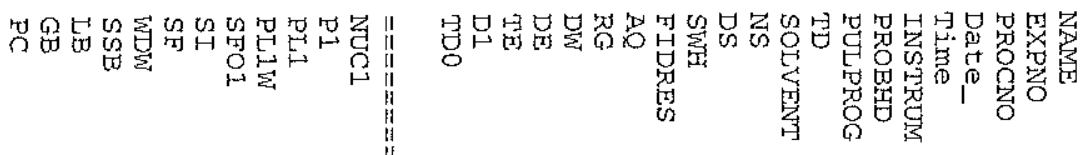

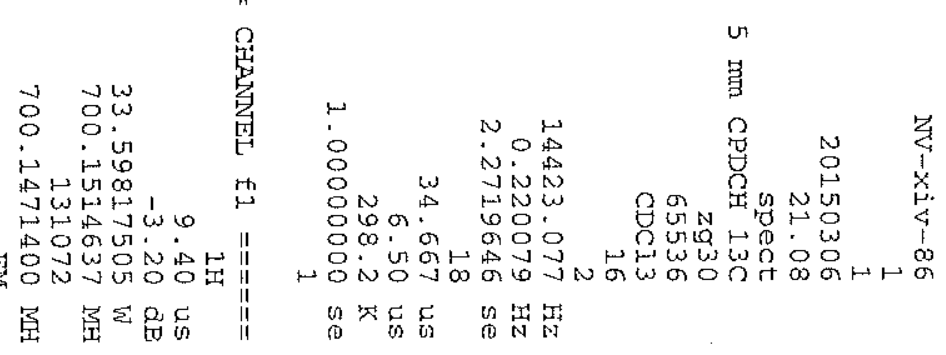




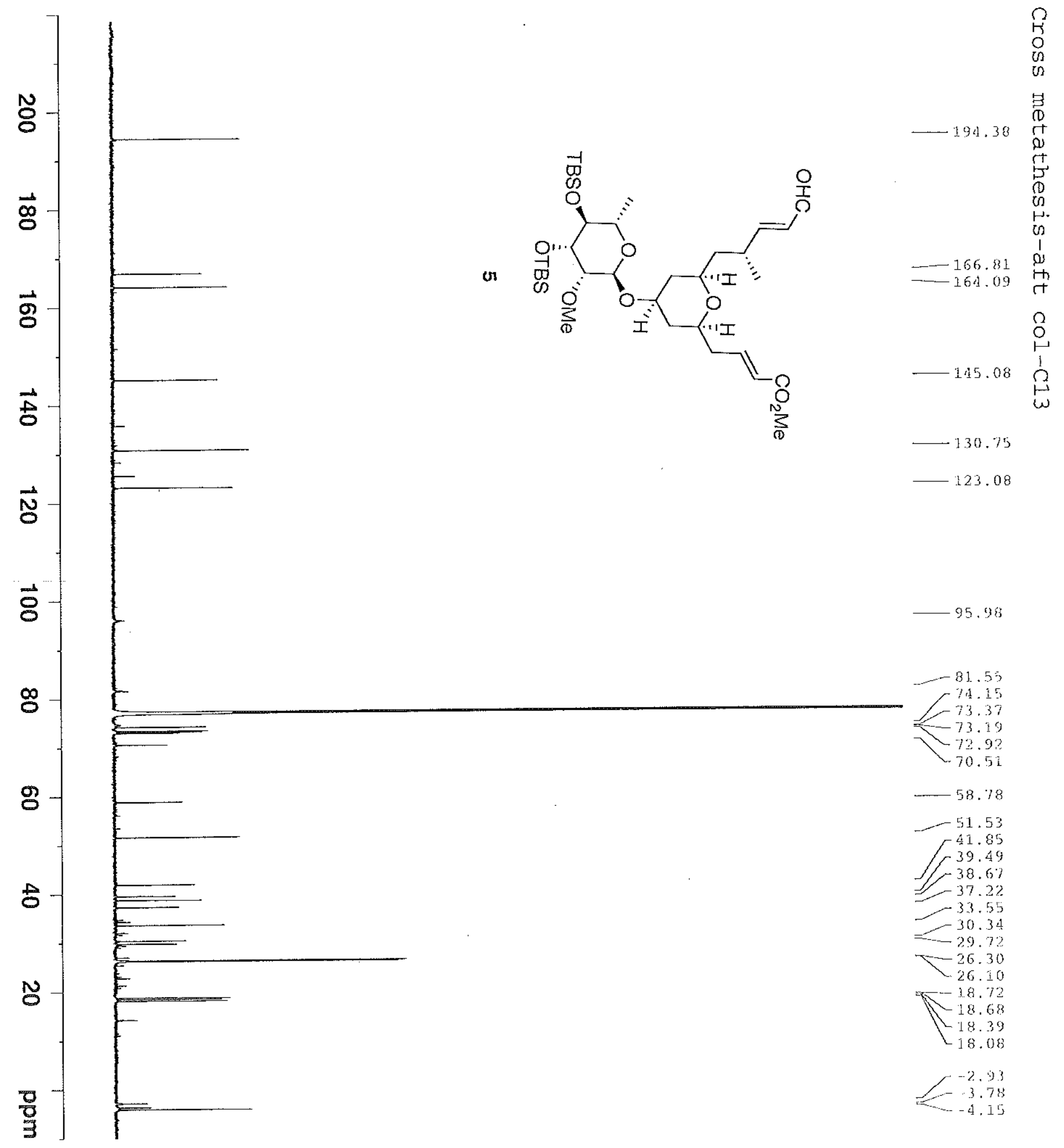

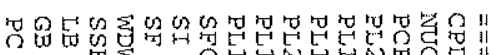

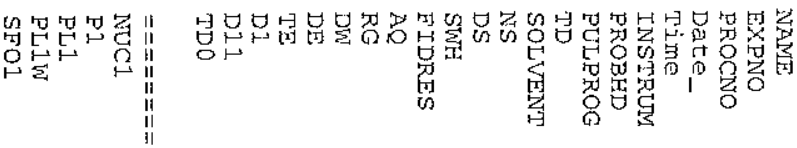

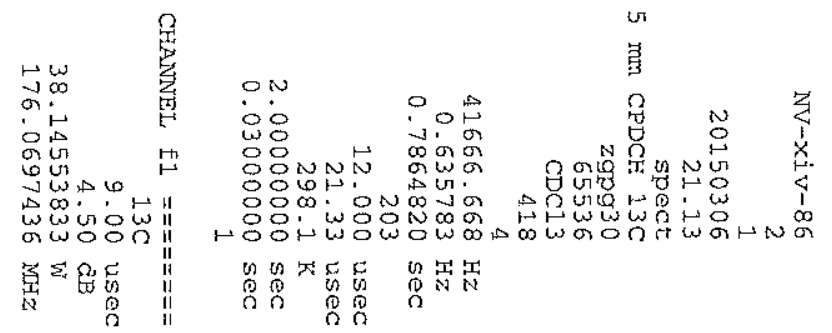

$\checkmark \omega \quad$ w

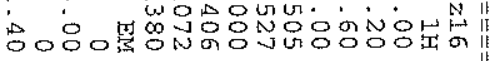

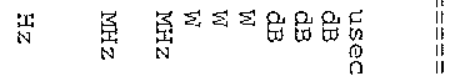




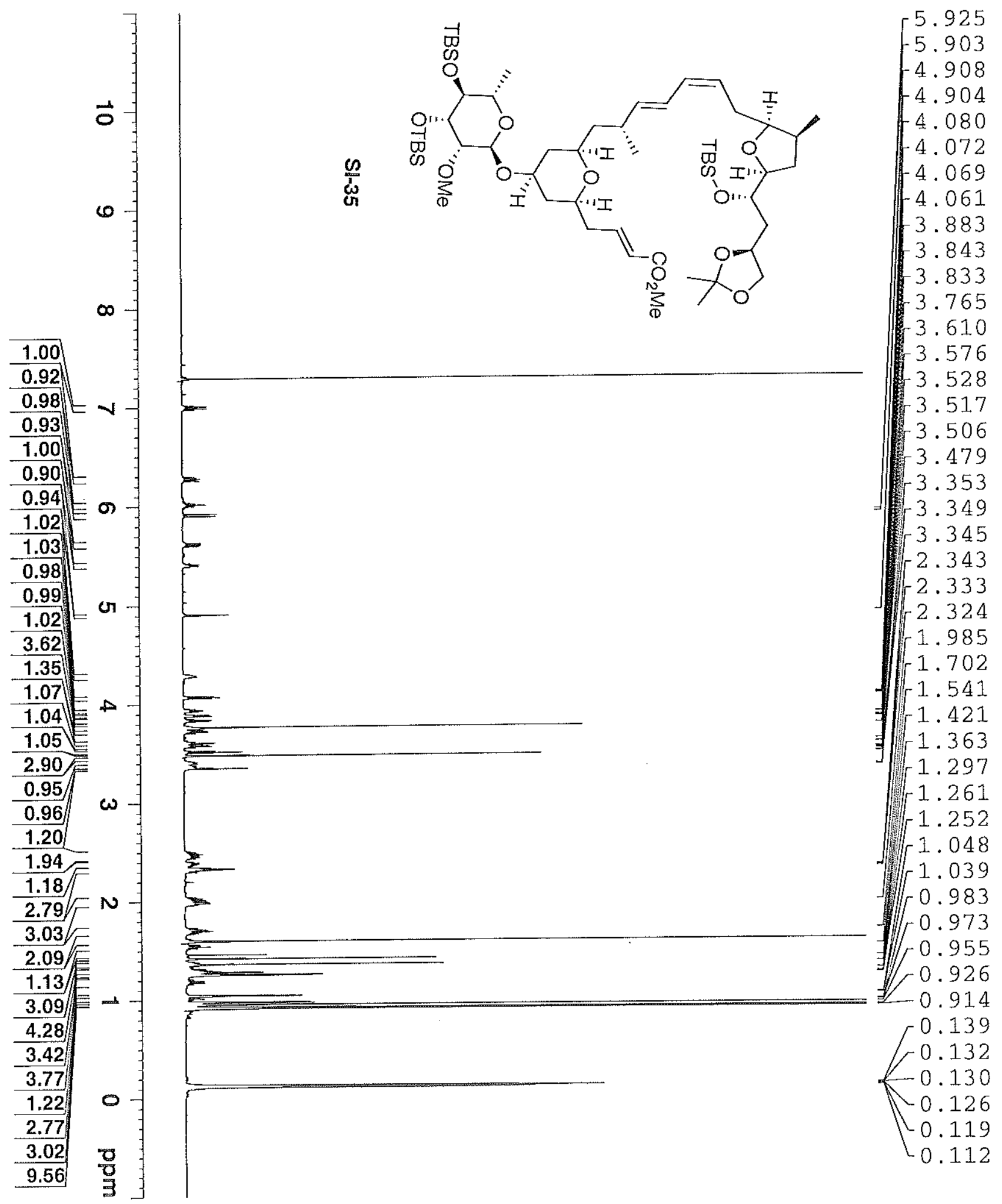

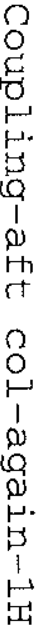

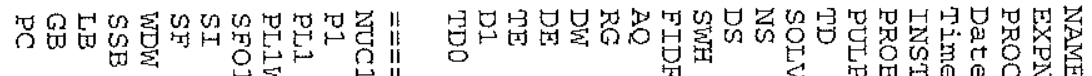




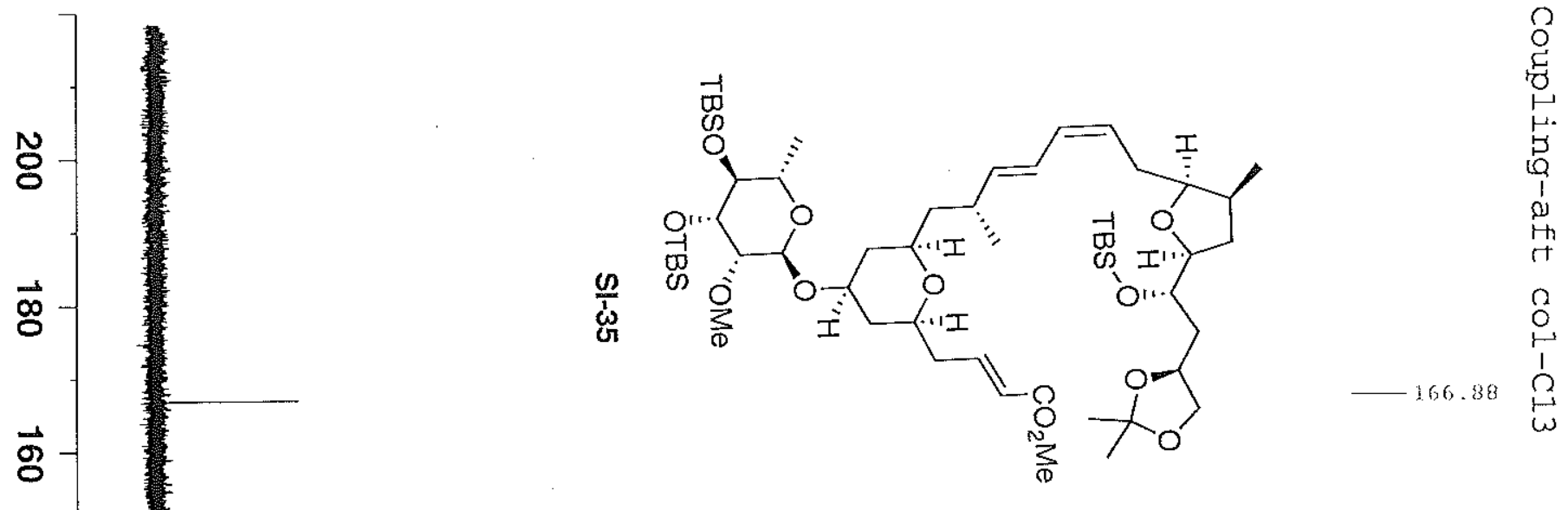

$-145.32$

140.75

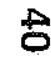

$\mathbb{N}$

$\vec{\circ}$

。

8

吕

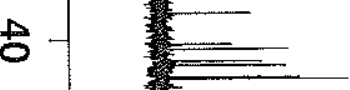

E

$-129.78$

$--126.70$

$-123.64$

.

108.57

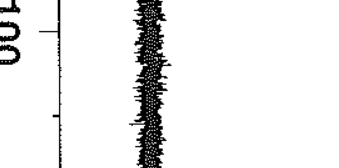

$\stackrel{\infty}{\circ}$
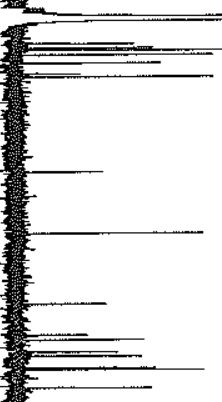

-
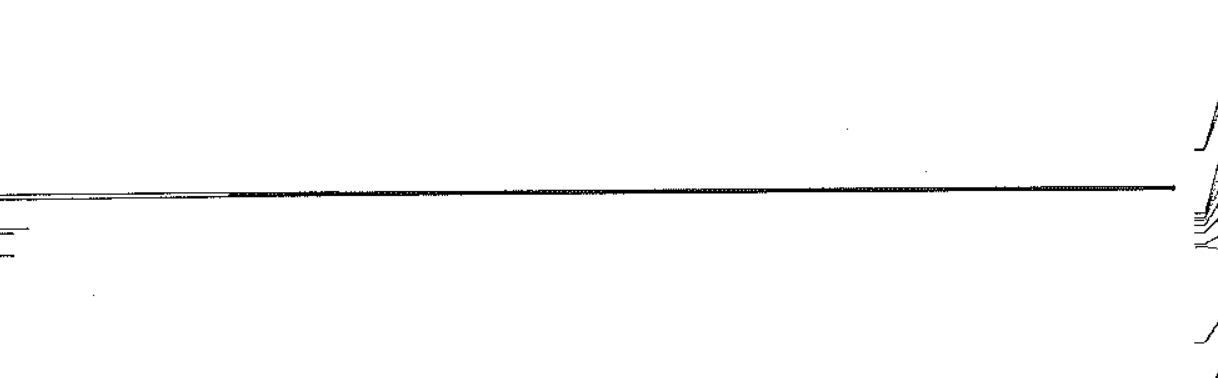

$\Gamma^{81.58}$

$\tau^{81} .42$

$\int^{74.02}$

$\int \Gamma_{-73}^{731}$

72.68
-71.72

- 70.42

58.78
51.49

$\int 43.49$

$\int \begin{aligned} & 51.49 \\ & 39.37\end{aligned}$

78.80

r 37.36

If) 36.836

Jf 35.47

35.22
$=-33.06$

$-29.72$

$\begin{array}{r}<9.54 \\ \hline\end{array}$

$-27.15$

$-26.32$

च -26.12

$-26.07$

$-25.83$

$-19.98$

$-18.69$

$\left[\begin{array}{r}18.50 \\ 18.28\end{array}\right.$

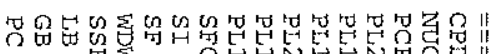

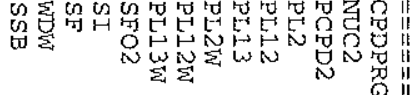

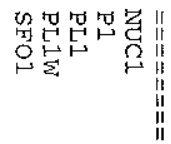

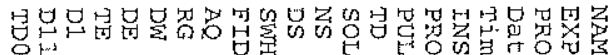

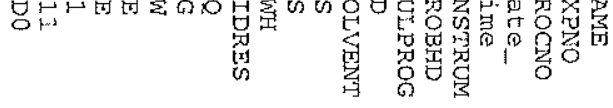

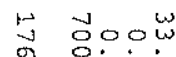

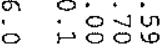

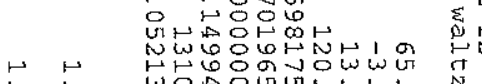

worouvow

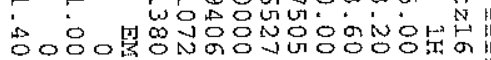

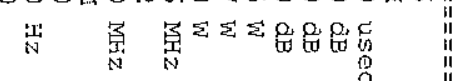
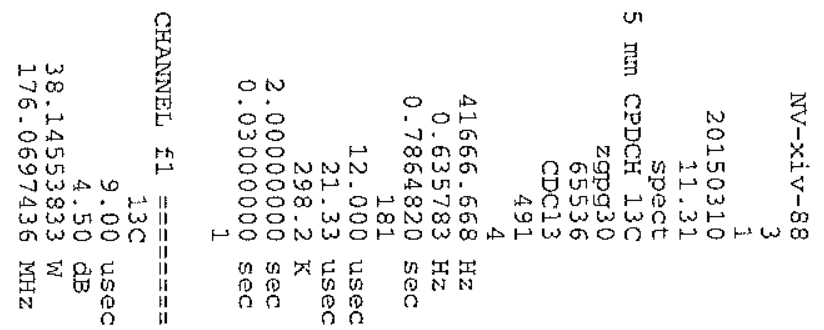


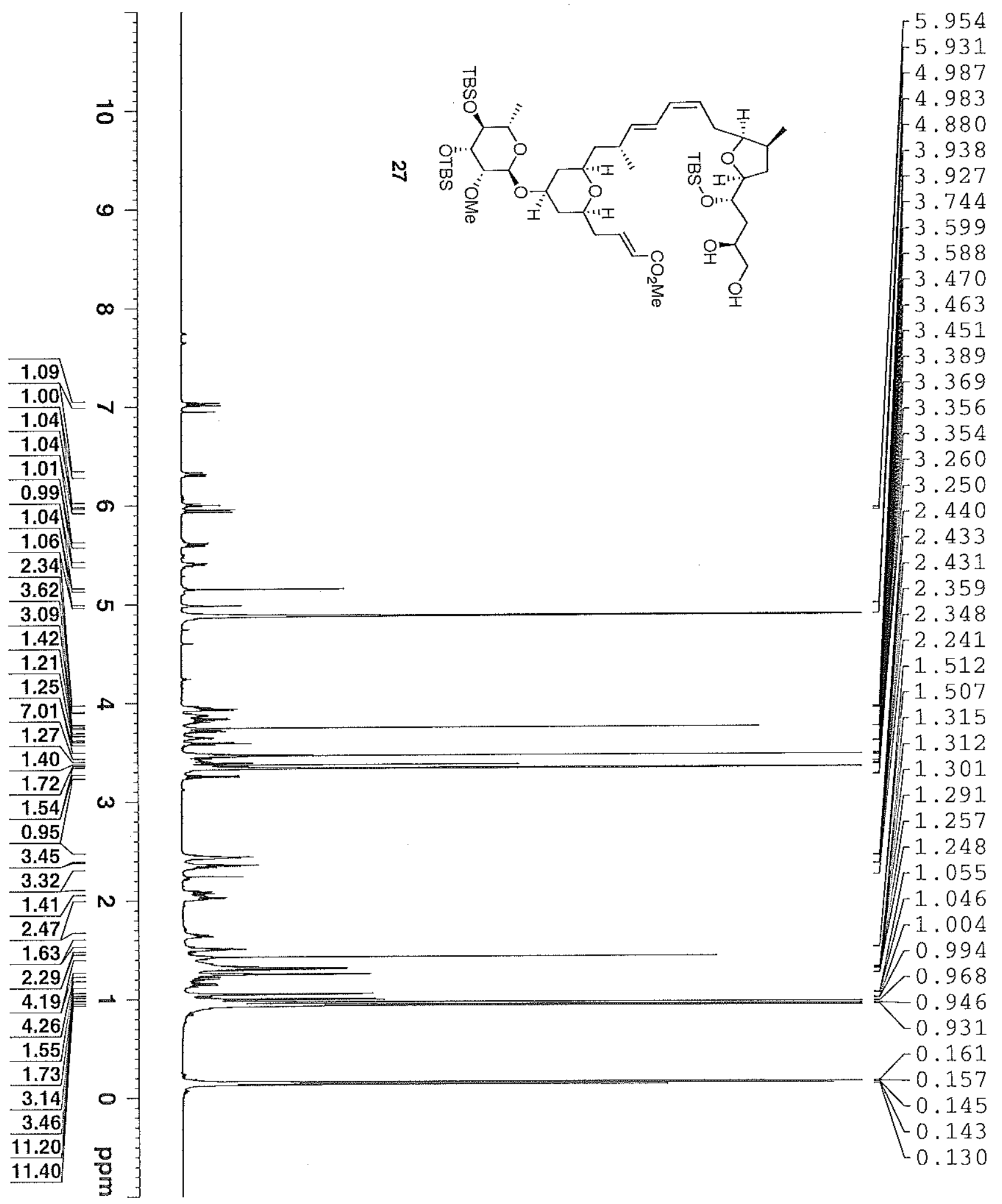

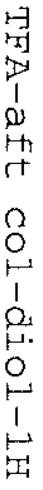

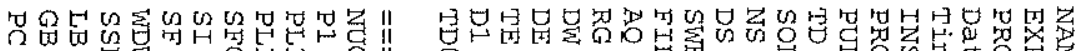

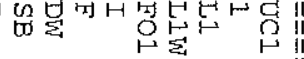

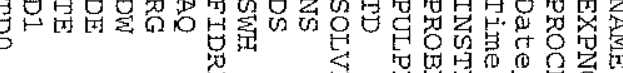




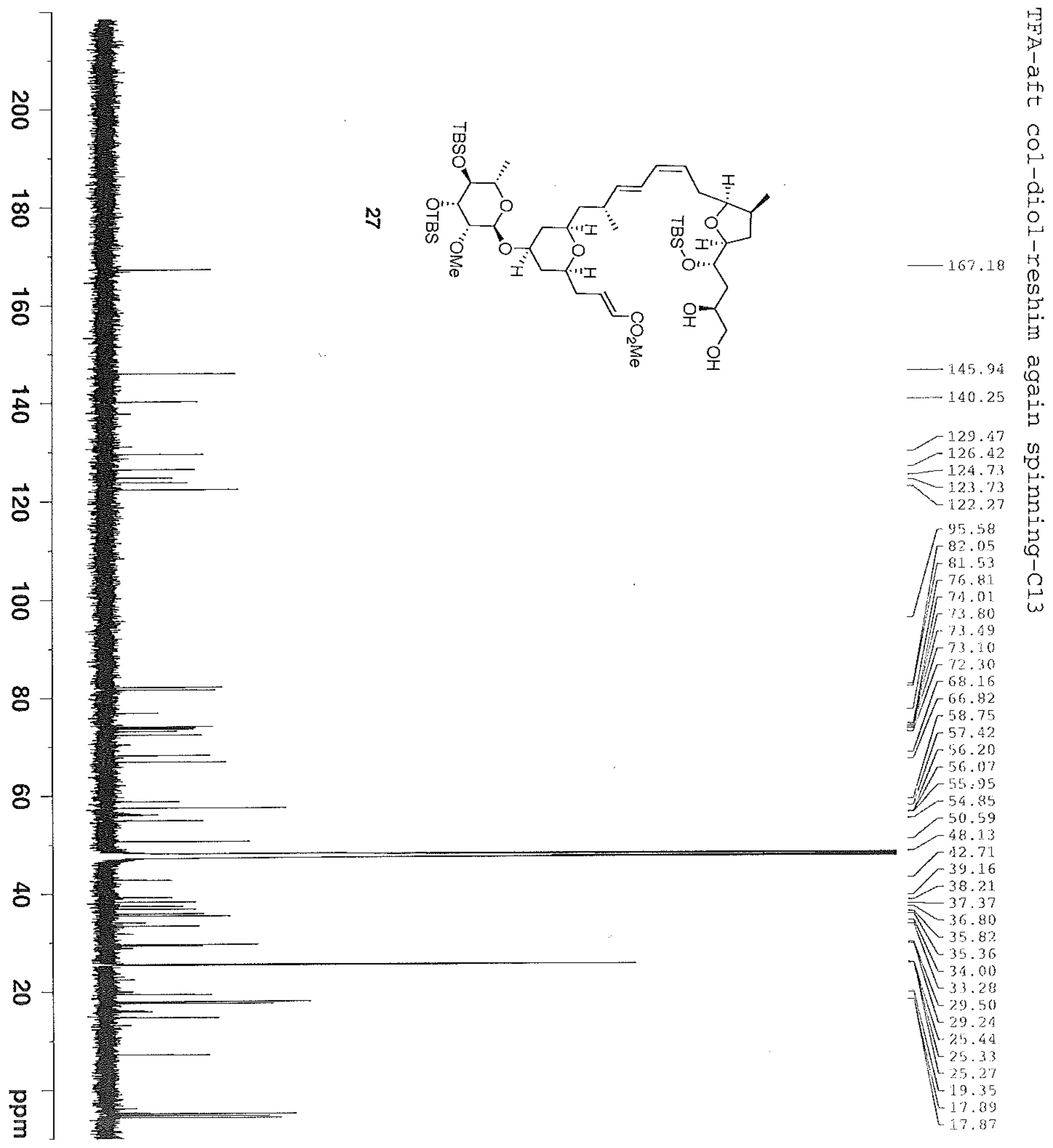

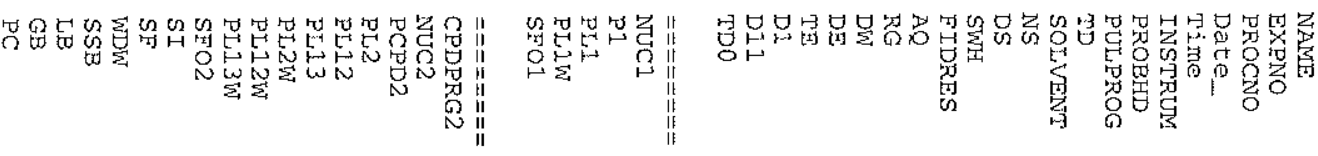

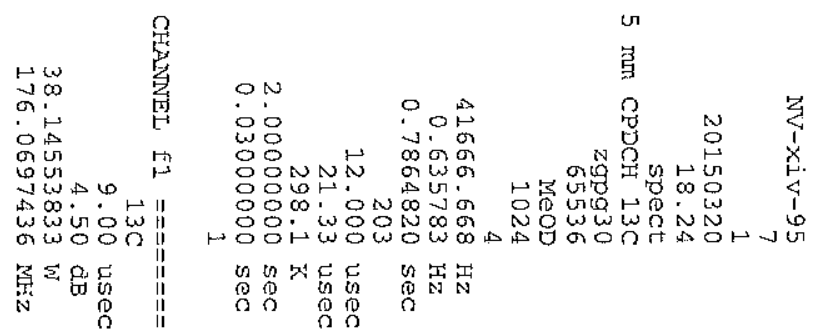




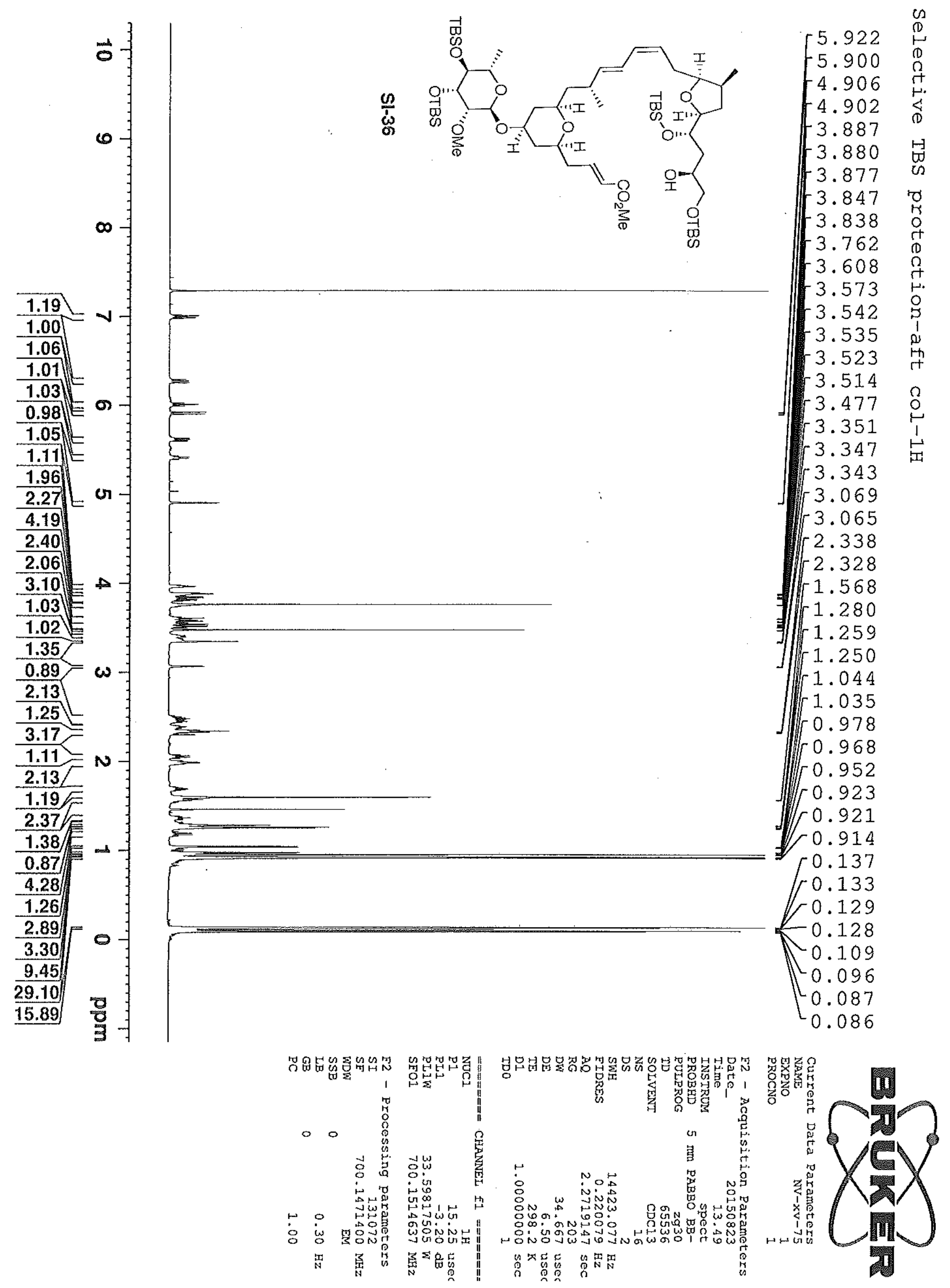




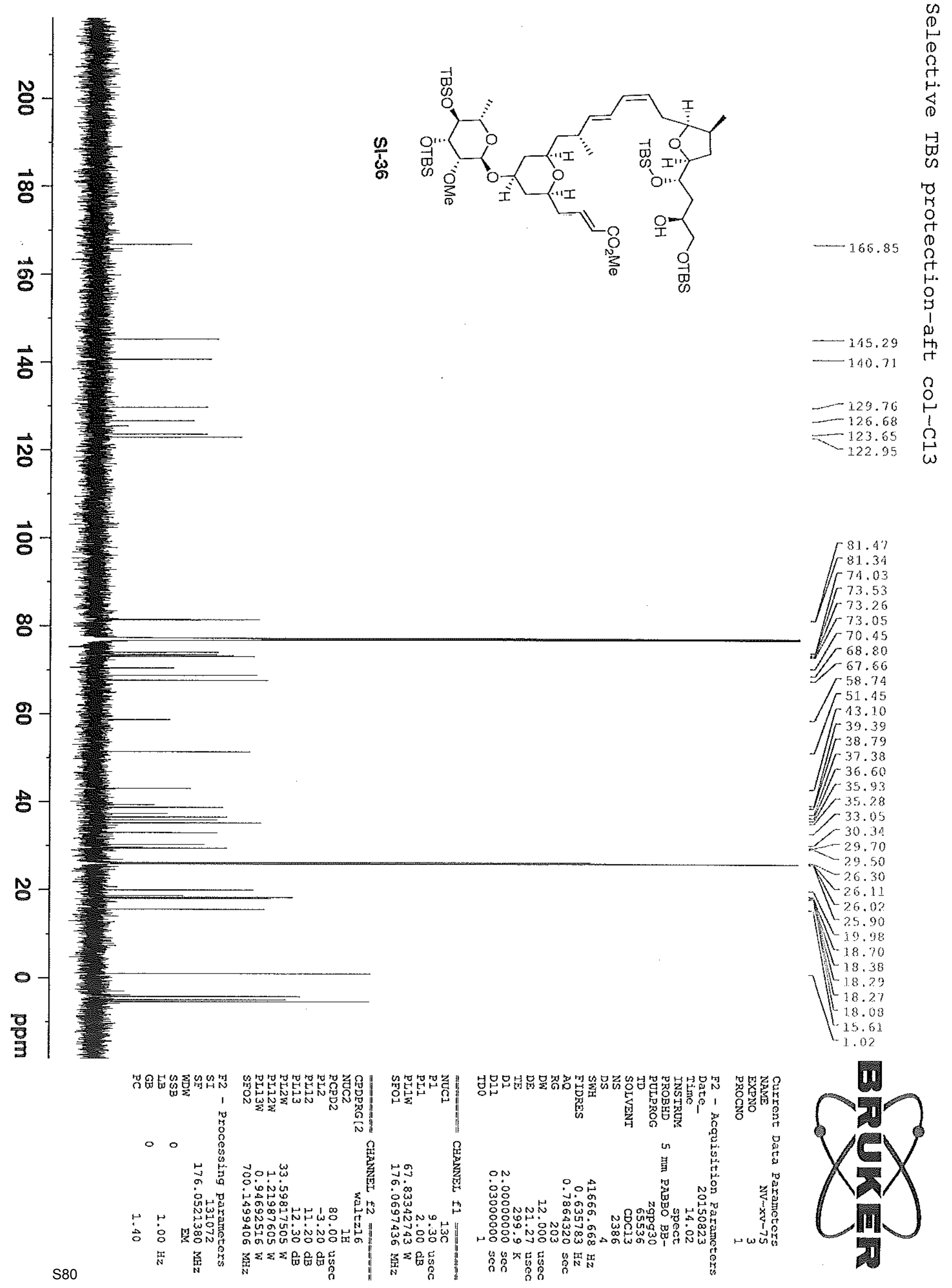




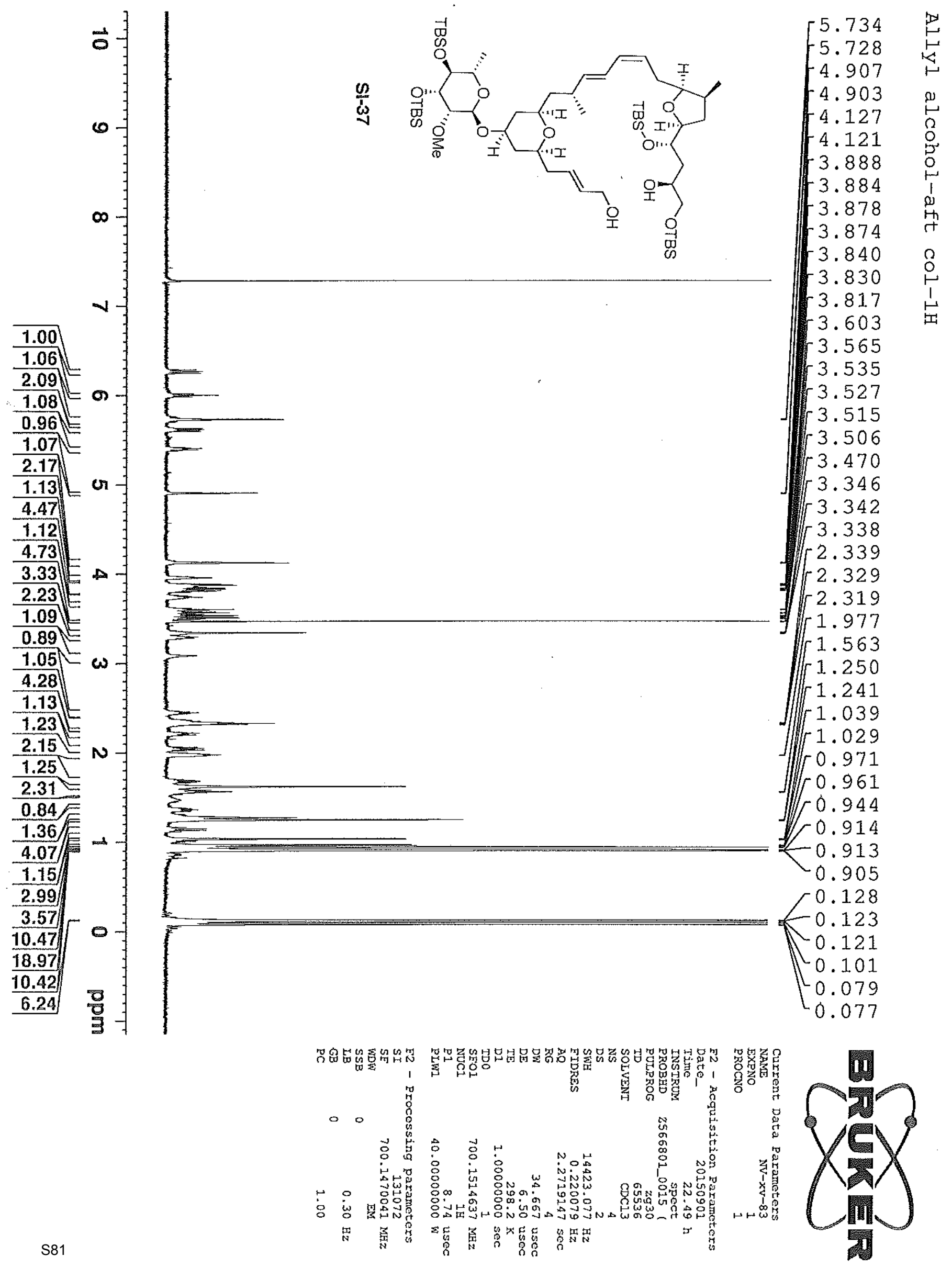




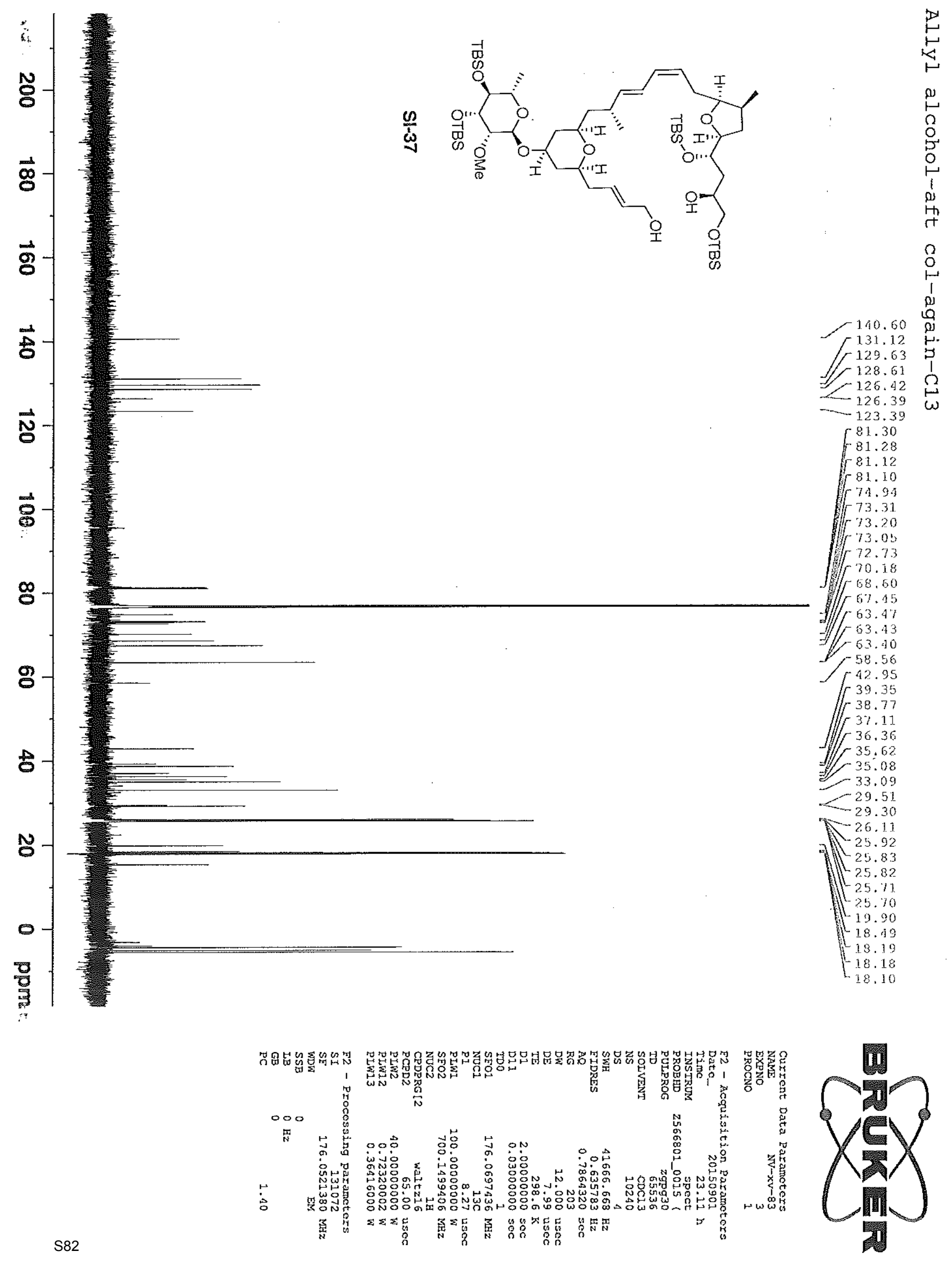



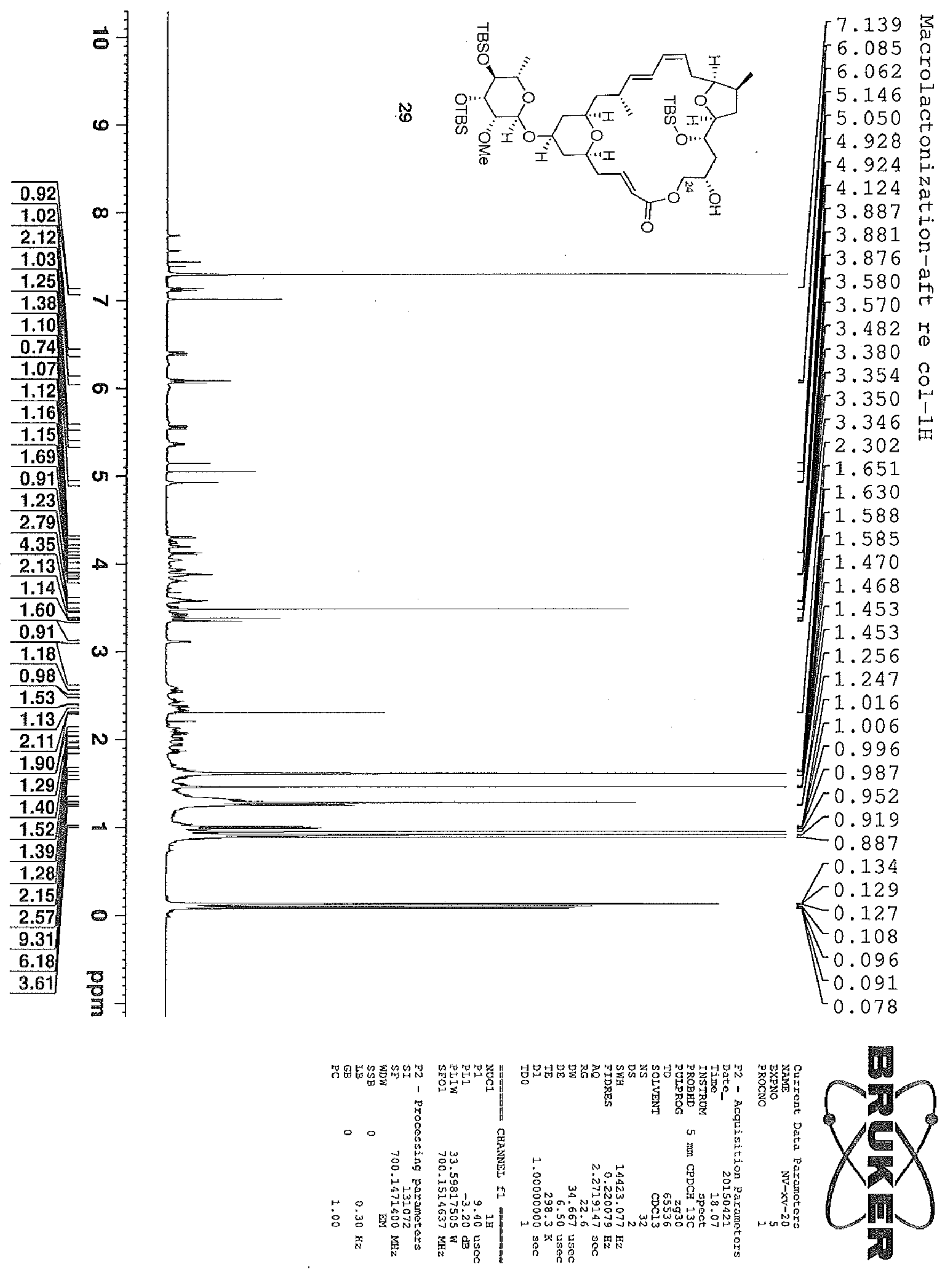


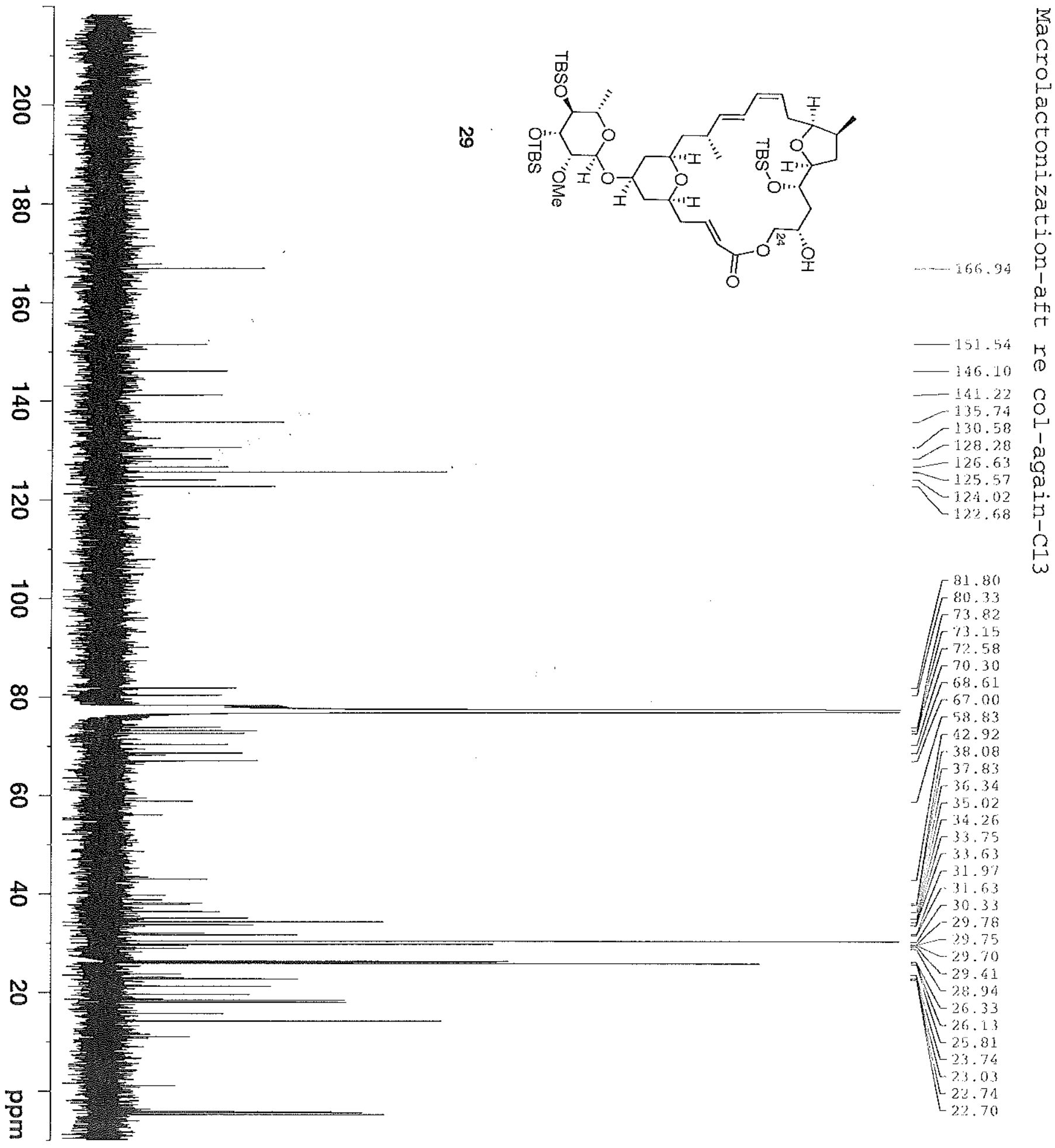

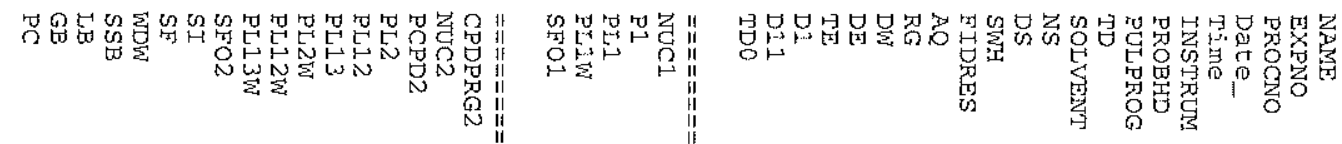

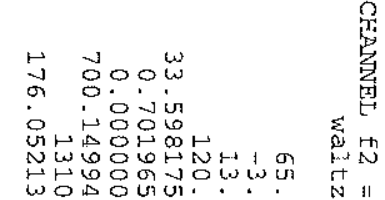

:

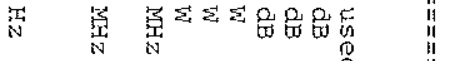

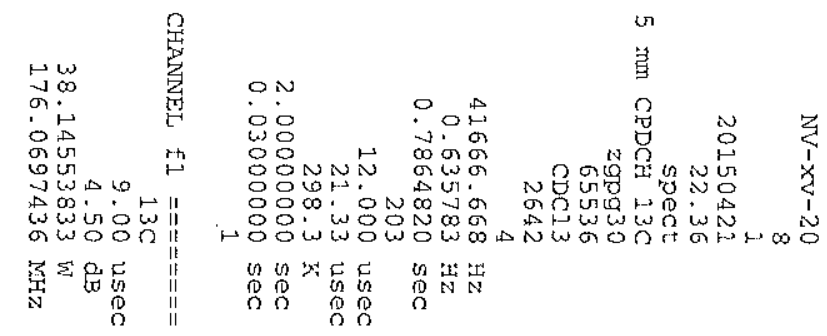



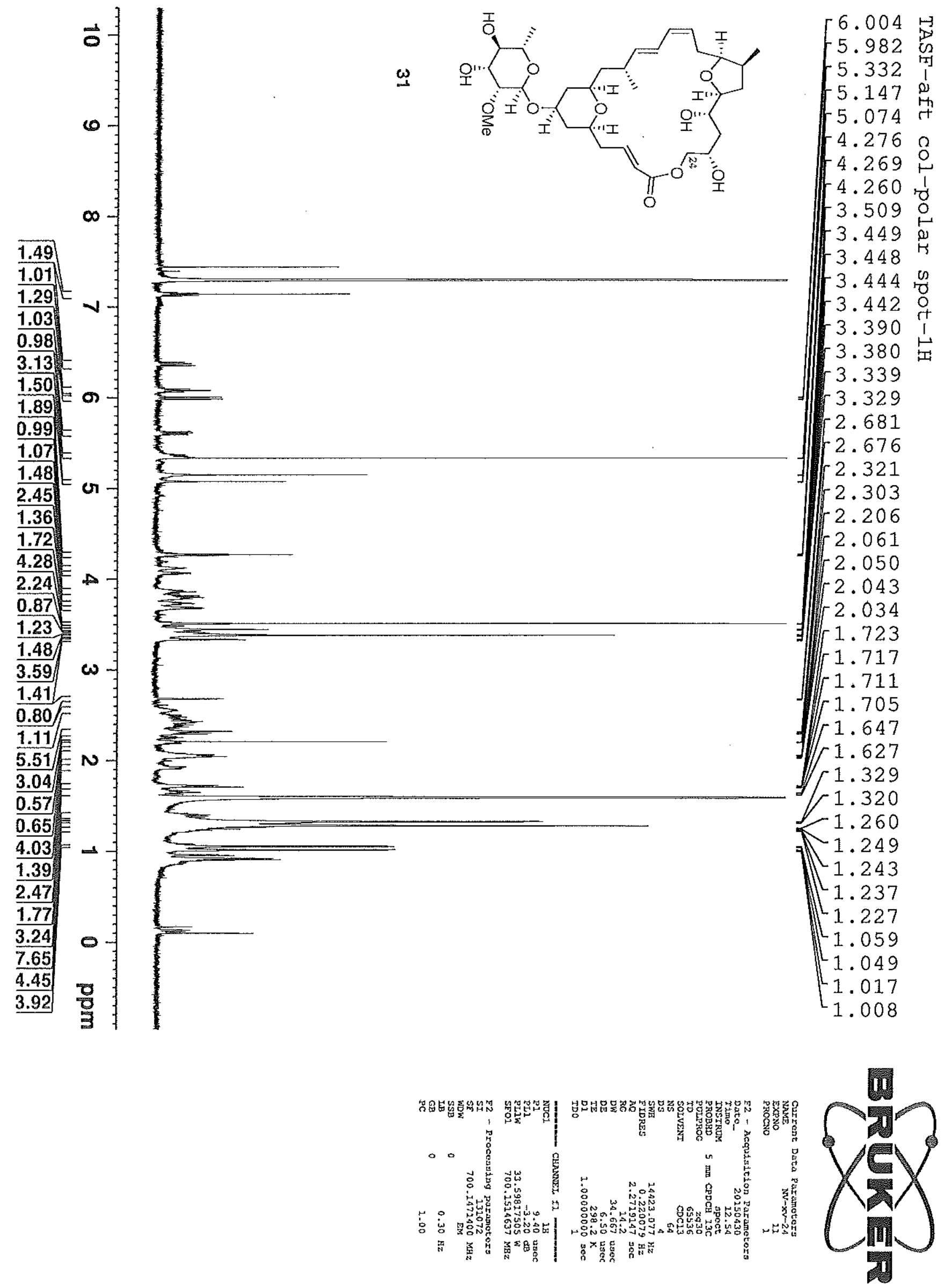


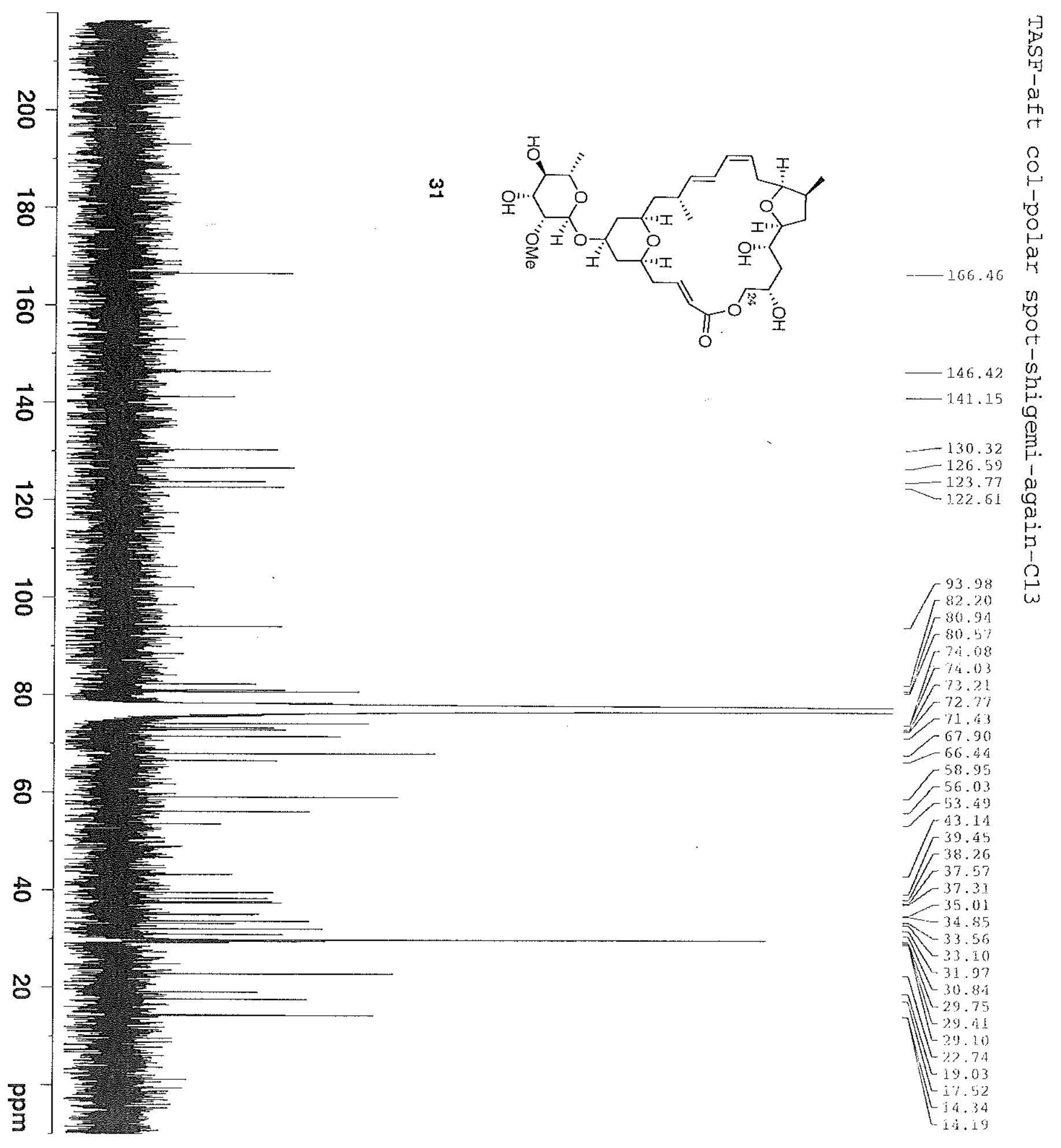

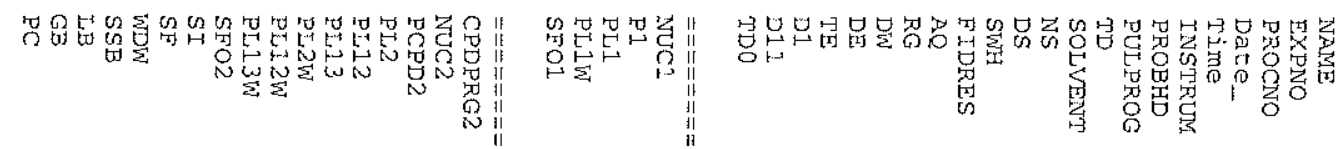



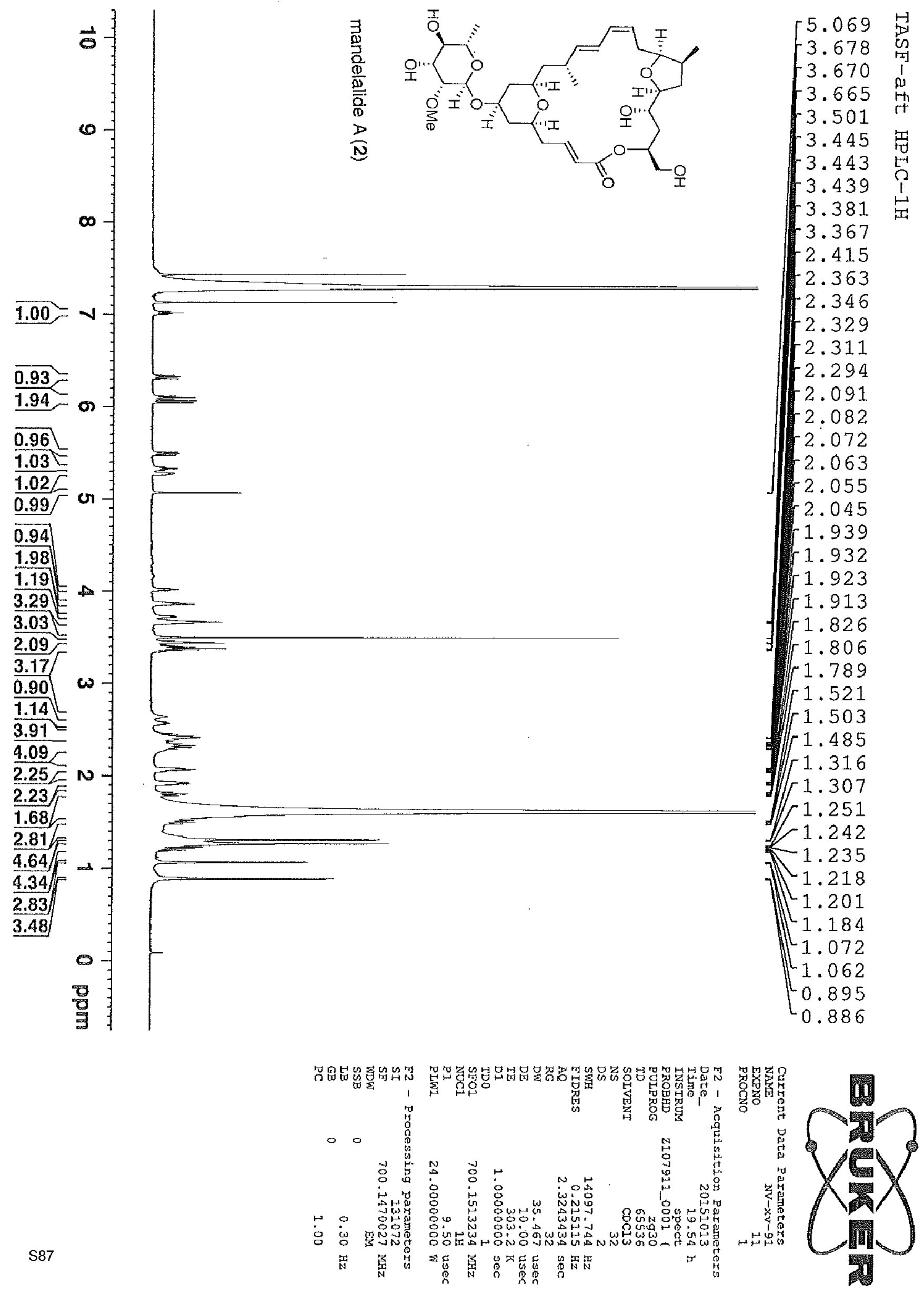


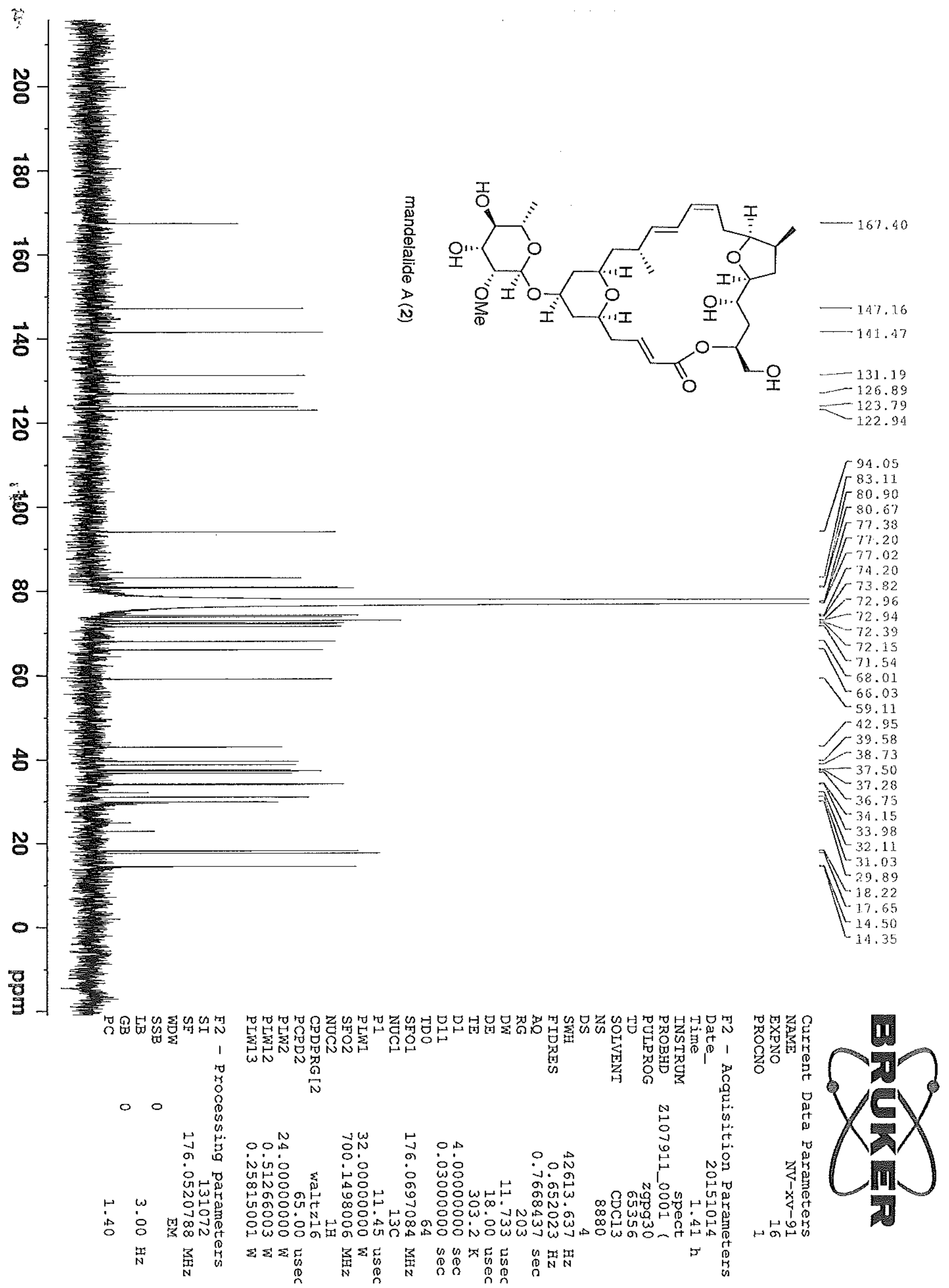


Synthetic mandelalide A (2)

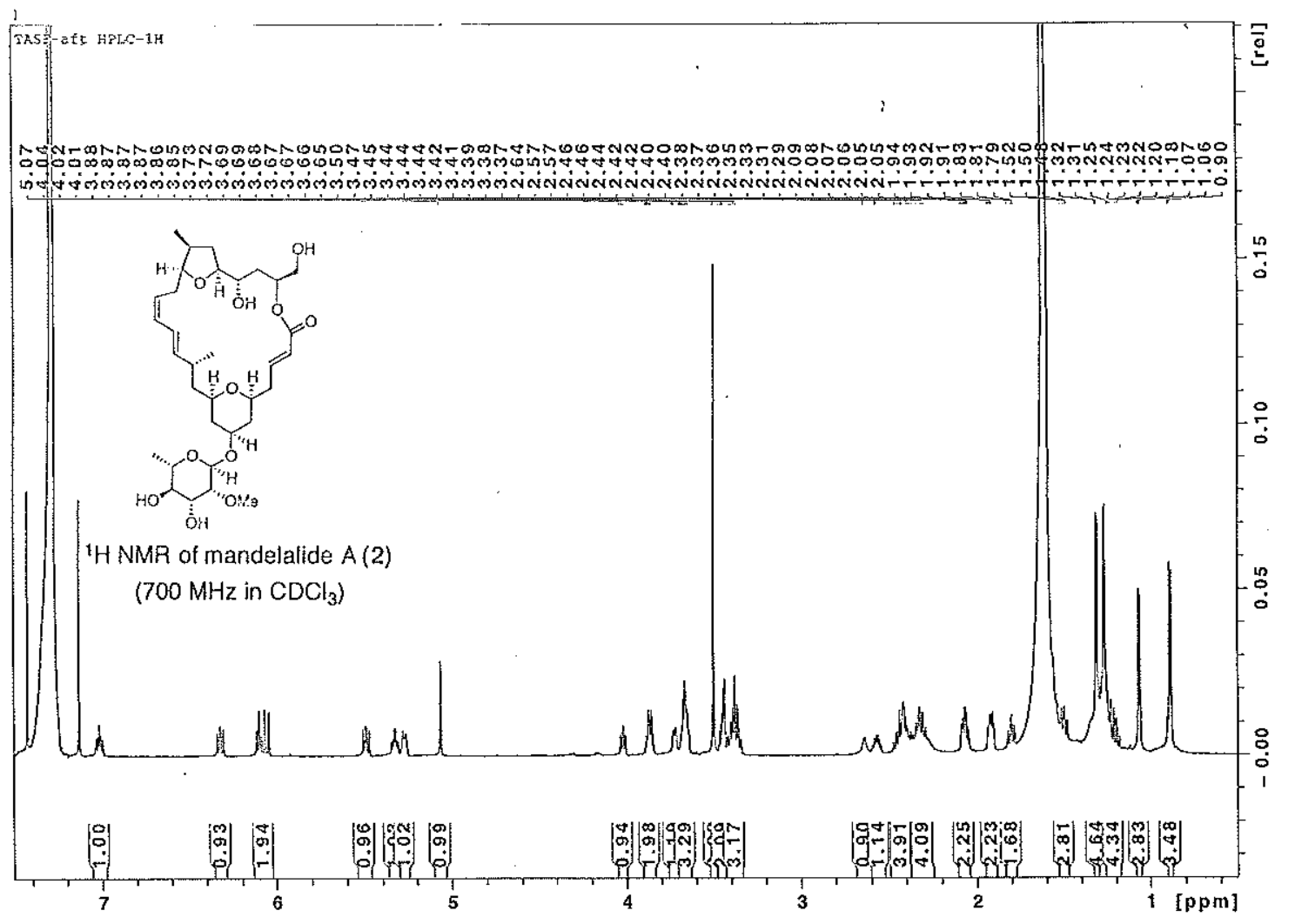

Isolated mandelalide A (2)

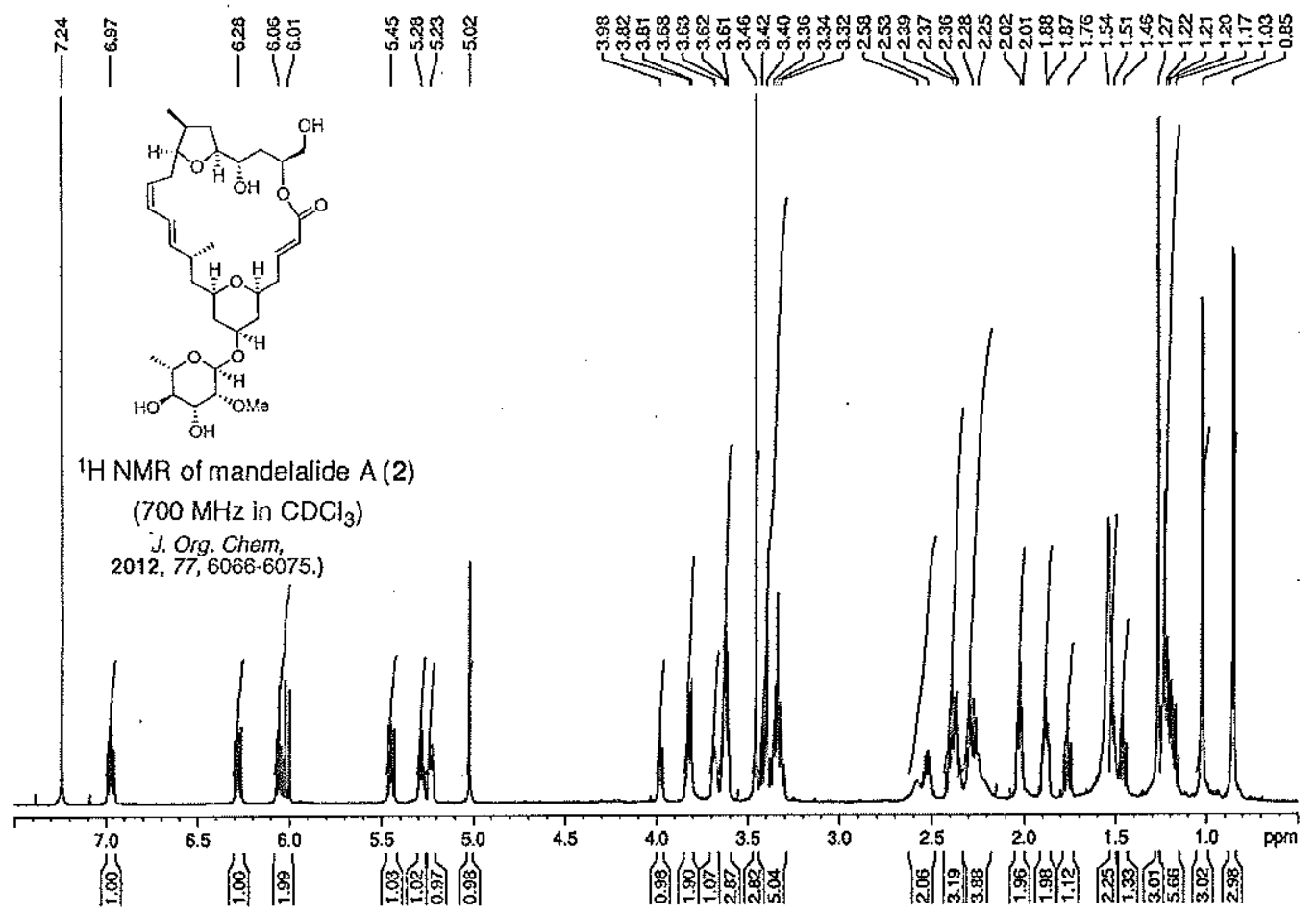




\section{Comparison of Synthesis and Isolation ${ }^{13} \mathrm{C}$ data for Mandelalide A (2):}

\begin{tabular}{|c|c|c|c|}
\hline Carbon No. & Synthetic $2(175 \mathrm{MHz})$ & Natural $2(175 \mathrm{MHz})^{\mathrm{a}}$ & Variance \\
\hline 1 & 167.4 & 167.4 & 0.0 \\
\hline 2 & 147.2 & 147.1 & -0.1 \\
\hline 3 & 141.5 & 141.5 & 0.0 \\
\hline 4 & 131.2 & 131.3 & 0.1 \\
\hline 5 & 126.9 & 126.9 & 0.0 \\
\hline 6 & 123.8 & 123.9 & 0.1 \\
\hline 7 & 122.9 & 123.1 & 0.2 \\
\hline 8 & 94.1 & 94.2 & 0.1 \\
\hline 9 & 83.1 & 83.2 & 0.1 \\
\hline 10 & 80.9 & 81.0 & 0.1 \\
\hline 11 & 80.7 & 80.8 & 0.1 \\
\hline 12 & 74.2 & 74.3 & 0.1 \\
\hline 13 & 73.8 & 73.9 & 0.1 \\
\hline 14 & 72.96 & 73.1 & 0.04 \\
\hline 15 & 72.94 & 73.0 & 0.06 \\
\hline 16 & 72.4 & 72.5 & 0.1 \\
\hline 17 & 72.2 & 72.3 & 0.1 \\
\hline 18 & 71.5 & 71.7 & 0.2 \\
\hline 19 & 68.0 & 68.1 & 0.1 \\
\hline 20 & 66.0 & 66.1 & 0.1 \\
\hline 21 & 59.1 & 59.1 & 0.0 \\
\hline 22 & 43.0 & 43.1 & 0.1 \\
\hline 23 & 39.6 & 39.7 & 0.1 \\
\hline 24 & 38.7 & 38.8 & 0.1 \\
\hline 25 & 37.5 & 37.6 & 0.1 \\
\hline 26 & 37.3 & 37.3 & 0.0 \\
\hline 27 & 36.8 & 36.8 & 0.0 \\
\hline 28 & 34.2 & 34.2 & 0.0 \\
\hline 29 & 34.0 & 34.1 & 0.1 \\
\hline 30 & 31.0 & 31.1 & 0.1 \\
\hline 31 & 18.2 & 18.3 & 0.1 \\
\hline 32 & 17.7 & 17.7 & 0.0 \\
\hline 33 & 14.5 & 14.5 & 0.0 \\
\hline
\end{tabular}

a Sikorska, J.; Hau, A. M.; Anklin, C.; Parker-Nance, S.; Davies-Coleman, M. T.; Ishmael, J. E.; McPhail, K. L. J. Org. Chem. 2012, 77, 6066-6075. Correction: J. Org. Chem. 2013, 78, 2812. 